Segmentação da estrutura cerebral hipocampo por meio de nuvem de similaridade

Fredy Edgar Carranza Athó 

SERVIÇO DE PÓS-GRADUAÇÃO DO ICMC-USP

Data de Depósito: 23-08-2011

Assinatura:

\title{
Segmentação da estrutura cerebral hipocampo por meio de nuvem de similaridade
}

\author{
Fredy Edgar Carranza Athó
}

Orientadora: Profa. Dra. Agma Juci Machado Traina

Dissertação apresentada ao Instituto de Ciências Matemáticas e de Computação - ICMC-USP, como parte dos requisitos para obtenção do título de Mestre em Ciências - Ciências de Computação e Matemática Computacional. VERSÃO REVISADA

USP - São Carlos

Agosto de 2011 
Ficha catalográfica elaborada pela Biblioteca Prof. Achille Bassi e Seção Técnica de Informática, ICMC/USP, com os dados fornecidos pelo(a) autor(a)

Carranza Athó, Fredy Edgar
Segmentação da estrutura cerebral hipocampo por
meio de nuvem de similaridade / Fredy Edgar Carranza
Athó; orientadora Agma Juci Machado Traina -- São
Carlos, 2011.
94 p.
Dissertação (Mestrado - Programa de Pós-Graduação en
Ciências de Computação e Matemática Computacional) --
Instituto de Ciências Matemáticas e de Computação,
Universidade de São Paulo, 2011.
1. segmentação automática do hipocampo. 2.
segmentação baseada em grafos. 3. consultas por
similaridade. 4. segmentação de imagens médicas. I.
Machado Traina, Agma Juci , orient. II. Título.


Segmentação automática da estrutura cerebral hipocampo por meio de nuvem de similaridade

Fredy Edgar Carranza Athó 
A las dos razones de mi vida, Aurora y Mariana, Mariana y Aurora, por enseñarme a compartir y amar más allá de las palabras y la distancia. 


\section{Agradecimentos}

A Deus.

A minha orientadora Profa. Dra. Agma Traina pelo apoio e incentivo para alcançar este objetivo.

Aos meus pais, Aurora e Fredy, e aos meus irmãos, Paúl e Pedro, pelo carinho e atenção em todos os momentos.

À minha esposa Mariana pelo amor e compreensão incessante.

Aos meus colegas do GBdI pelo apoio constante.

Ao CNPq pelo suporte financeiro. 
ATHÓ, F. C. Segmentação da estrutura de cerebral hipocampo por meio de nuvem de similaridade 2011. 89 f. Dissertação (Mestrado) - Instituto de Ciências Matemáticas e de Computação, Universidade de São Paulo, São Carlos, 2011.

O hipocampo é uma estrutura cerebral que possui importância primordial para o sistema de memória humana. Alterações no seus tecidos levam a doenças neurodegenerativas, tais como: epilepsia, esclerose múltipla e demência, entre outras. Para medir a atrofia do hipocampo é necessário isolá-lo do restante do cérebro. A separação do hipocampo das demais partes do cérebro ajuda aos especialistas na análise e o entendimento da redução de seu volume e deteç̧ão de qualquer anomalia presente. A extração do hipocampo é principalmente realizada de modo manual, a qual é demorada, pois depende da interação do usuário. A segmentação automática do hipocampo é investigada como uma alternativa para contornar tais limitações. Esta dissertação de mestrado apresenta um novo método de segmentação automático, denominado Modelo de Nuvem de Similaridade (Similarity Cloud Model - SimCM). O processo de segmentação é dividido em duas etapas principais: i) localização por similaridade e ii) ajuste de nuvem. A primeira operação utiliza a nuvem para localizar a posição mais provável do hipocampo no volume destino. A segunda etapa utiliza a nuvem para corrigir o delineamento final baseada em um novo método de cálculo de readequação dos pesos das arestas. Nosso método foi testado em um conjunto de 235 MRI combinando imagens de controle e de pacientes com epilepsia. Os resultados alcançados indicam um rendimento superior tanto em efetividade (qualidade da segmentação) e eficiência (tempo de processamento), comparado com modelos baseados em grafos e com modelos Bayesianos. Como trabalho futuro, pretendemos utilizar seleção de características para melhorar a construção da nuvem e o delineamento dos tecidos.

Palavras-chaves: segmentação automática do hipocampo, nuvem de similaridade, recuperação de imagens por conteúdo, consultas por similaridade, modelo de nuvens, transformada imagem floresta. 
ATHÓ, F. C. Hippocampus segmentation through similarity cloud model 2011. 89 f. Dissertação (Mestrado) - Instituto de Ciências Matemáticas e de Computação, Universidade de São Paulo, São Carlos, 2011.

The hippocampus is a particular structure that plays a main role in human memory systems. Tissue modifications of the hippocampus lead to neurodegenerative diseases as epilepsy, multiple sclerosis, and dementia, among others. To measure hippocampus atrophy, it is crucial to get its isolated representation from the whole brain volume. Separating the hippocampus from the brain helps physicians in better analyzing and understanding its volume reduction, and detecting any abnormal behavior. The extraction of the hippocampus is dominated by manual segmentation, which is time consuming mainly because it depends on user interaction. Therefore, automatic segmentation of the hippocampus has being investigated as an alternative solution to overcome such limitations. This master dissertation presents a new automatic segmentation method called Similarity Cloud Model (SimCM) based on hippocampus feature extraction. The segmentation process consists of two main operations: i) localization by similarity, and ii) cloud adjustment. The first operation uses the cloud to localize the most probable position of the hippocampus in a target volume. The second process invokes the cloud to correct the final labeling, based on a new method for arc-weight re-adjustment. Our method has been tested in a dataset of 235 MRIs combining healthy and epileptic patients. Results indicate superior performance, in terms of effectiveness (segmentation quality) and efficiency (processing time), in comparison with similar graph-based and Bayesian-based models. As future work, we intend to use feature selection to improve cloud construction and tissue delineation.

Keywords: automatica hippocampus segmentation, similarity cloud, content-based image retrieval, similarity queries, cloud model, image-forest transform. 


\section{Lista de Figuras}

1.1 Imagem de um hipocampo humanodelimitado por um especialista. Note-se que a (1) amígdala e o (2) gyrus parahipocampal possuim uma distribuição de intensidade similar $[65] \ldots \ldots \ldots \ldots$. . . . . . . . . . . 2

2.1 Exemplo de segmentação com uma imagem de dimensões $3 \times 3$. (a) São fornecidas como entrada as sementes $\mathcal{O}$ para o objeto e sementes $\mathcal{B}$ para o fundo. (b) Grafo representando os custos da imagem anterior com os custos nas arestas. A espessura da aresta reflete o seu valor. (c) O corte mínimo é calculado com base nas sementes fornecidas. (d) Cada nó da imagem foi marcado como fundo ou objeto dependendo da parte do corte onde ele se encontra [13]. . . . . . . . . . . . . . . . . . . . . . . 28

2.2 Aplicação da segmentação utilizando o GC. (a) Segmentação da parte óssea em uma fatia de tomografia computadorizada (b) Segmentação de um volume de ressonância magnética de $\operatorname{rim}[13] \ldots$. . . . . . . . . . . .

2.3 Representação da aplicação da IFT. (a) Um grafo de uma imagem onde os números indicam os valores das arestas e o quadro sombreado é o objeto procurado. As bordas da imagem são marcadas como sementes externas e o pixel branco interior é a semente interna. (b) O resultado da aplicação da IFT onde os números indicam os custos mínimos para chegar até uma semente. Os pixels de cor cinza indicam o fundo e os brancos, o objeto [8].

2.4 Exemplo de segmentação por meio da IFT por Competição de Sementes (IFT-SC) do (a) cérebro e (b) cerebelo [30]. . . . . . . . . . . . . . . 33

2.5 Segmentação de estruturas subcorticais produzida pelo FreeSufer. Cada cor indica um tipo diferente de região. O detalhe sobre a identificação dos tecidos pode ser obtido em $[5] \ldots \ldots$. . . . . . . . . . 36 
2.6 Exemplo de segmentação de um eletrocardiograma: (a) imagem original, (b) modelo na posição inicial, (c) modelo ajustado depois de 200 iterações $[22]$.

2.7 (a) Segmentação por meio de atlas e (b) segmentação pelo GC utilizando informação a priori do hipocampo (verde) e a amígdala (vermelho) [66] . . . 40

2.8 (a) Construção de uma nuvem baseada em segmentações prévias do cerebelo. (b) Clique formado por máscaras binárias do cerebelo para produzir um determinado cluster e finalmente uma nuvem $C_{i}$ [48].

2.9 Fatias de um volume MRI segmentado utilizando o CM. As nuvens foram aplicadas para a segmentação dos hemisférios e o cerebelo [48] . . . . . . . . 42

3.1 Representação de consultas por similaridade em um espaço bidimensional por meio da consulta (a) por abrangência e (b) pelos vizinhos mais próximos. O objeto $O_{q}$ é o centro da consulta e $r_{q}$ o raio de consulta. . . . . . . 46

3.2 (a) Imagem quantizada em 256 níveis de cinza e seu histograma associado.

(b) Tela de resultados de consulta do sistema SRIS baseado na comparação de histogramas de cor [14] . . . . . . . . . . . . . . . . . . . . . . . . . 48

3.3 Interface de usuário de IRMA para consultas por similaridade por meio da extração de característica de textura [40]. . . . . . . . . . . . . .

3.4 Tela do sistema SPIRS com a resposta da consulta baseada no atributo forma. O usuário faz o desenho de uma forma e são retornadas as imagens com a forma mais aproximada $[36]$. . . . . . . . . . . . . . . . 50

3.5 Representação das formas geométricas geradas no espaço Euclidiano 2D de acordo com a família de distâncias $\mathcal{L}^{p}$ pelos pontos equidistantes baseados nas distâncias (a) $\mathcal{L}^{1}$, (b) $\mathcal{L}^{2}$, (c) $\mathcal{L}^{\infty}$, (d) a superposição das três representações anteriores $[15] \ldots \ldots \ldots \ldots \ldots \ldots$. . . . . . . . . . . . 53

4.1 Representação do fluxo do Modelo de Nuvem de Similaridade onde é possível notar a importância da extração de características. . . . . . . . . . 56

4.2 (a) Curvas aproximadas sobre os histogramas acumulados para distintos valores de $\eta$. É possível ver a relação entre a escolha de $\eta$ e o efeito que tem sobre o descritor final representado em (b), (c) e (d) . . . . . . . . . 58

4.3 Representação da construção de uma Nuvem de Similaridade baseada na estrutura cerebral hipocampo.

4.4 (a) Estimação do tecido da GM obtida por biparticionamento automático do histograma, (b) resultado do processo de localização por similaridade, (c) segmentação primitiva e (b) resultado final pelo delineamento com ajuste da Nuvem de Similaridade.

4.5 Elementos usados na reconfiguração da Nuvem de Similaridade: (a) a máscara binária da GM $I_{G M}$ e (b) a segmentação primitiva $L$. . . . . . . 
5.1 Gráficos de barras representando o DC para o conjunto (a) de controle, (b) de pacientes e (c) completo. . . . . . . . . . . . . . . . . . 72

5.2 Resultado da aplicação do Corte de Grafos (GC) sobre uma imagem do conjunto de controle. As marcas azuis representam o contorno da segmentação obtida e as marcas vermelhas os erros encontrados quando foi feita a comparação com o ground-truth (máscaras produzidas pelo software FreeSurfer) . . . . . . . . . . . . . . . .

5.3 Resultado da aplicação do Modelo Bayesiano (BM) sobre uma imagem do conjunto de controle. As marcas azuis representam o contorno da segmentação obtida e as marcas vermelhas os erros encontrados quando foi feita a comparação com o ground-truth (máscaras produzidas pelo software FreeSurfer).

5.4 Resultado da aplicação do SimCM sobre uma imagem do conjunto de controle. As marcas azuis representam o contorno da segmentação obtida e as marcas vermelhas os erros encontrados quando foi feita a comparação com o ground-truth (máscaras produzidas pelo software FreeSurfer). . . . . . . .

5.5 Resultado da aplicação do Corte de Grafos (GC) sobre uma imagem do conjunto de paciente. As marcas azuis representam o contorno da segmentação obtida e as marcas vermelhas os erros encontrados quando foi feita a comparação com o ground-truth (máscaras produzidas pelo software FreeSurfer). . . . . . . . . . . . . . . . . .

5.6 Resultado da aplicação do Modelo Bayesiano (BM) sobre uma imagem do conjunto de paciente. As marcas azuis representam o contorno da segmentação obtida e as marcas vermelhas os erros encontrados quando foi feita a comparação com o ground-truth (máscaras produzidas pelo software FreeSurfer).

5.7 Resultado da aplicação do SimCM sobre uma imagem do conjunto de paciente. As marcas azuis representam o contorno da segmentação obtida e as marcas vermelhas os erros encontrados quando foi feita a comparação com o ground-truth (máscaras produzidas pelo software FreeSurfer). . . . .

5.8 Boxplots para os experimentos rodados sobre os conjuntos (a) controle, (b) paciente e (c) completo. . . . . . . . . . . . . . . . . . 79

5.9 Scatter plot comparando os volumes dos hipocampos no conjunto completo. 80

5.10 Curva de aprendizado do SimCM, CM e CMLS. O gráfico revela que o SimCM pode ser treinado satisfatoriamente com uma quantidade de imagens no intervalo do $25 \%$ ao $35 \%$ do total. . . . . . . . . . . . . . . 8

5.11 Comparação do tempo de resposta entre o SimCM e o BM, no qual o SimCM consegue reduzir o tempo em $65 \%$. . . . . . . . . . . . . . . . . 82 


\section{Lista de Tabelas}

2.1 Detalhes dos pesos das arestas dependendo da localização dos nós na imagem $[10] \ldots \ldots \ldots \ldots \ldots$

2.2 Tabela comparativa analisando os métodos de segmentação apresentados no decorrer do capítulo. . . . . . . . . . . . . . . . . . . . 43

5.1 Valores do coeficiente Dice (DC) para os experimentos executados. . . . . . 71 


\section{Lista de símbolos}

\begin{tabular}{l|l} 
Símbolo & Significado \\
\hline \hline $\mathcal{A}$ & Relação de adjacência \\
$\mathcal{B}$ & Região fundo (entende-se como as sementes do fundo) \\
$\mathcal{G}$ & Função Gaussiana \\
$\mathcal{O}$ & Região objeto (entende-se como as sementes do objeto) \\
$\mathcal{U}$ & Região de incerteza \\
$\mu-\sigma$ & Média - Desvio Padrão \\
$C=\left\{C_{1}, \ldots, C_{i}, \ldots, C_{n}\right\}$ & Conjunto de nuvens \\
$I_{G M}$ & Estimação da GM em $I$ \\
$I$ & Imagem \\
$p, q, s, t$ & Pixel ou voxel \\
$A$ & Algoritmo de delineamento \\
BM & Modelo Bayesiano \\
CBIR & Recuperação de Imagens Baseada em Conteúdo \\
CM & Modelo de Nuvens \\
CMLS & Modelo de Nuvens com Localização por Similaridade \\
CSF & Fluido cerebroespinal \\
DC & Coeficiente Dice \\
$f$ & Função de custo \\
F & Funcional de medida \\
GC & Corte mínimo de grafos \\
GM & Matéria cinzenta \\
IFT & Transformada Imagem Floresta \\
IFT-SC & IFT por Competição de sementes \\
$L$ & Imagem etiquetada \\
MBB & Retângulo envolvente mínimo \\
RVD & Diferença relativa de volume \\
SimCM & Modelo de Nuvem de Similaridade \\
WM & Matéria branca \\
\hline
\end{tabular}


Resumo

Abstract

1 Introdução $\quad 19$

1.1 Considerações iniciais . . . . . . . . . . . . . . . . . . . . . . . . . 19

1.2 A estrutura cerebral hipocampo . . . . . . . . . . . . . . . . . . 20

1.3 Motivação . . . . . . . . . . . . . . . . . . . 21

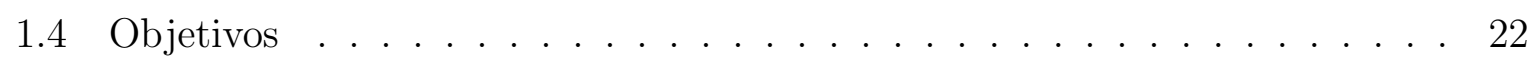

1.5 Organização do documento . . . . . . . . . . . . . . . . . 22

2 Segmentação de imagens médicas $\quad 25$

2.1 Considerações iniciais . . . . . . . . . . . . . . . . . . . . 25

2.2 Métodos baseados em imagem . . . . . . . . . . . . . . 26

2.2.1 Corte mínimo de grafos . . . . . . . . . . . . . . 26

2.2.2 Transformada imagem-floresta . . . . . . . . . . . . . . . . 29

2.2 .3 Relação entre a IFT e o GC . . . . . . . . . . . . . . . . . . . . . . 34

2.3 Métodos baseados em modelo . . . . . . . . . . . . . . . . 34

2.3.1 Registro em atlas de imagens: FreeSurfer . . . . . . . . . . . . 34

2.3 .2 Modelo Ativo de Forma . . . . . . . . . . . . . . . . . . . 37

2.4 Modelos híbridos . . . . . . . . . . . . . . . . . . . . . 38

2.4.1 Corte mínimo de grafos utilizando informação a priori . . . . . . . 38 
2.4.2 Modelo de sistema de nuvens . . . . . . . . . . . . . . . . . . . . 39

2.5 Comparação entre os métodos de segmentação . . . . . . . . . . . . . . . 43

2.6 Considerações finais . . . . . . . . . . . . . . . . . . . . . . . . . . . . . . . 44

3 Recuperação de Imagens por Conteúdo e Consultas por Similaridade 45

3.1 Considerações iniciais . . . . . . . . . . . . . . . . . . . . . . . . . . . 45

3.2 Consultas por similaridade . . . . . . . . . . . . . . 46

3.3 Extração de características . . . . . . . . . . . . . . . . . . . . . 47

3.3 .1 Cor . . . . . . . . . . . . . . . . . . 47

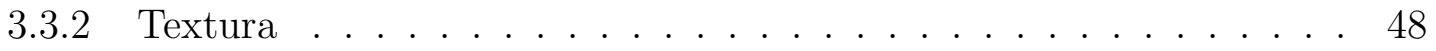

3.3 .3 Forma . . . . . . . . . . . . . . . . . 50

3.4 Funções de distância . . . . . . . . . . . . . . . . . . . . . . . . . . 52

3.5 Considerações finais . . . . . . . . . . . . . . . . . . . . . 54

4 Modelo de Nuvem de Similaridade $\quad 55$

4.1 Considerações iniciais . . . . . . . . . . . . . . . . . . . . . . . 55

4.2 Construção da Nuvem de Similaridade . . . . . . . . . . . . . . . 57

4.3 Localização por similaridade . . . . . . . . . . . . . . . . . 60

4.3 .1 Procedimento de busca . . . . . . . . . . . . . . . . . . . . 60

4.3.2 Extração e medição de similaridade . . . . . . . . . . . . . . . . . 61

4.4 Ajuste da Nuvem de Similaridade . . . . . . . . . . . . . . . . . . . . . . 64

4.4.1 Cálculo dos pesos das arestas . . . . . . . . . . . . . . 64

4.4.2 Redefinição das zonas da Nuvem de Similaridade . . . . . . . . 64

4.5 Considerações finais . . . . . . . . . . . . . . . . . . . . . 66

5 Experimentos e resultados $\quad 69$

5.1 Considerações iniciais . . . . . . . . . . . . . . . . . . . . . . . . . . 69

5.2 Conjunto de dados . . . . . . . . . . . . . . . . . . . . . . . . 69

5.3 Segmentação do hipocampo . . . . . . . . . . . . . . . . . . 70

5.4 Construção da nuvem . . . . . . . . . . . . . . . . . . . . . . . . . . 80

5.5 Tempo de resposta . . . . . . . . . . . . . . . . . . . 81

5.6 Considerações finais . . . . . . . . . . . . . . . . . . . . . . . . . 82

6 Conclusões e linhas de futuras pesquisas $\quad 83$

6.1 Considerações finais . . . . . . . . . . . . . . . . . . . . . . 83

6.2 Contribuições deste trabalho . . . . . . . . . . . . . . . . . . . . 83

6.3 Linhas de futuras pesquisas . . . . . . . . . . . . . . 85 


\section{Capítulo \\ 1 \\ Introdução}

\subsection{Considerações iniciais}

Os avanços na tecnologia de análise de imagens médicas têm tornado possível a aquisição de imagens tridimensionais de alta resolução da anatomia humana em distintas modalidades. Do mesmo modo, as coleções de imagens médicas estão sendo rapidamente expandidas em quantidade e diversidade, havendo uma crescente tendência para a formação de arquivos adequados para dar auxílio ao diagnóstico e à medicina preventiva [27].

Estes fatos, junto com a grande e crescente importância das imagens médicas na prática clínica e a necessidade da análise de imagens para extrair informações objetivas e quantitativas têm aumentado consideravelmente. Para citar alguns casos, em radioterapia as bordas dos volumes de irradiação e a vizinhança dos órgãos em risco são delineados em imagens tridimensionais e utilizados para calcular uma terapia de radiação adequada. Em neurologia, doenças degenerativas do cérebro, como a esclerose múltipla, a doença de Alzheimer e esquizofrenia, são estudadas determinando a forma do cérebro e as mudanças dos tecidos em imagens de ressonância magnética [63].

A segmentação de imagens cerebrais é uma das aplicações mais estudadas no processamento digital de imagens médicas. A segmentação de uma imagem cerebral tem como objetivo a detecção de estruturas anatômicas e patológicas do cérebro como hemisférios, tecidos, tumores e ventrículos. A detecção destas áreas cerebrais dentro de uma imagem se tornou um foco de investigação devido a sua importância em diversas aplicações clínicas, que abrangem o diagnóstico de doenças, planejamento pré-cirúrgico e cirurgia assistida por computador. 
Dentro das estruturas cerebrais mais importantes encontra-se o hipocampo, o qual está localizado no lobo médio temporal e que desempenha um papel crucial no âmbito dos processos de aprendizagem e memória. Esta estrutura é afetada por uma variedade de doenças neurodegenerativas graves colocando em risco a vida das pessoas [67]. Devido a essas implicações, o hipocampo tornou-se uma estrutura de intenso interesse na investigação médica que demanda a análise de imagens.

A obtenção de uma representação volumétrica do hipocampo é crucial para a análise das doenças que causam degeneração nesta estrutura e um processo de segmentação é necessário para determinar as medidas de interesse que propiciem o auxílio ao diagnóstico médico. Este procedimento é desafiador e gerou estudos e propostas de métodos semi e totalmente automáticos que ainda precisam ser melhorados.

A caracterização de uma estrutura tridimensional como o hipocampo, proporciona uma fonte valiosa de informações que não apenas permitem a análise visual, mas é um objeto de estudo para buscas por similaridade e, portanto, para a construção de sistemas de Recuperação de imagens baseada em conteúdo (Content-based image retrieval - CBIR). A possibilidade de comparar e recuperar objetos tridimensionais como os hipocampos, permite a associassociar a semelhança das suas características e fornecer informações importantes que ajudem no processo de segmentação automática. Isto é, obter a segmentação do hipocampo baseada na sua busca dentro de um volume tridimensional considerando uma imagem de consulta.

A segmentação automática do hipocampo é um problema aberto e que traz desafios para a área de processamento de imagens médicas. O interesse no estudo desta estrutura cerebral é de tal ordem que, no ano de 2008, como parte das conferências da Medical Image Computing and Computer Assisted Intervention Society (MICCAI 2008), foi realizado, pela primeira vez, um workshop dedicado exclusivamente aos estudos relacionados ao hipocampo e à sua análise utilizando técnicas de processamento de imagens [67].

\subsection{A estrutura cerebral hipocampo}

O hipocampo é uma pequena estrutura de matéria cinzenta (Gray Matter - GM) localizada simetricamente no lobo médio temporal de ambos hemisférios do cérebro. $\mathrm{O}$ hipocampo é adjacente a outras estruturas compostas de GM como a amígdala por exemplo. Adicionalmente, existe ao redor do hipocampo tecido pertencente à matéria branca (White Matter - WM) e fluido cerebrospinal (Cerebro Spinal Fluid) [3].

O hipocampo possui um contraste relativamente baixo com bordas difíceis de distinguir, principalmente no límite com a amígdala onde eles são separados somente por uma delgada linha cinzenta [65]. Na Figura 1.1 é possível notar que hipocampo delineado, em ciertas regiões, é parecido com tecidos de estruturas adjacentes. 


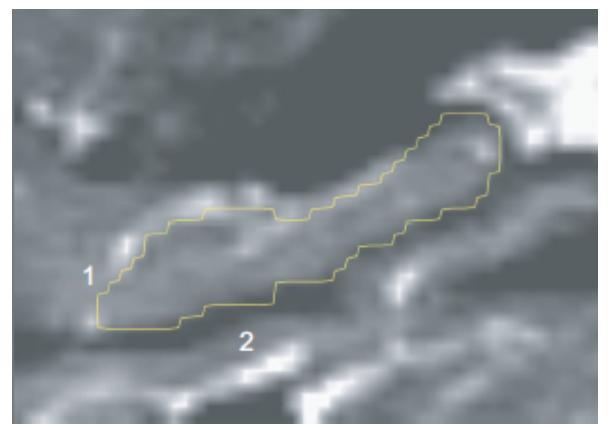

Figura 1.1: Imagem de um hipocampo humanodelimitado por um especialista. Note-se que a (1) amígdala e o (2) gyrus parahipocampal possuim uma distribuição de intensidade similar [65].

Existe controvérsia sobre o função específica do hipocampo, mas o acordo geral aponta que ele é essencial na consolidação de novas memórias sobre experiências pessoais [24]. Em uma analogía com um computador, o hipocampo atúa como a memória principal [37], isto é, salvando os dados que o cérebro está processando em um determinado momento e tomando a decisão sobre quais dados vão ser salvados no nossa memória permanentemente. Obviamente, a modificação nos tecidos do hipocampo produzem pertubações definitivas no nosso sistema e conduzem a doeças como Alzheimer [19], epilepsia [25], esquizofrenia [62] entre outras.

\subsection{Motivação}

A caracterização do hipocampo é um passo fundamental para a análise de sua degeneração utilizando imagens médicas. Desta maneira, técnicas para a segmentação e a representação das características volumétricas do hipocampo são fundamentais para que o especialista possa elaborar um diagnóstico baseado em imagens com maior confiança e precisão.

Até o momento, três diferentes abordagens têm sido propostas para a quantificação dos volumes hipocampais: segmentação manual, segmentação semiautomática e métodos totalmente automáticos [38]. Atualmente, a segmentação manual é considerada o padrão para a volumetria do hipocampo. No entanto, ela requer um grande investimento de tempo e esforço, além de sofrer de variabilidade inter e intraconcordância. As técnicas semiautomáticas reduzem consideravelmente a quantidade de tempo e esforço necessário para uma segmentação da estrutura cerebral. Entretanto, para grandes estudos, mesmo pequenas intervenções manuais são uma grande tarefa. Por esta razão, vários grupos têm proposto métodos de segmentação automática [20, 21, 31-33, 39, 41, 50]. Entretanto, existe uma grande variedade de propostas, estas abordagens não são amplamente utilizadas devido a suas limitações tais como: alto tempo de processamento, resultados insatisfatórios e limitada capacidade de serem aplicados a diferentes conjuntos de imagens $[51]$. 
Apesar da qualidade dos resultados obtidos pelos métodos já existentes, os processos de segmentação e visualização de estruturas cerebrais continuam sendo complexos, computacionalmente caros, dependentes da aplicação e demandam interação humana. Os métodos automáticos tradicionais consideram o uso de atlas de imagens, elevando o tempo de resposta de maneira drástica, quando na maioria dos casos, uma resposta rápida é requerida. Por outro lado, os métodos básicos de segmentação não possuem uma robustez suficiente para delinear uma estrutura tão complexa como o hipocampo. Existe então uma grande necessidade de providenciar aos especialistas médicos métodos automáticos de segmentação do hipocampo, que sejam rápidos, robustos e que apresentem resultados de boa qualidade.

\subsection{Objetivos}

O objetivo central deste trabalho é o desenvolvimento de um método automático de segmentação do hipocampo em volumes MRI. A proposta deve ter um tempo de resposta rápido e não precisar de intervenção do usuário.

De modo específico, são consideradas as seguintes premissas:

- Caracterizar do hipocampo por meio das suas propriedades mais relevantes e permitir sua comparação por similaridade.

- Dividir o processo de segmentação em duas tarefas fundamentais: localização do hipocampo por meio de busca por similaridade e delineamento baseado no reajuste do espaço de soluções.

- Integrar os conceitos de similaridade em um processo de segmentação automático que vise aumentar a qualidade das respostas.

- Desenvolver um algoritmo rápido baseado em segmentação por meio de grafos o qual inclua a análise de características para a ponderação dos pesos das arestas.

\subsection{Organização do documento}

O presente trabalho de pesquisa apresentou neste primeiro capítulo as considerações inicias para o entendimento do trabalho apresentado nesta dissertação, sua motivação do desenvolvimento desta proposta e a organização do documento. O conteúdo do trabalho está estruturado da seguinte maneira:

- No Capítulo 2 são abordados métodos de segmentação de imagens médicas mais relacionados com a proposta de mestrado. 
- O Capítulo 3 apresenta os conceitos sobre CBIR e consultas por similaridade visando introduzir a importância da extração de características e a sua aplicação na área médica.

- No Capítulo 4 é detalhada a proposta de mestrado, explicando a teoria utilizada, as definições e fórmulas, junto aos algoritmos dos procedimentos principais desenvolvidos.

- O Capítulo 5 expõe os experimentos e resultados obtidos utilizando o método de segmentação proposto e comparado-o com resultados obtidos com métodos similares na literatura.

- Finalmente, no Capítulo 6 são apresentadas as conclusões e linhas de pesquisas futuras. 


\section{Capítulo \\ 2 \\ Segmentação de imagens médicas}

\subsection{Considerações iniciais}

O desenvolvimento de algoritmos de segmentação de imagens médicas é necessário em um amplo domínio de aplicações devido à crescente demanda da análise e interpretação automática de imagens [1]. Entretanto, não existe uma teoria estabelecida para a segmentação automática de imagens médicas. Como consequência, nenhum dos métodos desenvolvidos até agora tornou-se um padrão. Pelo contrário, existe uma coleção de métodos ad hoc que são bastante populares [34].

Haralick [35] estabeleceu o seguinte guia qualitativo para uma boa segmentação: as regiões como resultado da segmentação de uma imagem devem ser uniformes e homogêneas em relação a alguma característica ou propriedade preestabelecida. As regiões interiores devem ser simples e sem muitas descontinuidades (buracos). Regiões adjacentes ao objeto procurado devem ter valores significativamente diferentes com respeito à característica sobre a qual ele é uniforme. As bordas de cada segmento devem ser simples, não irregulares e espacialmente exatas [57]. Por outro lado, Gonzalez e Woods [34] definem a segmentação sobre a base de dois princípios: descontinuidade e similaridade. A primeira restrição sugere que as bordas das regiões sejam suficientemente diferentes uma das outras, assim como do fundo para permitir a sua detecção baseada na descontinuidade local da intensidade. O segundo princípio está baseado na partição de uma imagem em regiões que são similares em um critério predefinido.

Levando estes conceitos ao contexto de aplicações reais e, em especial, com relação às imagens médicas, os métodos existentes podem ser classificados segundo a origem das 
restrições que produzem o resultado final. Isto é, qual é a fonte de informações que o método utiliza para distinguir entre o objeto e o fundo? Seguindo este principio, existem métodos baseados em imagem e métodos baseados em modelo [48].

\subsection{Métodos baseados em imagem}

Os métodos de segmentação baseados em imagem utilizam as informações extraídas da imagem objetivo como cor, forma, textura, etc. para determinar a separação dos objetos do fundo. O sucesso destes métodos está relacionado com a premissa de que os valores das propriedades extraídas são diferentes entre os objetos e o fundo. Para que isto seja possível, é necessário estabelecer intervalos de medida ou certas considerações sobre elas. Note-se que neste categoria de métodos, a segmentação depende somente da qualidade das propriedades extraídas e da capacidade de distinção dos parâmetros escolhidos.

\subsubsection{Corte mínimo de grafos}

As técnicas de segmentação de imagens baseadas em grafos representam o problema em termos de um grafo $G=(V, E)$ no qual cada nó $v_{i} \in V$ corresponde a um pixel da imagem e as arestas em $E$ indicam a conexão entre certos pares de pixels vizinhos. Um peso é associado a cada aresta do grafo, baseado em alguma propriedade dos pixels que conecta, como por exemplo, sua intensidade. Dependendo do método, pode existir ou não uma aresta conectando cada par de nós dentro da imagem.

A segmentação baseada no Corte mínimo de grafos (Minimum Cut Graph Segmentation - GC) [12], processa a imagem como um grafo, sobre o qual o corte mínimo é calculado em função das seguintes premissas: seja um grafo $G=(V, E)$ no qual existe um conjunto de nós $V$ e um conjunto de arestas não orientadas $E$ que os conectam, e para cada aresta $e$ é designada um custo não negativo $w_{e}$. O subconjunto de nós $s, t \subset V$ contém dois nós especiais chamados nós terminais, sendo $s$ a fonte e $t$ o destino. Então, um corte de um grafo ou simplesmente um corte denotado como Cut com fonte $s$ e destino $t$, é uma partição de nós no grafo em dois conjuntos disjuntos $S$ e $T$ nos quais a fonte $s$ está em $S$ e o destino $t$ em $T$.

O corte que representa a segmentação da imagem deve ser ótimo, considerando cada subconjunto do corte como o mais homogêneo possível. Este conceito de homogeneidade ótima pode ser alcançado por meio do cálculo do corte mínimo, que é definido como o corte que tem o custo mínimo entre todos os cortes possíveis. O custo de um corte $C u t=\{S, T\}$ é a soma dos pesos das arestas $(p, q)$ onde $p \in S$ e $q \in T$.

O GC pode ser resolvido utilizando restrições soft, isto é, não existem limitações para a busca da solução e é possível testar múltiplas possibilidades. Assim, este procedimento depende diretamente do custo das arestas calculado por um funcional de medida $F$. O 
funcional é definido sobre uma imagem $I$ em uma malha bidimensional e $\mathcal{A}$ um sistema de vizinhança de 8 -vizinhos. Além disso, seja $\alpha=\left(\alpha_{1}, \ldots, \alpha_{p}, \ldots, \alpha_{|P|}\right)$ um vetor binário onde as componentes $\alpha_{p}$ especificam designações para os pixels $p \in I$, e cada $\alpha_{p}$ pode ter a marca $o b j$ ou $b k g$ (do inglês object de objeto e background de fundo). O funcional $F(\alpha)$, no qual o vetor $\alpha$ define uma segmentação a qual possui restrições sobre suas regiões e bordas, é definido como:

$$
F(\alpha)=\lambda \cdot R(\alpha)+B(\alpha)
$$

na qual

$$
\begin{aligned}
& R(\alpha)=\sum_{p \in P} R_{p}\left(\alpha_{p}\right) \\
& B(\alpha)=\sum_{p, q \in N} B_{p, q} \cdot \delta\left(\alpha_{p}, \alpha_{q}\right)
\end{aligned}
$$

e

$$
\delta\left(\alpha_{p}, \alpha_{q}\right)=\left\{\begin{array}{l}
1: \alpha_{p} \neq \alpha_{q} \\
0: \text { caso contrário }
\end{array}\right.
$$

O coeficiente $\lambda \geq 0$ na Equação 2.1 especifica a importância relativa do termo de propriedades de região $R(\alpha)$ frente ao termo de propriedades da borda $B(\alpha)$. O termo $R(\alpha)$ determina penalidades individuais devido à designação da etiqueta do objeto ou fundo referente ao pixel $p . R_{p}(\cdot)$ poderia ser associado a um histograma de cor e refletir como a intensidade do pixel $p$ encaixa dentro desse modelo. Por outro lado, o termo $B(\alpha)$ identifica as propriedades das bordas da segmentação $\alpha$. O coeficiente $B_{p, q} \geq 0$ é interpretado como uma penalidade pela descontinuidade entre o pixel $p$ e $q$. O valor de $B_{p, q}$ é maior quando o valor das intensidades de $p$ e $q$ são similares ou menor no caso contrário. A minimização desta função de custo testando todas as combinações possíves fazem este problema computacionalmente caro.

A introdução de restrições hard no GC permite ao usuário etiquetar pixels indicando se eles são parte do fundo ou do objeto. Deste modo, os termos da função de custo são calculados sobre este conjunto de pixels escolhidos interativamente. Esta escolha determina dois conjuntos disjuntos de pixels denominados semente externas - pixels do fundo $\mathcal{B}$ - e sementes internas - pixels do objeto $\mathcal{O}$. Dado este tipo de restrições, é possível aproveitar os dados fornecidos pelo usuário definindo os pesos das arestas. Assim, cada pixel $p \in I$ da imagem tem duas arestas conectando o pixel com os nós terminais $s, t$ e dependendo do tipo de sistema de vizinhança $\mathcal{A}$ existem arestas conectando cada par de pixels $p, q$. Dessa maneira, são definidos o seguintes pesos para cada uma das arestas do grafo na Tabela 2.1, na qual $K=1+\max _{p \in I} \sum_{q:\{p, q\} \in \mathcal{A}} B_{p, q}$. 


\begin{tabular}{|c|c|c|}
\hline aresta & peso & restrição \\
\hline \hline$p, q$ & $B_{p, q}$ & $p, q \in \mathcal{A}$ \\
\hline \multirow{4}{*}{$p, s$} & $\lambda \cdot R_{p}(" b k g ")$ & $p \in I, p \notin \mathcal{O} \cup \mathcal{B}$ \\
\cline { 2 - 3 } & $K$ & $p \in \mathcal{O}$ \\
\cline { 2 - 3 } & 0 & $p \in \mathcal{B}$ \\
\hline \multirow{4}{*}{$p, t$} & $\lambda \cdot R_{p}(" o b j ")$ & $p \in I, p \notin \mathcal{O} \cup \mathcal{B}$ \\
\cline { 2 - 3 } & 0 & $p \in \mathcal{O}$ \\
\cline { 2 - 3 } & $K$ & $p \in \mathcal{B}$ \\
\hline
\end{tabular}

Tabela 2.1: Detalhes dos pesos das arestas dependendo da localização dos nós na imagem [10].

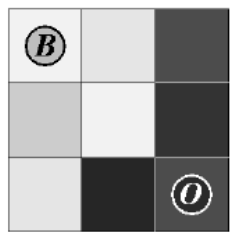

(a) Imagem com sementes

$\Downarrow$

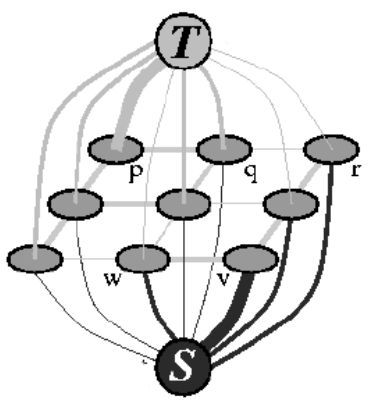

(b) Grafo

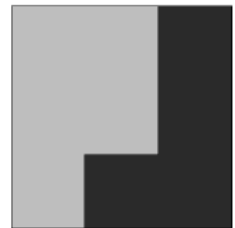

(d) Resultado da segmentação

$\Uparrow$

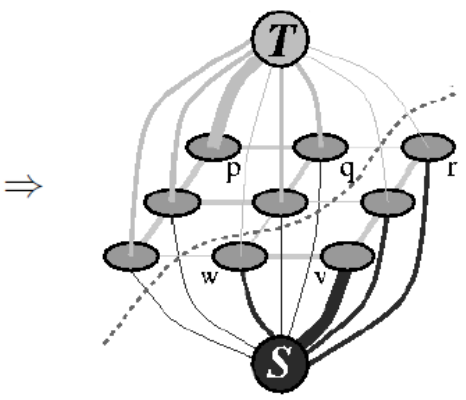

(c) Corte

Figura 2.1: Exemplo de segmentação com uma imagem de dimensões $3 \times 3$. (a) São fornecidas como entrada as sementes $\mathcal{O}$ para o objeto e sementes $\mathcal{B}$ para o fundo. (b) Grafo representando os custos da imagem anterior com os custos nas arestas. A espessura da aresta reflete o seu valor. (c) O corte mínimo é calculado com base nas sementes fornecidas. (d) Cada nó da imagem foi marcado como fundo ou objeto dependendo da parte do corte onde ele se encontra [13].

Com a descrição do grafo, é possível o cálculo do corte mínimo por meio do algoritmo proposto por Boykov e Kolmogorov [11] assumindo as restrições mencionadas nos parágrafos anteriores. Na Figura 2.1 é apresentada uma esquematização geral do processamento da imagem. Neste procedimento, um grafo da imagem é criado com dois terminais um para o fundo e outro para o objeto, no qual os custos das arestas estão definidos por 
meio da função de custo apresentada. O passo seguinte é calcular o corte mínimo separando os grupos associados aos terminais. Este corte mínimo achado é a segmentação da imagem inicial.

Como o sistema de vizinhança $\mathcal{A}$ não possui restrições, o método pode ser estendido para dados tridimensionais. Na Figura 2.2(a) é apresentado o resultado da segmentação utilizando o GC para a identificação da parte óssea em uma tomografia computadorizada abdominal e com um tempo de resposta de poucos segundos (entre 2 a 5 segundos). No caso de volumes, os testes realizados com dados de dimensões $(200 \times 200 \times 10)$ e $(512$ $\times 512 \times 50)$ obtiveram respostas em poucos minutos (2 a 5 minutos). Em particular, considerando volumes médicos, a Figura 2.2(b) apresenta o resultado da segmentação do córtex, medula e sistema coletor de um rim e obtendo como tempo de resposta 3 a 4 minutos incluindo a participação do especialista para indicar as sementes e correções posteriores. Estes experimentos realizados por Boykov ??, foram executados em um computador Pentium III 333MHz.

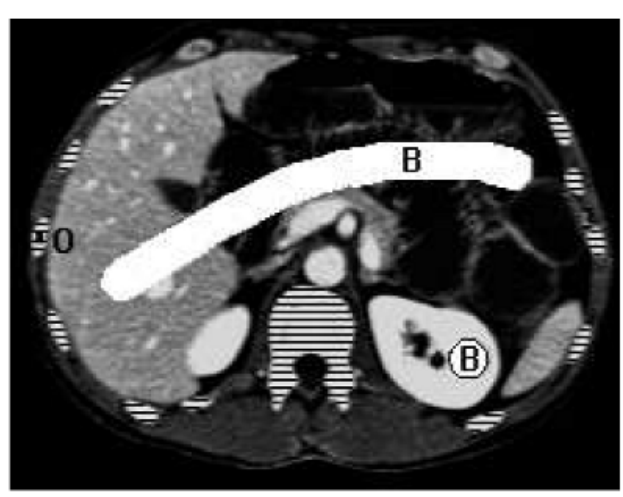

(a)
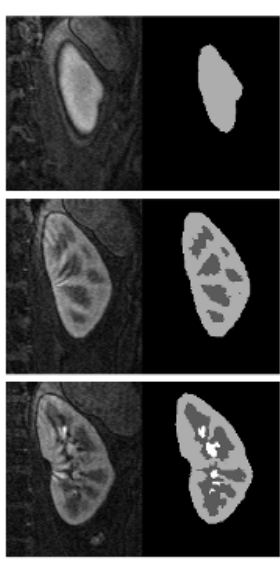
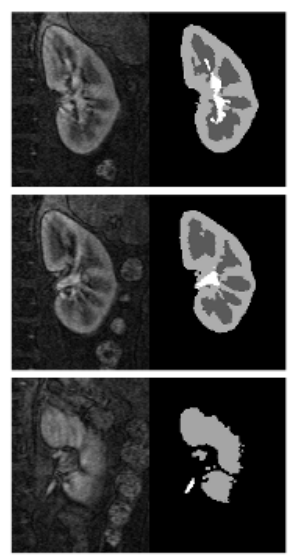

(b)

Figura 2.2: Aplicação da segmentação utilizando o GC. (a) Segmentação da parte óssea em uma fatia de tomografia computadorizada (b) Segmentação de um volume de ressonância magnética de rim [13].

\subsubsection{Transformada imagem-floresta}

A Transformada imagem-floresta (Image Forest Transform - IFT) [29] é definida como uma ferramenta para o projeto, implementação e avaliação de operadores para processamento de imagens baseados em conectividade e é utilizada de maneira interativa. A IFT usa como dados de entrada uma imagem $I$, uma função de custo $f$, um conjunto de pixels sementes $M$ e uma relação de adjacência $\mathcal{A}$, e retorna uma floresta de caminhos ótimos, na qual cada caminho que liga $t \in I$ até uma semente é ótimo. Na Figura 2.3(a) pode ser vista a representação de uma imagem como um grafo considerando uma relação de adjacência de 8-vizinhos com o conjunto de sementes para o objeto e o fundo. 
Os conceitos referidos na definição anterior são explicados a seguir.

- A relação de adjacência $\mathcal{A}$ é uma relação binária direcional entre os pixels da imagem $I$ que definem a existência das arestas.

- A função de custo de caminho $f$ indica o custo de um caminho entre pixels definindo deste modo os pesos das arestas.

- O conjunto de sementes $M$ é um conjunto de pixels pertencentes à imagem que definem o conjunto de raízes da floresta.

Baseado nas entradas da IFT é possível a construção de uma estrutura mais elaborada que facilita seu desempenho. É definido então o conceito de cena anotada. Esta estrutura de dados armazena os mapas de custo, raízes e predecessores da floresta associada à imagem $I$. A cena anotada é definida pelos seguintes parâmetros [7]:

- PRED: mapa de predecessores $(I \rightarrow I \cup$ nil $)$

- ROOT: mapa de raízes $\left(I \rightarrow I_{0}\right)$

- COST: mapa de custos ótimos $(I \rightarrow \mathbb{R})$

O mapa de predecessores indica qual é o pixel $P R E D(p)$ predecessor de cada pixel na floresta de caminhos mínimos, ou armazena um marcador nil para indicar que esse pixel é a raiz de uma árvore. O mapa de raízes indica qual é o pixel raiz $\operatorname{ROOT}(p)$ da árvore de caminhos mínimos a que cada pixel pertence. O mapa de custos COST armazena para cada pixel $p$ o custo $\operatorname{COST}(p)$ do caminho mínimo $\langle R O O T(p) \ldots p\rangle$. A função de custo de caminho $f$ cumpre com a seguinte definição de suavidade.

Definição Seja $\tau=\langle\operatorname{ROOT}(p), \ldots, p\rangle$ e $\pi=\tau \cdot\langle p, q\rangle$, onde $\tau$ é um caminho de custo mínimo entre $\operatorname{ROOT}(p)$ e $p$. Uma função de custo de caminho $f$ é dita suave se satisfizer as condições $C 1, C 2$ e $C 3$ para qualquer caminho $\pi$ em seu domínio:

- $\mathrm{C} 1: f(\tau) \leq f(\pi)$

- C2: $\tau$ é de custo mínimo

- C3: $f\left(\tau^{\prime} \cdot\langle p, q\rangle\right)=f(\pi)$ para todo caminho de custo mínimo $\tau^{\prime}$ que termina em $p$ 


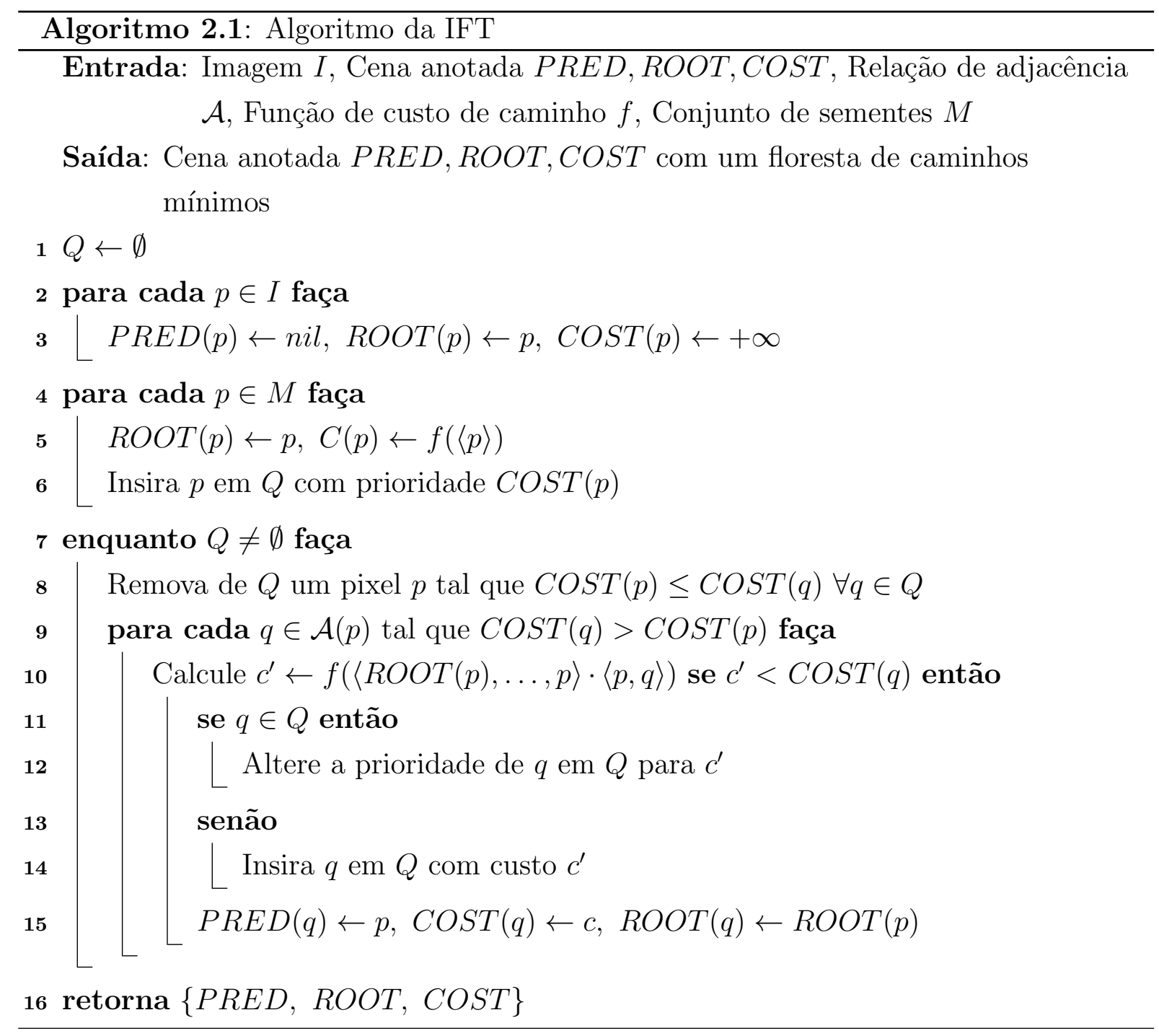

O algoritmo para o cálculo dos caminhos mínimos é uma adaptação do algoritmo de Dijkstra [28] o qual calcula os caminhos mais curtos partindo da uma única fonte. O Algoritmo 2.1 da IFT é o resultado de modificações para determinar os caminhos mínimos a partir dos pixels sementes - múltiplas fontes - e tendo como saída uma partição ótima do grafo.

O algoritmo começa declarando uma fila de prioridade $Q$ e inicializando os mapas PRED e COST com custos infinitos. No caso das raízes, todos os pixels começam tendo como raizes eles mesmos indicado no mapa ROOT. A seguir os pixels sementes $M$ são iniciados como raízes de árvores triviais e inseridos em $Q$. O passo seguinte é o procedimento principal, no qual são analisados cada uns dos pixels $p$ dentro da fila de prioridade tendo em consideração o que tenha o menor custo armazenado no mapa COST. Graças à relação de adjacência $\mathcal{A}$ são testados os pixels $q$ adjacentes a $p$, um por um, analisando o menor custo no mapa COST. Neste ponto é avaliado se o pixel $q$ deve ou não ser adicionado dentro do caminho mínimo que leva até $p$. Se isso for possível, o predecessor de $q$ e o custo do seu caminho são atualizados. Porém, é atribuído a $q$ a 
mesma raiz que $p$ no mapa $R O O T$. Com os dados atualizados, $q$ é inserido na fila de prioridade $Q$ caso ele não esteja nela. Quando a fila de prioridade fica sem nenhum pixel o algoritmo para e retorna como saída os mapas PRED, ROOT e COST. Na Figura 2.3(b) é apresentado o resultado da aplicação da IFT onde o objeto é satisfatoriamente separado do fundo por meio do cálculo dos caminhos mínimos.

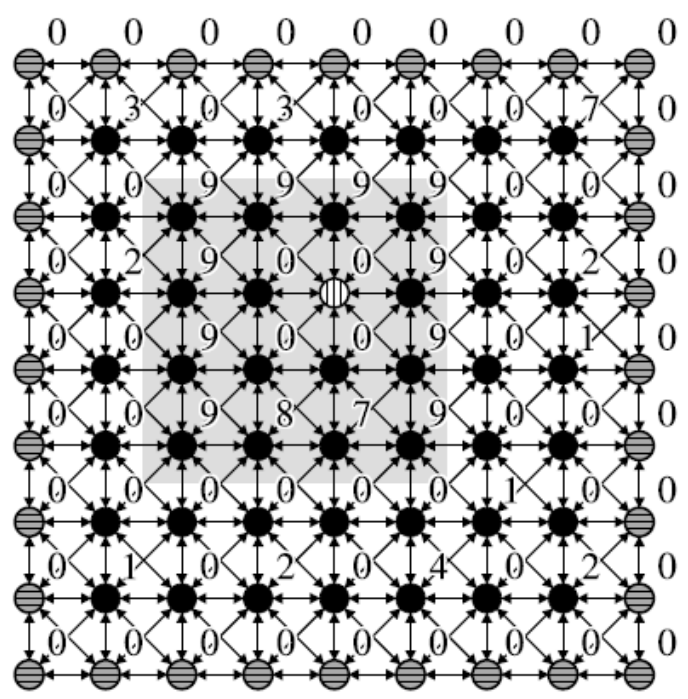

(a)

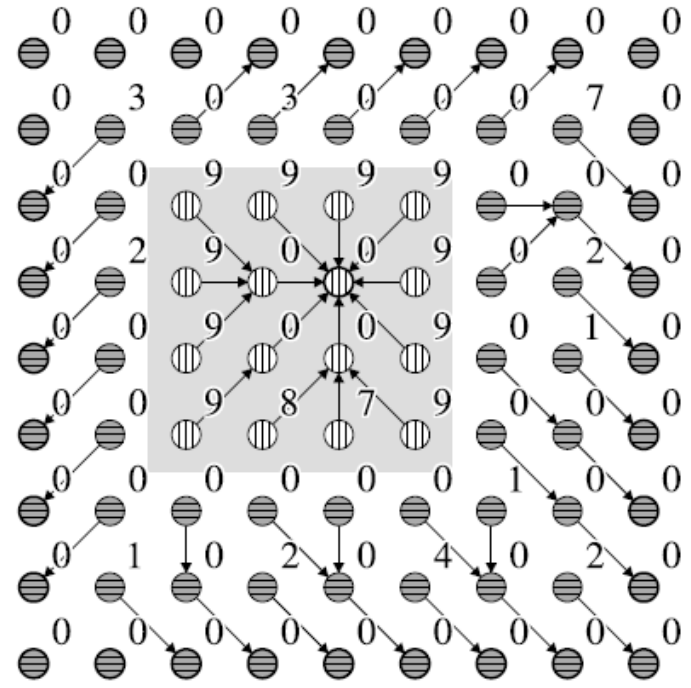

(b)

Figura 2.3: Representação da aplicação da IFT. (a) Um grafo de uma imagem onde os números indicam os valores das arestas e o quadro sombreado é o objeto procurado. As bordas da imagem são marcadas como sementes externas e o pixel branco interior é a semente interna. (b) O resultado da aplicação da IFT onde os números indicam os custos mínimos para chegar até uma semente. Os pixels de cor cinza indicam o fundo e os brancos, o objeto [8].

O conjunto de sementes fornecido pode ser restrito só a pixels dentro do objeto alvo ou a múltiplas regiões, como no caso de uma segmentação binária na qual são procurados o fundo e o objeto. A competição para a obtenção da floresta de caminhos mínimos com sementes em objetos distintos produz pixels de zona de empate (tie-zone pixels), pois apresentam mais de um caminho mínimo possível para duas sementes distintas. Um conjunto maximal de pixels de zona de empate que formam uma subárvore é denominado uma zona de empate. Este problema é resolvido por meio de políticas de inserção na fila $Q$ na qual podem ser utilizadas as estratégias primeiro a entrar, primeiro a sair (FIFO: first-in first-out) ou último a entrar, primeiro a sair (LIFO: last-in first-out).

A saída da IFT fornece um contexto ótimo para a aplicação de operadores de segmentação baseados em conectividade e um exemplo claro de método que utiliza este tipo de procedimentos é a transformada Watershed por meio de marcadores [9]. A ideia central do algoritmo, sem a utilização de marcadores, é baseada em conceitos topográficos onde a imagem é considerada uma superfície a qual é inundada a cada iteração. A superfície é 
construída por meio da intensidade presente nos pixels da imagem, dessa forma, existem partes altas e baixas que vão ser inundadas em tempos diferentes. Quando regiões adjacentes estão sendo inundadas e vão sumir para conformar uma única região, o algoritmo determina a existência de linhas divisórias entre as regiões. Este procedimento leva muitas vezes ao problema da super segmentação (over segmentation), sendo por esta razão, incluídos os marcadores. Estes marcadores podem ser internos ou externos, determinando as zonas pertencentes ao objeto ou ao fundo. Dessa maneira, o algoritmo tem conhecimento adicional que permite discernir melhor os objetos e apresentar um resultado mais adequado.

A transformada Watershed por meio de marcadores pode ser eficientemente implementada com a IFT e é denominada IFT por Competição de Sementes (IFT by Seed Competition - IFT-SC) [44] [49], utilizando a função de custo definida na Equação 2.4.

$$
\begin{gathered}
f(\langle t\rangle)=0 \\
f(\pi \cdot\langle s, t\rangle)=\max (f(\pi), \operatorname{grad}(t))
\end{gathered}
$$

onde $\operatorname{grad}(t)$ é o valor do gradiente no pixel $t$.

A IFT-SC apresenta tempos de resposta da ordem de segundos, aproximadamente entre 17 e 20 segundos no caso da segmentação de volumes cerebrais com uma média de 6 milhões de voxels. O resultado da segmentação completa de cérebro e cerebelo, considerando as correções do especialista, é apresentado na Figura 2.4. O experimento obteve um tempo de resposta de 9 minutos, o que faz este método comparável com o GC considerando o tempo de resposta. Estes experimentos realizados por Falcão [30], foram executados em um computador Athlon 1100 com 384 de RAM.

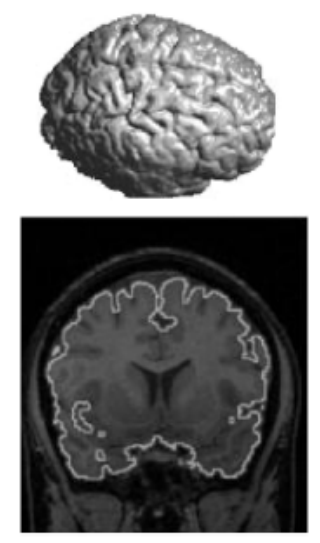

(a)

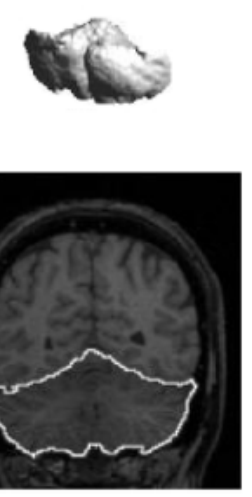

(b)

Figura 2.4: Exemplo de segmentação por meio da IFT por Competição de Sementes (IFT-SC) do (a) cérebro e (b) cerebelo [30]. 


\subsubsection{Relação entre a IFT e o GC}

A segmentação baseada na IFT-SC e o GC podem ser adaptadas para produzir os mesmos resultados e ser submetidas a uma análise comparativa. Deste modo, é possível obter certas conclusões sobre a sua aplicação [49]:

- O algoritmo do GC, utilizando restrições soft, depende da disponibilidade de mapas de probabilidade para conseguir calcular os valores para os termos $R$ e $B$. Esta dependência restringe a aplicação deste método para casos onde este tipo de informações encontrem-se disponíveis.

- O algoritmo da IFT pode ser comparado com o algoritmo do GC com restrições hard, pois neste caso o GC torna-se semiautomático e apresenta um procedimento de trabalho similar. Porém, o algoritmo da IFT possui um tempo de resposta linear, enquanto, o GC possue um algoritmo com custo polinomial.

- O GC possui um problema de sensibilidade a bordas finas - arestas com pesos pequenos - fazendo-o sensível a estas variações. A IFT devido à segmentação baseada no cálculo dos caminhos mínimos consegue delinear com maior robutez a imagem de entrada.

- O GC é uma implementação limitada da IFT, pois o GC não providencia como saída uma floresta de caminhos mínimos, nem um mapa de custos, tendo a imagem etiquetada como única saída.

\subsection{Métodos baseados em modelo}

Os métodos de segmentação baseados em modelo utilizam informações de um conjunto de objetos previamente identificados para segmentar uma nova imagem. Este conjunto de objetos é utilizado como imagens de treinamento para produzir um determinado modelo o qual representa as propriedades mais relevantes deste conjunto que ajudam ao reconhecimento dele. As propriedades extraídas e a maneira na qual elas são processadas geram um leque de distintos métodos de segmentação. Apessar disso, os métodos mais utilizados na prática para a segmentação de imagens médicas baseiam-se no uso de atlas de imagens o qual é explicado a seguir.

\subsubsection{Registro em atlas de imagens: FreeSurfer}

Um dos procedimentos mais utilizados na identificação de estruturas cerebrais é a segmentação baseada em atlas [20] [39] [42] [50] [2] [21]. Um atlas é composto de estruturas anatômicas delineadas e rotuladas com referência a uma imagem, no caso desta pesquisa, 
uma imagem do cérebro [59]. Os atlas são essenciais para a análise de imagens cerebrais, porque fornecem informações precisas e um ambiente de trabalho eficaz para sintetizar os resultados de diferentes estudos. Eles servem como modelos padrão nos quais as imagens do cérebro podem ser sobrepostas para posterior comparação e integração [46].

O processo de casamento de uma imagem específica a um atlas é conhecido como registro de uma imagem. Normalmente consiste em determinar uma transformação geométrica que alinha os pontos nesta imagem, denominada imagem original, com os pontos correspondentes de outra imagem, conhecida como a imagem de referência. O resultado do registro leva à identificação da estrutura de interesse. A maioria dos métodos de registro emprega os seguintes passos [68]:

- Detecção de características. Objetos salientes e distintivos são detectados manualmente ou, no melhor, caso de modo automático, como bordas, contornos, cantos, interseção de linhas, etc. Para o processamento posterior, estas características podem ser representadas por seus pontos mais significativos como centro de gravidade, terminações de linhas, subamostragem de pontos, entre outros, os quais são chamados pontos de controle.

- Pareamento de características. Neste passo é realizada a operação de correspondência das características detectadas na imagem original com a imagem de referência. São utilizados descritores de características e medidas de similaridade junto com relações espaciais.

- Estimação do modelo de transformação. São estimadas as funções de transformação para o alinhamento da imagem original com a imagem de referência. Os parâmetros das funções de mapeamento são calculados com base nas características extraídas.

- Amostragem e transformação da imagem. A imagem original é transformada por meio das funções de transformação. Os valores de coordenadas espaciais que não resultaram em valores inteiros são calculados por processos de interpolação.

Um caso de estudo importante é o software FreeSurfer [32] [33] [5], o qual é uma ferramenta automática de reconstrução e segmentação de tecidos cerebrais baseado no registro de atlas. O FreeSurfer é uma ferramenta poderosa, pois consegue identificar 37 classes de estruturas subcorticais diferentes incluindo entre elas o hipocampo.

O atlas utilizado pelo FreeSurfer é construído com base em imagens de treino do cérebro rotuladas manualmente. Todas elas são alinhadas no espaço de Tailarich [64] para encontrar uma correspondência voxel-a-voxel para todas as imagens. Para cada um das posições dos voxels existe uma etiqueta correspondente e um valor de intensidade. Assim, para cada um dos voxels são calculados três tipos de probabilidades. Primeiro, 
a probabilidade de que um voxel corresponda a uma determinada classe, isto é, qual é a etiqueta mais provável para ser atribuída. A segunda probabilidade considerada a vizinhança do voxel, calculando a probabilidade baseada na classificação dos voxels vizinhos. O terceiro valor considera a probabilidade de certa intensidade acontecer dentro de um tipo particular de classe.

O processo de segmentação consiste em encontrar a classe adequada para cada voxel da imagem de entrada, considerando a melhor combinação de etiquetas, a qual maximize as os valores das probabilidades calculadas com base no conjunto de treino. Para atingir este objetivo, são calculados dois novos valores probabilísticos. O primeiro é definido pela probabilidade de uma determinada classe ser indicada em um voxel da imagem de entrada, multiplicada pela verossimilhança do valor de intensidade de que este voxel pertença a esta mesma classe. A segunda probabilidade é baseada no valor de intensidade do voxel tomando como referência o conjunto de treino. Deste modo, para cada voxel da imagem de entrada é atribuído o rótulo da classe que obteve a maior probabilidade. Com esta segmentação inicial, as probabilidades de cada voxel são recalculadas considerando as distribuições das suas vizinhanças. Este procedimento é repetido até que duas segmentações consecutivas sejam iguais.

O resultado final é de alta qualidade e um ponto de referência na literatura atual. A Figura 2.5 apresenta o resultado calculado pelo FreeSurfer identificando diversas estruturas subcorticais. O tempo de resposta obtido para a execução do FreeSurfer utilizando todo o processo de segmentação foi de aproximadamente $3 \mathrm{~h}$ e $45 \mathrm{~min}$ em um computador Pentium i7 2.67 Ghz com 6 Gb de memória.

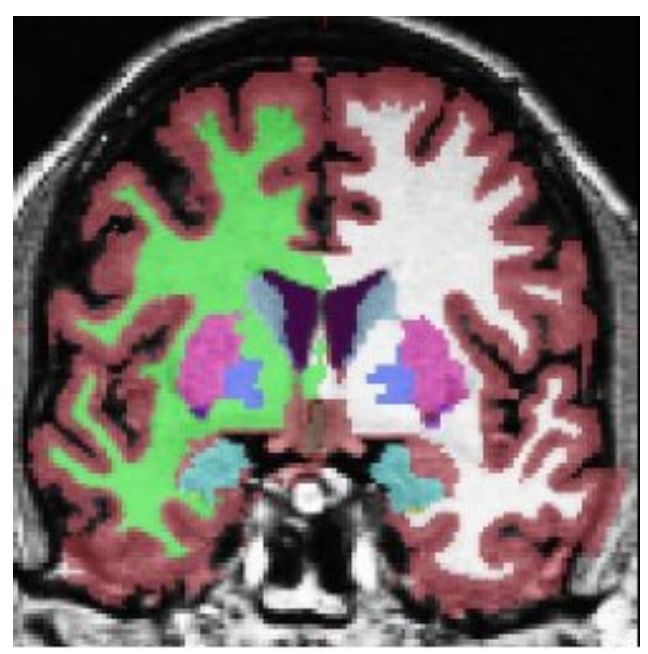

Figura 2.5: Segmentação de estruturas subcorticais produzida pelo FreeSufer. Cada cor indica um tipo diferente de região. O detalhe sobre a identificação dos tecidos pode ser obtido em [5] 


\subsubsection{Modelo Ativo de Forma}

O Modelo Ativo de Forma (Active Shape Model - ASM) [22] é outro método baseado em modelo e utilizado atualmente, o qual é construído estabelecendo um conjunto de pontos de referência nas imagens de treino. Os pontos são manualmente selecionados e utilizados como referência para o alinhamento das imagens de treino. Cada conjunto de pontos é alinhado a outro, por meio de operações de translação, rotação e escala. Este processo de alinhamento permite o estudo da forma dos objetos em um sistema de coordenadas similar e é denominado o espaço modelo do ASM. Para fornecer a representação da variabilidade - quantificar a diferença entre os pontos referência das imagens - é definido o Modelo de Distribuição de Pontos (Point Distribution Model - PDM) que será detalhado a seguir.

Sejam $n$ formas alinhadas $a_{1}, a_{2}, \cdots, a_{n}$ definidas sobre o espaço modelo, no qual $a_{i}=\left(x_{i 0}, y_{i 0}, \cdots, x_{n 0}, y_{n 0}\right)^{T}$ é um vetor de $2 n$ dimensões que descreve as coordenadas dos $n$ pontos na $i$-ésima forma. A forma média é definida como:

$$
\bar{a}=\frac{1}{n} \sum_{i=1}^{n} a_{i}
$$

Deste modo, também é descrita a matriz de covariância $C O V$ :

$$
C O V=\frac{1}{n-1} \sum_{i=1}^{n}\left(a_{i}-\bar{a}\right)\left(a_{i}-\bar{a}\right)^{T}
$$

A quantidade relevante de pontos de referência é determinada escolhendo os pontos que correspondem aos autovalores mais altos nesta matriz. Assim, só um subconjunto dos pontos iniciais é selecionado para alinhar uma nova forma. Assim, usando Análise de Componentes Principais (Principal Component Analysis - PCA), qualquer exemplo de entrada $a$ pode ser aproximado por

$$
a \approx \bar{a}+\epsilon b
$$

no qual $\epsilon=\left(\epsilon_{1} \epsilon_{2} \cdots \epsilon_{m}\right)$ é a matriz dos $m$ autovetores escolhidos e $b=\left(b_{1} b_{2} \cdots p_{m}\right)^{T}$ é um vetor de pesos que ajustam as modificações dos pontos originais do modelo chamado parâmetros da forma.

A obtenção dos pesos é um processo iterativo que consiste no ajuste de parâmetros de pose: translação, rotação e escala e os parâmetros da forma. Para cada modificação feita, a forma inicial deve parecer-se com a média estabelecida. Desta maneira, quando os parâmetros são atualizados seus valores são limitados dentro de um limiar específico permitindo que a forma sempre seja similar aos modelos no conjunto de treino. Como o ajuste para cada iteração não é perfeito, é utilizado o método dos mínimos quadrados para reduzir o erro. Obviamente, para um erro maior os parâmetros são ajustados com maior intensidade na próxima iteração ou menor intensidade caso contrário. Finalmente, o ajuste 
é finalizado quando as modificações feitas entre uma iteração e outra são insignificantes. Um exemplo de segmentação feita usando ASM é o apresentado na Figura 2.6.

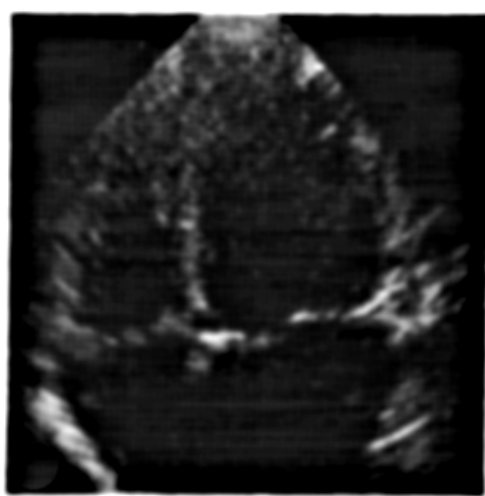

(a)

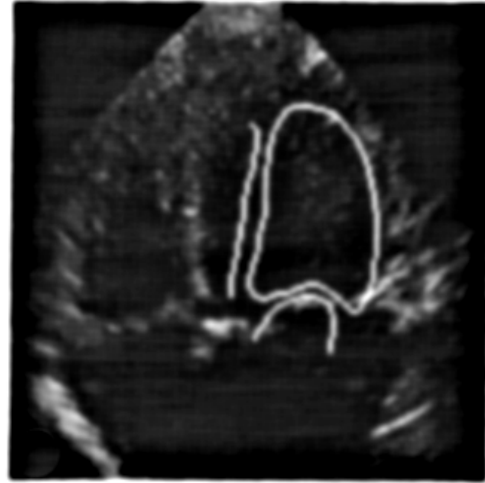

(b)

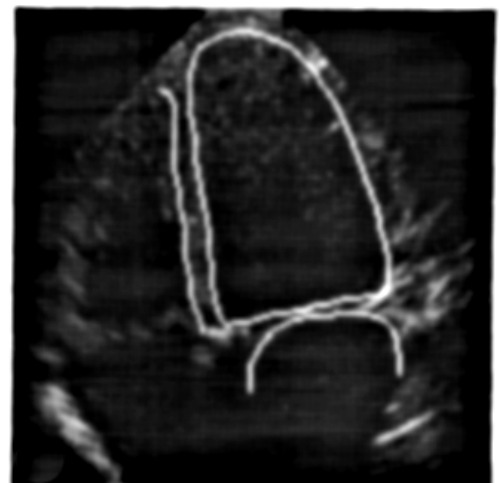

(c)

Figura 2.6: Exemplo de segmentação de um eletrocardiograma: (a) imagem original, (b) modelo na posição inicial, (c) modelo ajustado depois de 200 iterações $[22]$.

\subsection{Modelos híbridos}

Os métodos baseados em imagem utilizam somente propriedades da mesma imagem para fornecer um resultado, entretanto a falta de informação global sobre a localização do objeto conduz muitas vezes à falta de reconhecimento - o método atua sobre uma área qualquer da imagem sem considerar a verdadeira posição do objeto - especialmente em imagens complexas como são as imagens médicas. Por outro lado, nos métodos baseados em modelos muitas vezes são desprezadas informações importantes da imagem, pois o resultado final é forçado para encaixar-se ao modelo previamente estabelecido. Os métodos híbridos combinam características destes dois tipos de métodos com o objetivo de superar as desvantagens da primeira abordagem sem perder a qualidade da segmentação obtida.

\subsubsection{Corte mínimo de grafos utilizando informação a priori}

A segmentação baseada no GC (definida na seção 2.2.1) é um método baseado somente nas propriedades da imagem e depende do conhecimento prévio do usuário, pois se as sementes não são fornecidas, o método pode não funcionar corretamente. A solução para esse problema, é a inclusão de informação a priori para formar algum modelo que permita ter uma base probabilística do tipo de comportamento que tem as imagens médicas. Dessa maneira, é possível adaptar os parâmetros da função de minimização de energia para determinados tipos de órgãos.

Para a utilização de informação a priori é preciso ter uma determinada quantidade de imagens que sirvam como padrão para uma posterior estimativa em uma imagem objetivo. O enfoque mais apropriado para a construção destes padrões é elaborar um 
modelo probabilístico por meio do registro de diferentes atlas em uma única imagem objetivo. Todos os resultados deste processo de registro são considerados para a obtenção de um modelo que permita extrair informação sobre as propriedades do objeto alvo da segmentação.

$\mathrm{Na}$ literatura são relevantes os trabalhos propostos por Wolz et al. [66], van der Lijn et al. [42] e Liang et al. [41] que utilizam o conceito de corte mínimo de grafos e estão envolvidos nos processos de segmentação de órgãos cerebrais. Os dois primeiros, de modo particular, estão orientados à segmentação do hipocampo tendo obtido resultados promissores. A seguir é descrito de modo geral o trabalho de Wolz et al. que é o mais recente.

Wolz et al. [66] propõem um trabalho geral para a segmentação de estruturas subcorticais, uma delas o hipocampo. O processo começa com o registro da imagem objetivo por meio da propagação de etiquetas utilizando múltiplos atlas. Uma vez obtido o registro dos atlas na imagem objetivo é possível calcular dois modelos que possam ser aproveitados dentro do termo $R_{p}$ (Equação 2.2). O primeiro deles é um modelo de informação espacial a priori, que oferece um valor numérico sobre a probabilidade de um determinado pixel possuir alguma etiqueta em particular. O segundo modelo, é conformado pela estimativa da intensidade da imagem. É analisada a probabilidade de um pixel que pertence a uma determinada região possuir uma intensidade em particular. Estes dois modelos são colocados juntos do termo de propriedades da região.

O termo $B_{p}$ (Equação 2.2) é composto por uma função que indique a probabilidade de um pixel e sua vizinhança terem uma determinada etiqueta. Para atingir este objetivo, é necessário considerar as etiquetas designadas ao pixel analisado e à vizinhança dele por meio da construção de um mapa que penaliza esta medida quando a diferença de intensidades é superior a certo limiar. Se a intensidade dos pixels vizinhos é similar, então a probabilidade de que os pixels tenham a mesma etiqueta é maior e menor no caso contrário. Na Figura 2.7 é apresentado o resultado da aplicação desta técnica comparada com a segmentação por meio de atlas sobre duas estruturas subcorticais.

\subsubsection{Modelo de sistema de nuvens}

Uma proposta de interesse nesta pesquisa é o Modelo de Nuvens (Cloud Model - CM) [47] o qual utiliza a capacidade do reconhecimento dos métodos baseados em modelo e a qualidade do delineamento dos métodos baseados em imagem.

O Modelo de Nuvens demanda um conjunto de três elementos: um conjunto de nuvens $C=\left\{C_{1}, C_{2}, \cdots, C_{n}\right\}$, um algoritmo de delineamento $A$ - o qual fornece as características de um método baseado em imagem, e um funcional $F$. Uma nuvem $C_{i} \subset C$ é definida em base a um conjunto de treinamento de imagens binárias que são segmentações sobre alguma região de interesse. As imagens são transladadas até um ponto de referência 


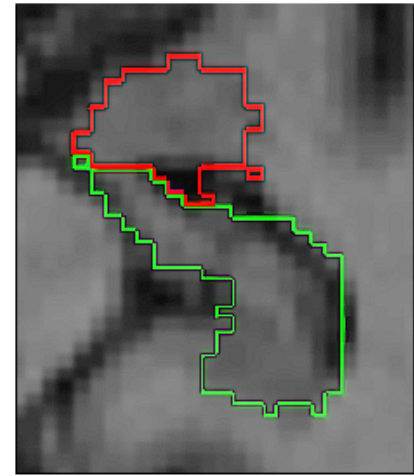

(a)

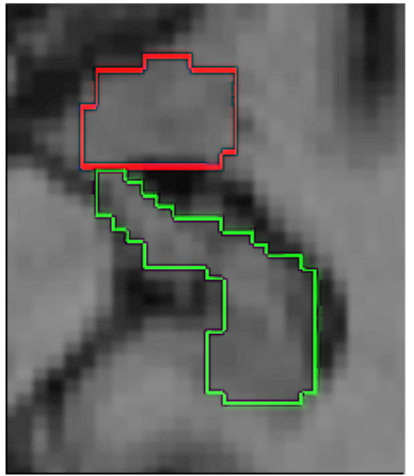

(b)

Figura 2.7: (a) Segmentação por meio de atlas e (b) segmentação pelo GC utilizando informação a priori do hipocampo (verde) e a amígdala (vermelho) [66].

comum e a média delas é calculada. O resultado deste processo é uma imagem difusa que tem a aparência de uma nuvem real, como é mostrado na Figura 2.8 (a). Cada nuvem possui três regiões i) objeto $\mathcal{O}_{C}$ : a região interior que possui os voxels que pertencem a todas as instâncias do conjunto de treinamento, ii) fundo $\mathcal{B}_{C}$ : a região exterior que possui os voxels que não pertencem a nenhum objeto e iii) incerteza $\mathcal{U}_{C}$ : a região média composta pelos voxels que pertencem a algumas, mas não a todas as instâncias.

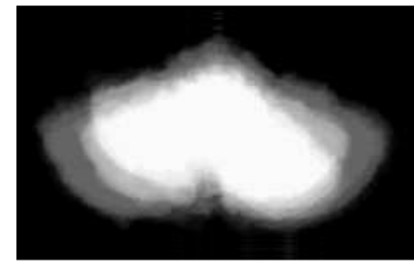

(a)

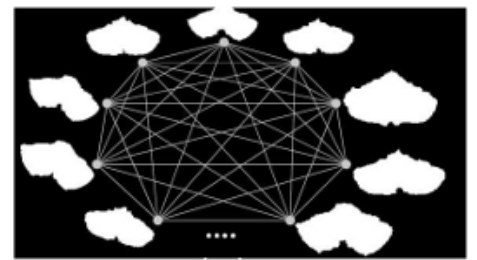

(b)

Figura 2.8: (a) Construção de uma nuvem baseada em segmentações prévias do cerebelo. (b) Clique formado por máscaras binárias do cerebelo para produzir um determinado cluster e finalmente uma nuvem $C_{i}$ [48].

O algoritmo de delinamento $A$ - segundo elemento do Modelo de Nuvens - nesta proposta é a IFT-SC (Algoritmo 2.1). Assim, para segmentar uma nova imagem $I$, a nuvem $C_{i}$ movimenta-se sobre ela e para cada posição $p \in I$ o algoritmo $A$ é executado dentro da zona de incerteza obtendo uma segmentação candidata ou denominada também imagem etiquetada $L_{p}$. Como a IFT-SC é um algoritmo interativo e é necessário fornecer as sementes, definem-se como sementes dois grupos de voxels: as sementes que concorreram para conquistar aqueles voxels mais parecidos com o fundo - todos os voxels de $\mathcal{B}_{C}$ - e as sementes que identificaram aos voxels mais parecidos com o objeto - todos os voxels de $\mathcal{O}_{C}$. Deste modo, a IFT-SC executa-se sem problemas e o resultado obtido é a imagem etiquetada $L_{p}$.

O funcional $F$, mencionado anteriormente como o terceiro elemento, será utilizado para avaliar cada segmentação produzida por IFT-SC quando percorre a imagem inteira. 
$F$ é definido com base na aplicação requerida, assim na proposta original, $F$ foi definido como a contagem de voxels com menor diferença à média de tons de cinza dos voxels que representam a matéria cinzenta, pois a intenção é procurar distinguir os hemisférios cerebrais e o cerebelo. O funcional é aplicado sobre $L_{p}$ cada vez que a IFT-SC é executada na posição $p$. Esta medição permite avaliar a qualidade de cada segmentação produzida e ao final do percurso da nuvem, saber qual é a melhor posição e assim a segmentação final é obtida.

O conjunto de nuvens $C$ é produzido pelo agrupamento das máscaras binárias do conjunto de treinamento. O procedimento é baseado na busca de cliques máximos num grafo completo, no qual os nós são cada uma das máscaras binárias e os pesos das arestas o valor do coeficiente Dice ${ }^{1}$ entre as máscaras. Os cliques máximos são considerados em relação a um limiar, somente aqueles pares de nós que possuam arestas com valores maiores são processados. Assim, se o limiar de similaridade é muito baixo o procedimento retornará um número grande de grupos, caso de um limiar muito alto a quantidade de agrupamentos é pequena. Cada grupo encontrado é a entrada para a construção de uma nuvem $C_{i}$ formando o conjunto final $C$.

Na Figura 2.9 é apresentado um exemplo de segmentação por meio do CM. O conjunto de treinamento utilizado foram máscaras binárias para os dois hemisférios cerebrais e o cerebelo. A aplicação deste método neste contexto leva um tempo aproximado de dois minutos num computador convencional com um processador de $3 \mathrm{Ghz}$ [48].

\section{Modelo de sistema de nuvens com Localização por similaridade}

O Modelo de Sistema de Nuvens com Localização por Similaridade Cloud Model with Localization by Similarity - CMLS é um modelo híbrido que introduz os conceitos de similaridade para melhorar a localização da estrutura procurada. Este método foi uma primeira tentativa desenvolvida no trabalho de mestrado com o objetivo de segmentar o hipocampo.

Este método está baseado no CM, explicado com maior detalhe na seção anterior, entretanto, o CMLS possui a grande diferença de fornecer ao funcional $F$ parâmetros para análise da similaridade. Deste modo, o método considera características que avaliam a similaridade entre a nuvem $C$ e a imagem objetivo $I$. Cada vez que a nuvem é posicionada sobre um pixel $p \in I$ são analisados todos os pixels cobertos pela nuvem sobre $I$, utilizando um perfil de intensidade baseado na seguinte função Gaussiana $\mathcal{G}$ :

$$
\mathcal{G}(I, p)=\frac{1}{\sqrt{2 \pi} \sigma} \exp \left[-\frac{1}{2}\left(\frac{I-\mu}{\sigma}\right)^{2}\right]
$$

\footnotetext{
${ }^{1}$ A definição do coeficiente Dice encontra-se na Seção 5.3
} 


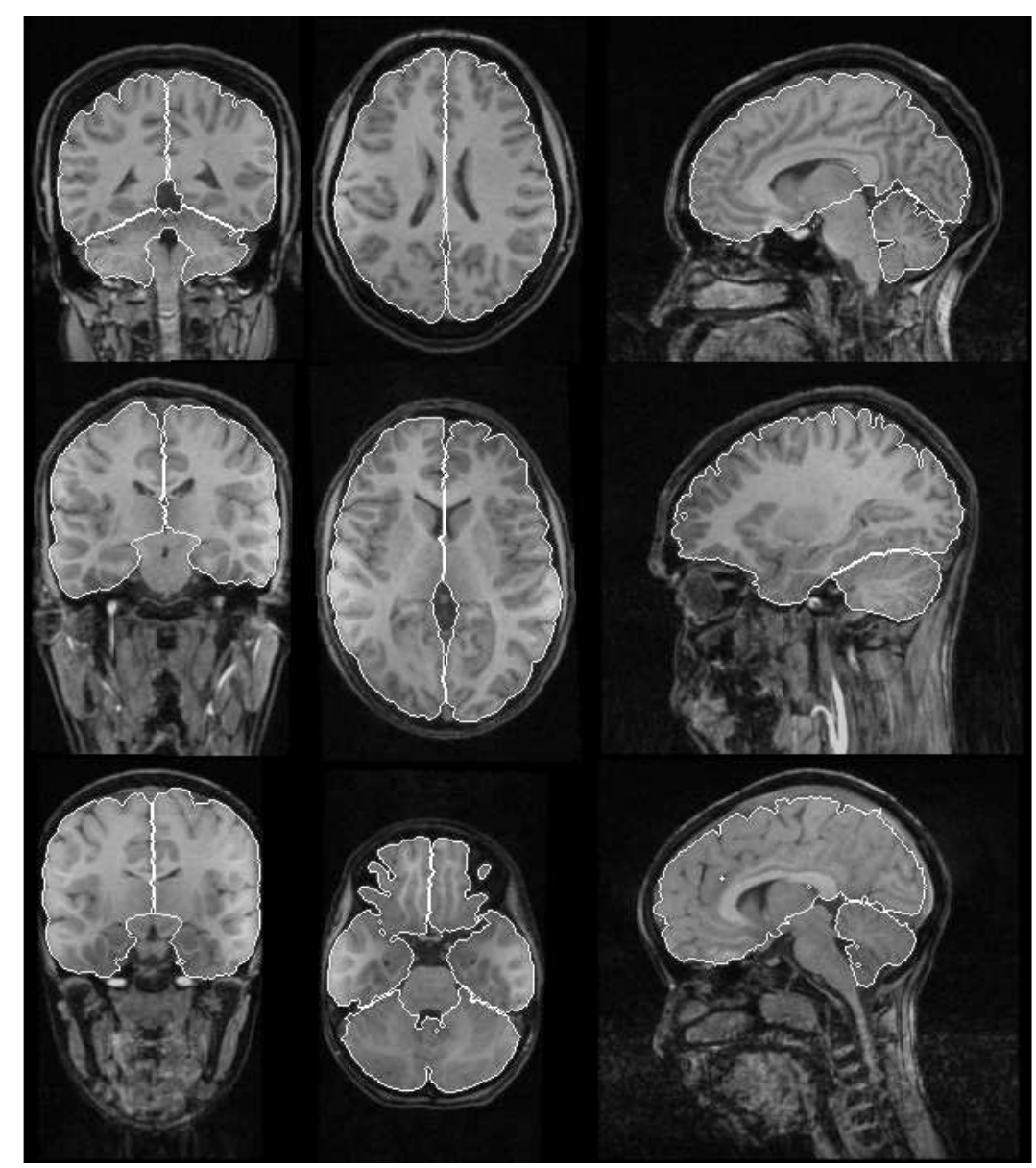

Figura 2.9: Fatias de um volume MRI segmentado utilizando o CM. As nuvens foram aplicadas para a segmentação dos hemisférios e o cerebelo [48].

na qual, $\mu$ e $\sigma$ representam a média e desvio padrão de níveis de cinza das imagens de treino que ajudaram na construção da nuvem.

Esta função mede a probabilidade de certa região de $I$ ser mais similar com a nuvem levando em consideração a sua intensidade. A medida final é determinada pelo somatório de todas as probabilidades individuais medidas sobre cada pixel. Obviamente, a região mais parecida com a nuvem é aquela que apresenta um maior nível de probabilidade acumulada. O processo de segmentação é finalizado aplicando o algoritmo de delineamento sobre a região ganhadora.

Os resultados obtidos por meio desta implementação conduzem a uma melhora pequena no processo de segmentação e por esta razão é deixado como um método adicional e não como foco central desta dissertação. A proposta de mestrado é discutida com mais profundidade no Capítulo 4. 


\subsection{Comparação entre os métodos de segmentação}

Considerando os métodos descritos anteriormente é apresentada na Tabela 2.2 uma comparação geral entre eles. Foram selecionados quatro critérios de comparação que ajudam a distinguir as diferenças relacionadas com aplicações em imagens. O primeiro é o Tipo de Operação a qual indica a forma como é tratada a imagem para ser segmentada. $\mathrm{O}$ próximo parâmetro é Imagem Objetivo, apontando o conjunto de imagens utilizado pela proposta original. O grau de interatividade é medido pela terceira característica denominada Dependência do Usuário. Finalmente, é analisada a Aplicação Médica, que refere-se ao uso da técnica dentro do contexto de imagens médicas.

Os três primeiro parâmetros - Tipo de Operação, Imagem Objetivo e Dependência do Usuário - são campos que facilitam a medição objetiva. Isto é, as informações utilizadas para estabelecer os valores na tabela, estão baseadas nos artigos originais destas propostas e que foram referenciados nas seções anteriores. No caso particular da última características - Aplicação Médica -, ela foi medida utilizando como referência a quantidade de artigos retornados pelo buscador Google Scholar google.scholar.com, quando foi feita a busca relacionada a cada método. Para evitar algum tipo de resultado errado, foram inseridas na busca, o nome do método, o nome do autor e o termo medical, com a intenção de obter resultados associados à aplicação na medicina. Devido que cada uns dos métodos tem antiguidade diferente, eles são divididos sobre o total de anos que o método leva existindo na literatura. Deste modo, os valores indicados na Tabela 2.2 para o campo Aplicação Médica, expressam a porcentagem de participação de cada um dos métodos sobre o total de resultados retornados pelo buscador.

\begin{tabular}{|c|c|c|c|c|l|}
\hline $\begin{array}{c}\text { Critério } \\
\text { Método }\end{array}$ & FreeSurfer & ASM & CM & GC & IFT-SC \\
\hline \hline $\begin{array}{c}\text { Tipo de } \\
\text { Operação }\end{array}$ & Regional & Pontual & $\begin{array}{c}\text { Pontual } / \\
\text { Regional }\end{array}$ & Pontual & Pontual \\
\hline $\begin{array}{c}\text { Imagem } \\
\text { Objetivo }\end{array}$ & $\begin{array}{c}\text { Segmentação } \\
\text { completa do } \\
\text { cérebro }\end{array}$ & $\begin{array}{c}\text { Ecocardio- } \\
\text { grama e } \\
\text { imagens } \\
\text { industrias }\end{array}$ & $\begin{array}{c}\text { GM / WM } \\
/ \text { CSF } \\
\text { vídeo e } \\
\text { imagens } \\
\text { industriais }\end{array}$ & $\begin{array}{l}\text { Cerebelo e } \\
\text { hemisférios } \\
\text { cerebrais }\end{array}$ \\
\hline $\begin{array}{c}\text { Dependência } \\
\text { do usuário }\end{array}$ & Automático & Automático & Automático & Interativo & Interativo \\
\hline $\begin{array}{c}\text { Aplicação } \\
\text { médica }\end{array}$ & $\begin{array}{c}\text { Alto } \\
(41.57 \%)\end{array}$ & $\begin{array}{c}\text { Médio } \\
(27.42 \%)\end{array}$ & $\begin{array}{c}\text { Baixo } \\
(1.44 \%)\end{array}$ & $\begin{array}{c}\text { Médio } \\
(24.77 \%)\end{array}$ & $\begin{array}{l}\text { Baixo } \\
(4.67 \%)\end{array}$ \\
\hline
\end{tabular}

Tabela 2.2: Tabela comparativa analisando os métodos de segmentação apresentados no decorrer do capítulo. 


\subsection{Considerações finais}

Este capítulo apresentou uma breve revisão e discussão sobre métodos de segmentação de imagens médicas, que foram selecionados por serem apropriados ao domínio de imagens (hipocampo) que este projeto de mestrado trata. Os métodos foram classificados segundo a origem das informações que permitem o cálculo da segmentação, dividindo assim os métodos em: métodos baseados na imagem e métodos baseados no modelo. Tal discussão visou embasar o leitor para que possa acompanhar o trabalho realizado e apresentado nesta dissertação de mestrado. 


\section{Capítulo \\ 3 \\ Recuperação de Imagens por Conteúdo e Consultas por Similaridade}

\subsection{Considerações iniciais}

Consultas de imagens por similaridade procuram respostas baseadas nas propriedades visuais da imagem considerando o que o analista humano percebe como similaridade. A comparação das imagens ou uma parte delas está intimamente relacionada com o tipo de propriedades comparadas e a maneira como são avaliadas. Assim, é preciso a execução de duas tarefas primordiais: a extração de características da imagem e a definição de funções de distância. As consultas por similaridade facilitam as comparações de uma ou várias imagens modelos com um repositório. Por exemplo, tendo imagens modelos de malformações ósseas da coluna o especialista poderia obter, de modo automático, todos aqueles exames que apresentem o mesmo comportamento. Da mesma maneira, um radiologista poderia selecionar um tipo de tecido dentro de um estudo de ressonância magnética e obter quais outras regiões são da mesma classe do tecido selecionado.

Embora exista um grande potencial associado a esta tecnologia, a maioria das pesquisas têm sido direcionadas para o seu uso dentro de sistemas de Recuperação de Imagens Baseada em Conteúdo (Content-based Image Retrieval - CBIR). Um sistema CBIR permite ao especialista gerenciar um repositório com uma grande quantidade de imagens, facilitando na área médica, por exemplo, a pesquisa e ensino com base no conteúdo da informação visual [52] [4]. Por esta razão os exemplos mencionados ao decorrer do capítulo estão relacionados com este tipo de sistemas. 


\subsection{Consultas por similaridade}

A busca de imagens por similaridade consiste na recuperação de imagens semelhantes à especificada, segundo algum critério fornecido pelo usuário. Para fornecer a resposta existem dois tipos de consultas comuns: a consulta por abrangência (Range Query) e a consulta aos $k$ vizinhos mais próximos (k-Nearest Neighbor Query).

As consultas por abrangência consistem na busca de objetos que tenham até um determinado nível de similaridade com o objeto de referência. Isto é, dado um conjunto de objetos $O=\left\{o_{1}, o_{2}, \ldots, o_{n}\right\}$ pertencentes a um domínio $D$, uma função de distância $d$ (explicada com mais detalhe na Seção 3.4), um objeto de consulta $o_{q}$ também pertencente ao domínio e uma distância máxima $r_{q}$, o resultado da busca por abrangência é dado por range $\left(o_{q}, r_{q}\right)=O^{\text {range }}=\left\{o^{\prime} \mid o^{\prime} \in O, d\left(o^{\prime}, o_{q}\right) \leq r_{q}\right\}$. A Figura 3.1(a) apresenta o resultado de uma consulta por abrangência no domínio bidimensional utilizando a função de distância Euclidiana $\left(\mathcal{L}^{2}\right)$.

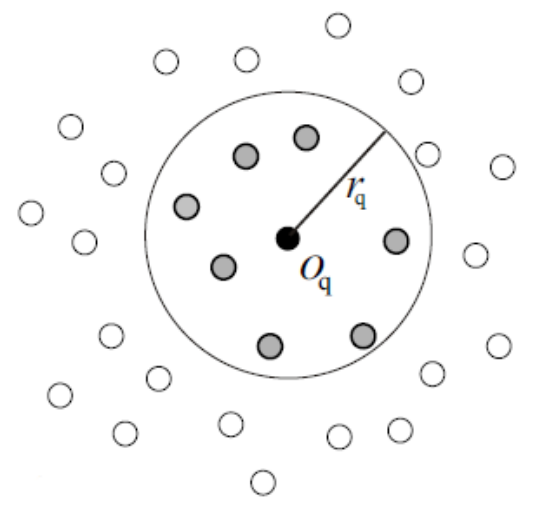

(a)

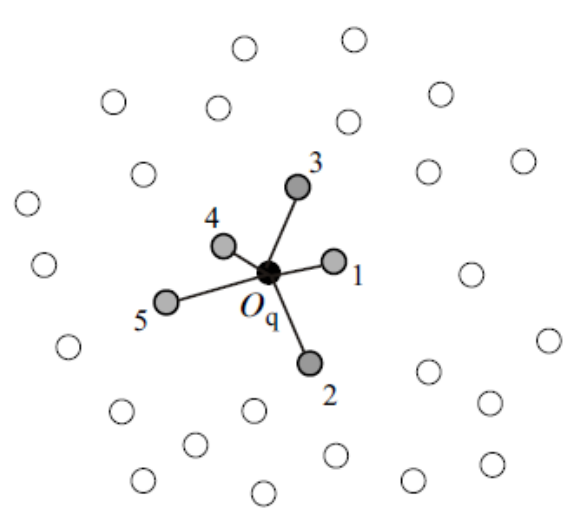

(b)

Figura 3.1: Representação de consultas por similaridade em um espaço bidimensional por meio da consulta (a) por abrangência e (b) pelos vizinhos mais próximos. O objeto $O_{q}$ é o centro da consulta e $r_{q}$ o raio de consulta.

A consulta aos vizinhos mais próximos consiste na busca dos $k$ objetos mais similares ao objeto de consulta. Em outras palavras, dado um conjunto de objetos $O=\left\{o_{1}, o_{2}, \ldots, o_{n}\right\}$ pertencentes a um domínio $D$, uma função de distância $d$, um objeto de consulta $o_{q}$ que também pertence ao domínio e um número inteiro $k$, o resultado da busca pelos vizinhos mais próximos é dado por: $k-N N\left(o_{q}, k\right)=O^{k n n}=\left\{o^{\prime} \mid o^{\prime} \in O, \forall o \in O-O^{k n n}, d\left(o_{q}, o^{\prime}\right) \leq\right.$ $\left.d\left(o_{q}, o\right),\left|O^{k n n}\right|=k\right\}$. A Figura 3.1(b) apresenta o resultado de uma consulta aos 5 vizinhos mais próximos em um domínio bidimensional por meio da função de distancia Euclidiana. 


\subsection{Extração de características}

Uma característica é uma função de uma ou mais variáveis, calculada de modo que quantifique alguma propriedade de um objeto. Nesta pesquisa em particular os objetos são as imagens médicas. Tendo em consideração que o domínio dos objetos estudados envolve imagens, um conjunto $n$ de características constitui o vetor de características da imagem. É possível então definir um espaço $n$-dimensional no qual todos os $n$ elementos deste vetor possam ser localizados, e desta forma, qualquer objeto que corresponda a um ponto neste espaço pertence ao denominado espaço de características [14].

As propriedades que uma imagem pode apresentar são muitas e algumas delas têm mais relevância que outras. A pergunta que precisa ser respondida é: quais das características devem ser extraídas, de modo que seja possível obter uma recuperação com significado real para o usuário? Neste contexto, a busca tem sido restringida como uma especificação das condições invariantes mínimas que modelam a intenção do usuário e mantêm o menor possível a diferença entre o solicitado pelo usuário e o que o sistema oferece como resposta. Esta última diferença é conhecida como lacuna semântica. As maiores contribuições que estudam as imagens como objeto de busca, têm um enfoque na extração de características como cor, textura e forma, discutidas a seguir.

\subsubsection{Cor}

O uso da cor no processamento das imagens é motivado por dois fatores principais. Primeiro, a cor é uma característica poderosa que simplifica a identificação de um objeto e sua extração dentro de uma cena. O processamento computacional da cor é importante pois embora os humanos possam discenir uma quantidade razoável de cores, conseguimos somente enxergar duas dúzias de níveis de cinza [34].

O histograma de cor de uma imagem é uma das representações mais utilizadas para expor uma imagem baseada nesta característica. No caso mais simples, uma imagem é descrita em níveis de cinza e tendo por convenção a cor branca como valor 1 (ou o maior valor que depende da profundidade da imagem) e o preto como 0 (ou o menor valor). O histograma de cor deste tipo de imagens é conhecido como histograma de níveis de cinza e é uma representação que indica o número de vezes que cada nível de cinza aparece na imagem. Frequentemente, o histograma é representado por um gráfico de barras em duas dimensões com o eixo $x$ indicando o nível de cinza e no eixo $y$ a quantidade de vezes que ele ocorre, como é apresentado na Figura 3.2(a). Um exemplo da aplicação do histograma de cor para a recuperação de imagens por conteúdo é o sistema SRIS (Sistema de Recuperação de Imagens por Similaridade) [14] (ver Figura 3.2(b)). 


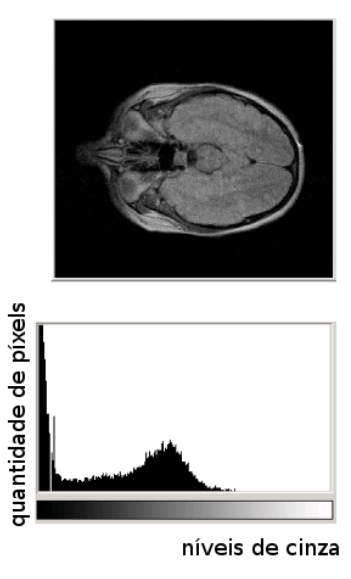

(a)

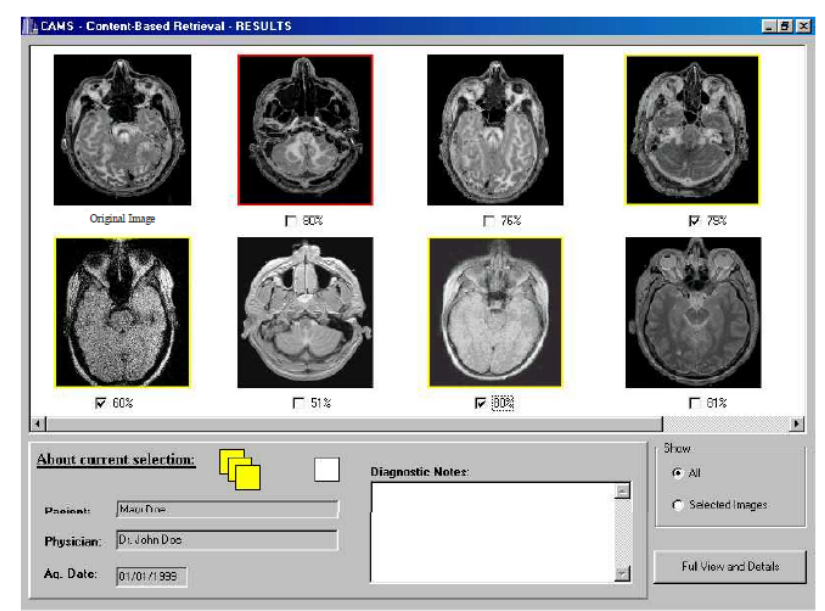

(b)

Figura 3.2: (a) Imagem quantizada em 256 níveis de cinza e seu histograma associado. (b) Tela de resultados de consulta do sistema SRIS baseado na comparação de histogramas de cor [14].

Além do histograma de cor, existem múltiplos descritores que conseguem representar uma imagem baseada no atributo cor. Uma técnica derivada diretamente do histograma é a aplicação do histograma de cor local (local color histogram - LCH). O método divide a imagem em múltiplas regiões de igual tamanho e o histograma de cada uma delas é calculado e quantizado de modo que possam formar uma matriz final que representa o descritor da imagem [45]. Outro exemplo de técnica baseada em cor é a aplicação da classificação pixel borda/interior (border/interior pixel classification - BIC), na qual todos os pixels são analisados para determinar se podem ser classificados como borda ou interior em um espaço de cor de 64 cores [61]. Uma técnica bastante conhecida é o vetor de coerência de cor (color coherence vector - CCV). Nessa técnica a coerência da cor é definida como grau de pertinência de um pixel a uma região larga da mesma cor e o descritor é formado pela informação da classificação das regiões como coerentes o incoerentes [55] [61].

\subsubsection{Textura}

O atributo de textura em uma imagem está relacionado com os padrões de granularidade e repetitividade de certas superfícies dentro dela. Por exemplo, vidro, paredes de tijolo, pelúcia ou pétalas de flor são distintos tanto pela suavidade de suas superfícies como pelos padrões produzidos por elas. Estes padrões podem ser o resultado das propriedades físicas do objeto ou simplesmente resultado da reflexão da luz na superfície. Apesar do reconhecimento de uma textura ser fácil para as pessoas, isso não acontece de modo similar com procedimentos automáticos, pois para esta tarefa muitas vezes é necessária a utilização de técnicas computacionais complexas [26] [17]. 


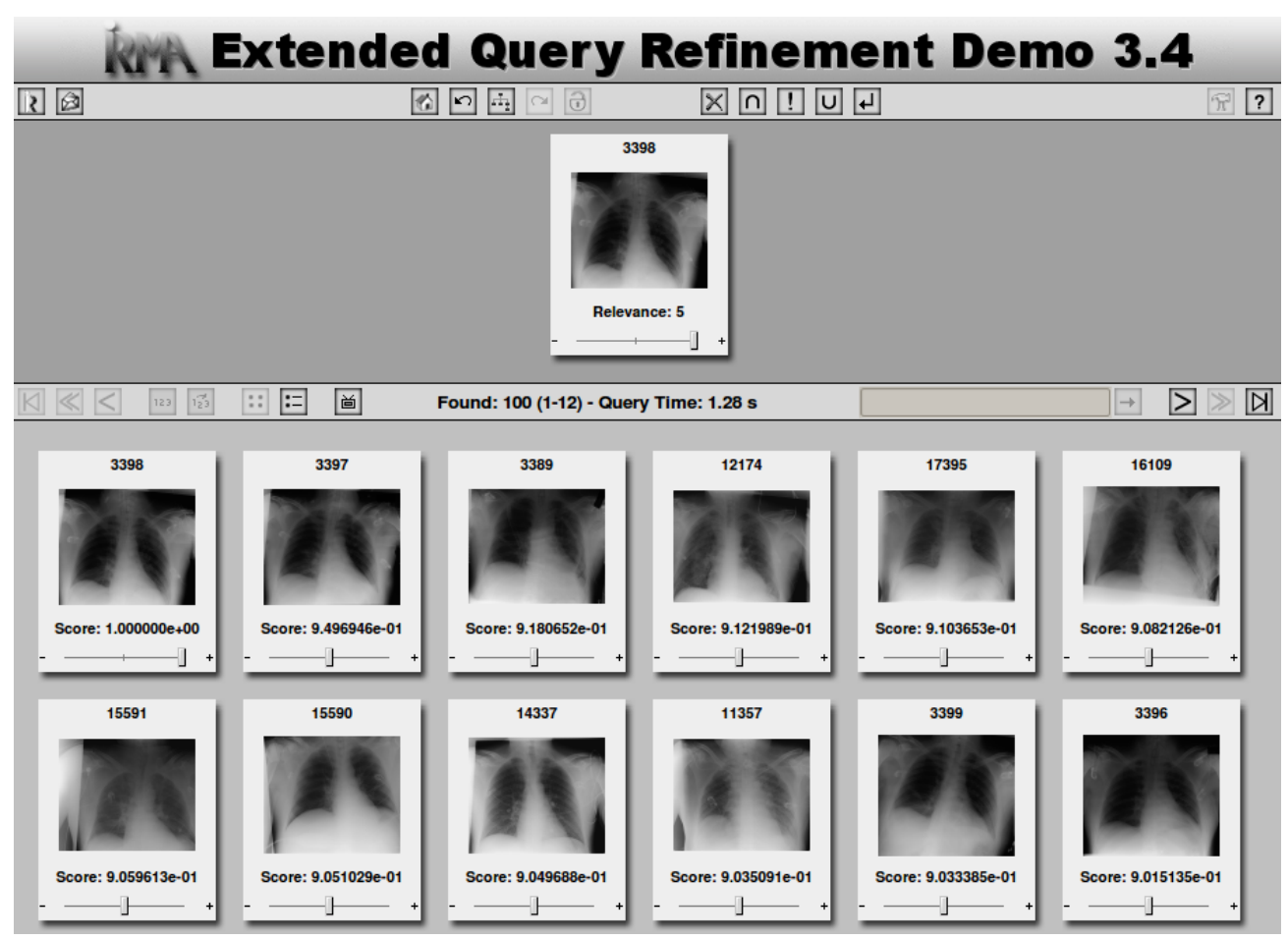

Figura 3.3: Interface de usuário de IRMA para consultas por similaridade por meio da extração de característica de textura [40].

Basicamente, os métodos de representação de textura podem ser classificados em duas categorias: estruturais e estatísticos. O enfoque estrutural está dentro da classificação e segmentação de imagens que possuem comportamentos bem definidos, em outras palavras, um comportamento determinístico. Nesse caso, as imagens são compostas por um padrão repetitivo de elementos estruturais denominados textels. Os métodos estruturais incluindo operadores morfológicos e grafos de adjacência descrevem as texturas identificando primitivas estruturais e suas posições. Esses métodos são mais efetivos quando são aplicados a imagens com texturas regulares. Considerando que a maioria das texturas na natureza não possui este tipo de comportamento, a utilização dos métodos estruturais serve a um conjunto limitado de problemas.

Por outro lado, um enfoque estatístico requer a análise numérica dos pixels. As informações extraídas não estão baseadas em algum tipo de estrutura ou distribuição espacial de padrões. Um enfoque estatístico para a descrição de textura é gerar a transformada de Fourier da imagem e depois agrupar os dados transformados de modo que seja obtido um conjunto de medidas. As medidas mais utilizadas neste contexto são: a magnitude, a entropia, a energia e a inércia. Uma vantagem da transformada de Fourier é ela ser invariante às operações de translação e dependendo do tratamento das medidas calculadas é possível obter invariância à rotação. Outro método estatístico muito utilizado corresponde às matrizes de coocorrência. Esta proposta foi uns dos primeiros intentos para descrever e depois classificar texturas. As matrizes de co-ocorrência contêm elementos 
que representam quantidades de pares de pixels de uma cor em particular separados por alguma distância em uma determinada inclinação [54].

Um dos sistemas CBIR mais populares e que utiliza a característica de textura como atributo para a extração de características é o IRMA (Image Retrieval in Medical Applications - Recuperação de Imagens em Aplicações Médicas) [40] (ver Figura 3.3). Este sistema oferece suporte para a classificação de radiografias baseada em medidas de textura e intensidade extraídas globalmente das imagens. Em determinados contextos, isto pode se tornar uma desvantagem, pois muitas das consultas precisam de uma resposta baseada em detalhes e não simplesmente em características globais.

\subsubsection{Forma}

A informação de forma é usualmente descrita só depois que as imagens tenham sido segmentadas em regiões ou objetos. A segmentação precisa e robusta das imagens é difícil de atingir e, portanto o uso de características de forma tem sido limitado a aplicações onde a informação de objetos e regiões estejam disponíveis [43].

Um dos métodos mais tradicionais para a caracterização de imagens por meio da forma são os descritores de Fourier. Este método é aplicado quando o contorno da forma foi previamente extraído. Assim, considerando a borda do objeto como uma sequência cerrada de pixels, são calculadas representações de contorno, como curvatura, distância ao centróide e função de coordenada complexa. Finalmente, é obtida a transformada de Fourier destes três tipos de representações, o que conduz na formação de um conjunto de coeficientes complexos que representam a forma do objeto [43].

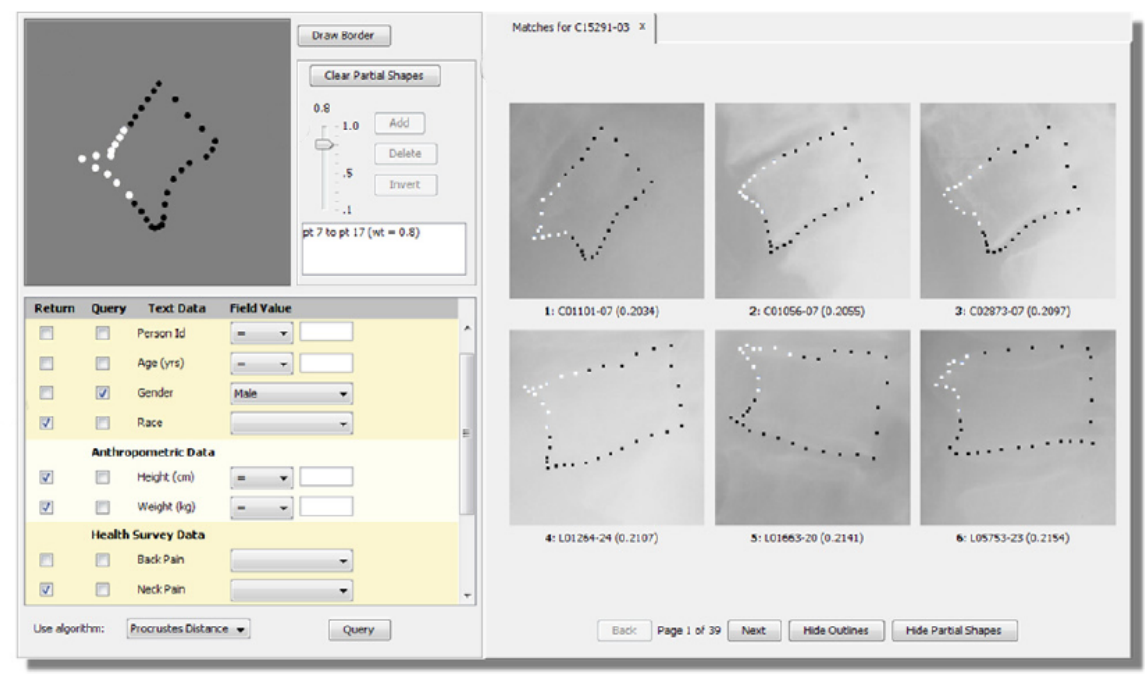

Figura 3.4: Tela do sistema SPIRS com a resposta da consulta baseada no atributo forma. O usuário faz o desenho de uma forma e são retornadas as imagens com a forma mais aproximada [36]. 
A extração do atributo forma no contexto da análise de imagens médicas é muito relevante devido ao fato que múltiplos órgãos humanos possuem formas claramente identificáveis. As formas do coração, cérebro, rins e vários ossos são conhecidas e em casos normais elas não mudam muito da forma tradicional. Entretanto, as doenças podem afetar a estrutura dos órgãos e provocar modificações nestas formas [58]. Por esta razão, os métodos para a caracterização da forma têm sido amplamente desenvolvidos e integrados dentro de sistemas CBIR. Um exemplo deles é o sistema SPIRS (Spine Pathology \& Image Retrieval System) [36] (ver Figura 3.4) que trabalha sobre imagens de radiografia da espinha vertebral no qual o usuário fornece de um esboço como consulta além de certos parâmetros textuais e são retornadas imagens de vértebras similares.

As técnicas mencionadas anteriormente não têm um enfoque determinado para objetos tridimensionais, característica particular dos objetos embutidos dentro de imagens de ressonância magnética, que é o enfoque desta pesquisa. Para objetos tridimensionais, é possível utilizar representações sobre a distribuição do volume no seu Retângulo Envolvente Mínimo (Minimum Bounding Box - MBB). Medidas como a média e desvio padrão do MBB são concentradas em um vetor de características. Do mesmo modo, existem momentos invariantes $3 D$ os quais fornecem uma maneira simples e rápida para caracterizar a forma. Estes métodos são definidos por equações do segundo e terceiro grau apresentadas a seguir [53]:

$$
m_{i j k}^{0}=\int_{-\infty}^{+\infty} \int_{-\infty}^{+\infty} \int_{-\infty}^{+\infty} x^{i} y^{j} z^{k} I(x, y, z) d x d y d z
$$

onde $(x, y, z)$ são as coordenadas do voxel $I(x, y, z)$ é o valor do voxel localizado naquelas coordenadas. Estes momentos podem ser acrescentados com invariância à translação por meio de:

$$
m_{i j k}^{1}=\int_{-\infty}^{+\infty} \int_{-\infty}^{+\infty} \int_{-\infty}^{+\infty}(x-\bar{x})^{i}(y-\bar{x})^{j}(z-\bar{z})^{k} I(x, y, z) d x d y d z
$$

onde $\bar{x}, \bar{y}$ e $\bar{z}$ são as coordenadas dos centroides de $I(x, y, z)$, calculadas do seguinte modo:

$$
\bar{x}=\frac{m_{100}^{0}}{m_{000}^{0}}, \quad \bar{y}=\frac{m_{010}^{0}}{m_{000}^{0}}, \quad \bar{z}=\frac{m_{001}^{0}}{m_{000}^{0}}
$$

Para obter invariância à escala é feita a seguinte normalização:

$$
m_{i j k}=\frac{m_{i j k}^{1}}{m_{000}^{1} \frac{i+j+k}{3}+1}
$$

Assim, são finalmente definidos os seguintes cinco momentos: 


$$
\begin{aligned}
M_{1}= & m_{200}+m_{020}+m_{002} \\
M_{2}= & m_{200} m_{020}+m_{200} m_{002}+m_{020} m_{002}-m_{101}^{2}-m_{110}^{2}-m_{011}^{2} \\
M_{3}= & m_{200} m_{020} m_{002}-m_{002} m_{110}^{2}+2 m_{110} m_{101} m_{011}-m_{020} m_{101}^{2}-m_{200} m_{011}^{2} \\
M_{4}= & m_{300}^{2}+m_{030}^{2}+m_{003}^{2}+3 m_{210}^{2}+3 m_{201}^{2}+3 m_{120}^{2}+6 m_{111}^{2}+3 m_{102}^{2}+3 m_{021}^{2}+3 m_{012}^{2} \\
M_{5}= & m_{400}^{2}+m_{040}^{2}+m_{004}^{2}+4 m_{310}^{2}+4 m_{301}^{2}+6 m_{220}^{2}+12 m_{211}^{2}+6 m_{202}^{2} \\
& +4 m_{130}^{2}+12 m_{121}^{2}+12 m_{112}^{2}+4 m_{103}^{2}+4 m_{031}^{2}+6 m_{022}^{2}+4 m_{013}^{2}
\end{aligned}
$$

\subsection{Funções de distância}

Depois de ter extraído as características das imagens e ter obtido sua representação em vetores numéricos, a operação que possibilita estabelecer o nível de semelhança entre duas imagens de um repositório baseia-se em uma função de distância (dissimilaridade). É importante definir adequadamente esta função em relação ao conjunto de características proposto com o objetivo de que a inferência da similaridade entre as imagens possa corresponder da melhor maneira ao concebido pelo usuário do sistema [6].

Existem na literatura numerosas funções de distância que tem sido estudadas e analisadas por suas vantagens e desvantagens [15] [16] [18]. Por exemplo, funções mais simples produzem um cálculo muito rápido, podendo fazer a comparação de imagens de modo escalável, o que é uma qualidade desejável em aplicações de tempo real. Entretanto, muitas vezes não são suficientemente eficazes para serem utilizadas. Os fatores que caracterizam as funções de distância são: o tipo de entrada, método de cálculo, complexidade computacional e se a função é uma métrica ou não [26].

De modo geral, as funções de distância são definidas sobre um universo $X$ no qual um subconjunto $U$ de objetos válidos, denominado dicionário, banco de dados ou simplesmente conjunto de elementos representará a coleção de objetos na qual se realiza a busca. Uma função de distância $d: X \times X \rightarrow \mathbb{R}$, é denotada $d$ e chamada distância entre dois elementos $(x, y) \in X$ se possui as seguintes propriedades:

- Não negatividade: $\forall x, y \in X, d(x, y) \geq 0$

- Simetria: $\forall x, y \in X, d(x, y)=d(y, x)$

- Reflexividade: $\forall x \in X, d(x, x)=0$

Se $d$ além das propriedades anteriores satisfaz:

- Desigualdade triangular: $\forall x, y, z \in X, d(x, y) \leq d(x, z)+d(z, y)$

então d é chamada uma função de distância métrica ou simplesmente métrica [18]. 


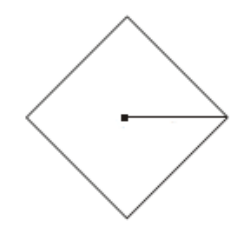

(a)

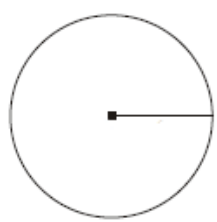

(b)

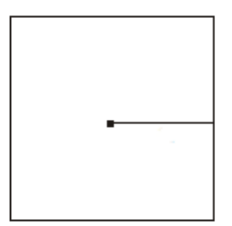

(c)

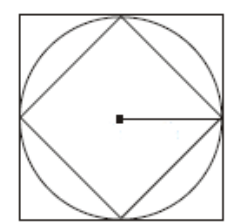

(d)

Figura 3.5: Representação das formas geométricas geradas no espaço Euclidiano 2D de acordo com a família de distâncias $\mathcal{L}^{p}$ pelos pontos equidistantes baseados nas distâncias (a) $\mathcal{L}^{1}$, (b) $\mathcal{L}^{2}$, (c) $\mathcal{L}^{\infty}$, (d) a superposição das três representações anteriores [15].

Dentro da área de $C B I R$ têm sido estudadas muitas funções, métricas e não métricas. Uma das mais conhecidas e que é apresentada nesta seção é a familia de distâncias de Minkowski (família $\mathcal{L}^{p}$ ). Para a definição desta família de distâncias são definidos dois vetores $P=\left(p_{0}, p_{1}, \ldots, p_{n-1}\right)$ e $Q=\left(q_{0}, q_{1}, \ldots, q_{n-1}\right)$ de $N$ características, os quais representam os valores de entrada de $\mathcal{L}^{p}$ a qual é definida da seguinte forma:

$$
\mathcal{L}^{p}(P, Q)=\left(\sum_{i=0}^{N-1}\left(p_{i}-q_{i}\right)^{p}\right)^{\frac{1}{p}}
$$

Esta família de funções contém três exemplos bem conhecidos. A primeira delas é a função $\mathcal{L}^{1}$ conhecida como distância Manhattan ou City block a qual corresponde ao somatório do módulo das diferenças entre os elementos dos vetores e é definida formalmente como:

$$
\mathcal{L}^{1}(P, Q)=\sum_{i=0}^{N-1}\left|p_{i}-q_{i}\right|
$$

A distância $\mathcal{L}^{2}$, comumente utilizada para o cálculo de distância entre vetores, é definida da seguinte maneira:

$$
\mathcal{L}^{2}(P, Q)=\sqrt{\sum_{i=0}^{N-1}\left(p_{i}-q_{i}\right)^{2}}
$$

Na equação 3.8, se $p$ tende ao infinito, obtém-se a função de distância $\mathcal{L}^{\infty}$, conhecida também como Infinity ou Chebychev, a qual é definida como:

$$
\mathcal{L}^{\infty}(P, Q)=\max _{0 \leq i<N}\left[\left|p_{i}-q_{i}\right|\right]
$$

Na Figura 3.5 são apresentadas as formas geométricas das regiões com mesma distância geradas pelas funções da família $\mathcal{L}^{p}$. De modo particular, a geometria calculada pela função $\mathcal{L}^{1}$ na Figura 3.5(a), $\mathcal{L}^{2}$ na Figura 3.5(b) e $\mathcal{L}^{\infty}$ na Figura 3.5(c) considerando um espaço bidimensional. A sobreposição das representações geométricas das funções na 
Figura 3.5(d) distingue os subespaços os quais englobam as diferentes funções de distância $[15]$.

\subsection{Considerações finais}

Este capítulo sumarizou os principais conceitos envolvendo consultas por similaridade e recuperação por conteúdo. Seu objetivo foi contextualizar o leitor no conteúdo necessário para acompanhar o panorama da pesquisa realizada nesta dissertação de mestrado. Foram apresentados diferentes sistemas CBIR cada um deles utilizando um tipo de extrator diferente e orientados a um conjunto de imagens distinto. Deste modo, o Capítulo 2 e o Capítulo 3 apresentaram uma referência teórica visando contextualizar e permitir o entendimento da proposta de mestrado. Assim, nos capítulos seguintes serão abordados os tópicos relacionados diretamente com o método proposto. 


\section{Capítulo \\ 4 \\ Modelo de Nuvem de Similaridade}

Neste capítulo é apresentado o modelo de segmentação de imagens desenvolvido no período do mestrado. O problema central desta pesquisa foi desenvolver um método automático, eficaz e eficiente para segmentar o hipocampo. Para atingir este objetivo partimos de uma premissa principal: o uso dos métodos de segmentação híbridos em combinação com as consultas por similaridade poderia propiciar bons resultados. A razão desta proposta é o aproveitamento da eficiência dos métodos híbridos e o poder de discriminação que as buscas por similaridade oferecem. Deste modo, esta pesquisa introduz um novo método automático de segmentação denominado Modelo de Nuvem de Similaridade (Similarity Cloud Model - SimCM) que está baseado em uma operação de duas tarefas principais: reconhecimento - o qual permite a localização do hipocampo dentro do volume MRI e delineamento - o qual identifica os limites dos tecidos do hipocampo frente às estruturas vizinhas.

\subsection{Considerações iniciais}

O trabalho desenvolvido foi inspirado nos conceitos de recuperação de imagens por conteúdo. Assim, a primeira premissa veio do processamento de CBIR, que requer uma imagem como entrada e um conjunto de imagens para ser comparada. Seguindo esta linha de pensamento, o modelo proposto define como entrada da consulta a nuvem $C$ e como espaço de busca o conjunto de todas as regiões dentro da imagem objetivo $I$ a ser segmentada, na qual a nuvem é capaz de sobrepor-se. Cada vez que a imagem é transladada sobre um voxel particular $p \in I$, a região sobreposta converte-se em uma 
região candidata e é avaliada por um funcional $F$ baseado na comparação de suas características. Deste modo, a busca pela melhor posição da nuvem, é uma consulta dentro de uma imagem tridimensional utilizando análise da similaridade. Este fato conduz no desenvolvimento de um novo conceito: a Nuvem de Similaridade. Neste modelo, a nuvem é definida pelo agrupamento de imagens de treinamento utilizando extração e comparação de características, e com isto providenciando maior robustez e qualidade.

Na Figura 4.1 é possível visualizar o pipeline completo do modelo proposto. As contribuições dos trabalhos correlatos podem ser classificadas utilizando os procedimentos ilustrados neste pipeline da maneira seguinte: os conceitos de CBIR e consultas por similaridade são aproveitados nos processos $(1,3,4)$, as vantagens do delineamento da IFT-SC são utilizadas em $(4,5)$ e o Modelo de Nuvens é estendido e melhorado nos procedimentos $(1,4,5)$. O fluxo de trabalho é divido em três partes principais: entrada, pré-processmento e a execução do modulo principal do SimCM. Devido que o SimCM é um método baseado no Modelo de Nuvens (2.4.2), ele requer de um conjunto de treinamento como entrada uma única vez, o qual serve para a elaboração das nuvens. Do mesmo modo, a imagem objetivo para ser segmentada é requerida. No pré-processamento é considerada a construção das nuvens (1) junto ao cálculo dos pesos das arestas do grafo que representa a imagem de entrada (2). A segmentação final é obtida por meio da busca por similaridade (4) e o ajuste da nuvem (5) no módulo correspondente ao processamento do SimCM. A extração de características (3) encontra-se presente durante toda a execução da segmentação.

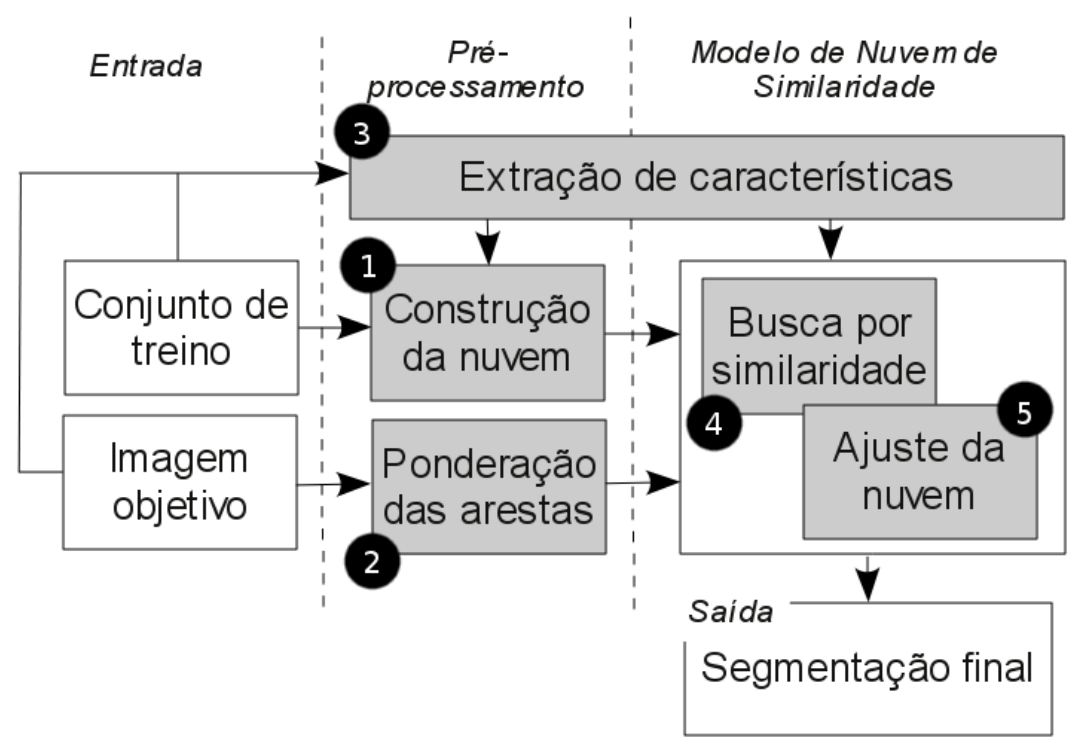

Figura 4.1: Representação do fluxo do Modelo de Nuvem de Similaridade onde é possível notar a importância da extração de características. 


\subsection{Construção da Nuvem de Similaridade}

Levando em consideração o primeiro problema exposto para a segmentação do hipocampo: reconhecimento, é proposto um novo modelo para calcular a sua posição dentro do cérebro. O método utiliza nuvens para localizá-lo dentro de um espaço tridimensional.

A busca do hipocampo torna-se muito mais efetiva quando é utilizado um conjunto de nuvens, pois cada uma delas poderia estar orientada para a detecção de algum tipo de disfunção ou malformação do hipocampo. Assim, a construção do conjunto de nuvens $C$ precisa de um processo de seleção e agrupamento. Para a formação dos grupos são utilizados conceitos de similaridade - todos eles apontando as características relevantes do hipocampo. Portanto, os MBB que contêm os hipocampos são extraídos para que possam ser caracterizados. São consideradas três propriedades chave: volume, forma e simetria. Estas características são as mesmas analisadas pelos especialistas envolvidos no diagnóstico de doenças que afetam o hipocampo. Sob esta condição, os grupos formados são mais específicos e permitem a identificação de novas classes que de maneira visual seriam trabalhosas ou até inviáveis de detectar. No entanto, deve-se observar que a classificação do hipocampo está fora do escopo desta pesquisa e não será abordado no decorrer deste capítulo.

A primeira característica a ser extraída é o volume e será representada pelo histograma de volume. O seu cálculo requer como entrada os MBB dos hipocampos, tanto o esquerdo como direito. Assim, o MBB é divido em $\eta$ regiões cúbicas, porém cada cubo pode conter voxels do fundo, do objeto, ou dos dois. Para cada uma das $\eta$ regiões é calculado o volume relativo (Relative Volume $R V$ ), definido por:

$$
R V=\frac{\text { quantidade de voxels do hipocampo }}{\text { quantidade de voxels total }}
$$

O cálculo do RV para todas as regiões cúbicas retorna um vetor de valores $r v=$ $\left\{r v_{1}, \ldots, r v_{\eta}\right\}$ sobre o qual é definido o histograma de volume da maneira seguinte:

$$
\operatorname{VOL}\left(r v_{i}\right)=\sum_{j=1}^{\eta} r v_{j}, \forall r v_{j} \in r v \mid r v_{j}=r v_{i}
$$

no qual, $r v_{i}$ representa o valor do bin do histograma.

A escolha da quantidade de regiões depende da aplicação, por este motivo é sugerido escolher o valor de $\eta$ baseado na seguinte premissa: o $\eta$ mais adequado é aquele que proporciona ao histograma de volume acumulado um comportamento linear e uniformemente distribuído. Por exemplo, a escolha de um $\eta$ muito grande ou muito pequeno pode levar a um histograma com uma maior quantidade de voxels em certas regiões. Com ajuda do histograma acumulado é possível aproximar uma curva sobre ele e verificar se existe um bin do histograma desproporcional ao resto. Na Figura 4.2 é apresentado o resultado do 
teste considerando três valores de $\eta$. Observa-se que uma quantidade excessiva ou uma muito pequena de regiões produz histogramas de volume desbalanceados, como apresentados nas Figuras 4.2 (b) (d). Por outro lado, o objetivo é tentar ajustar o valor de $\eta$ para o que o histograma esteja balanceado e exista sempre - ou na maioria dos casos bins com alguma quantidade de elementos como é o exemplo da Figura 4.2 (c).

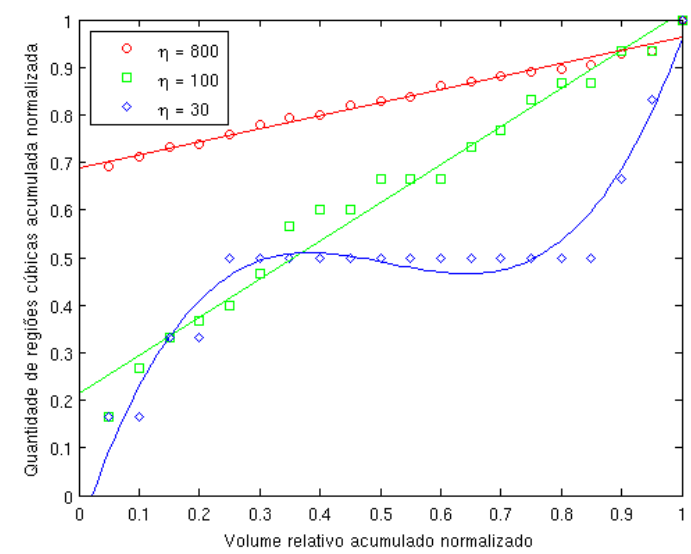

(a)

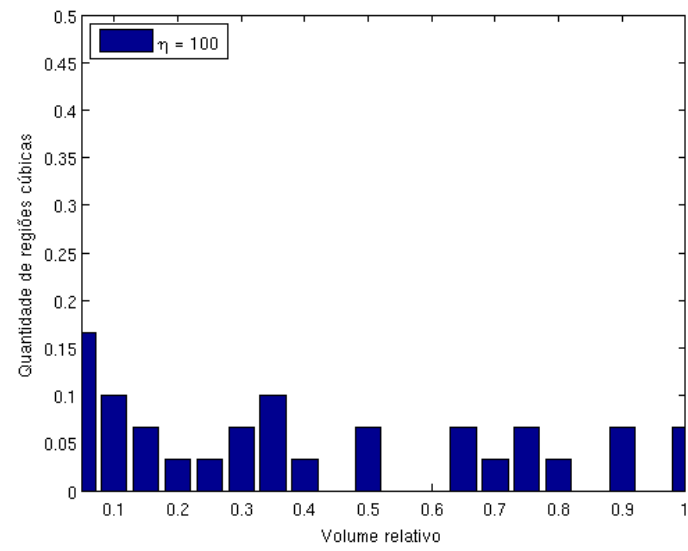

(c)

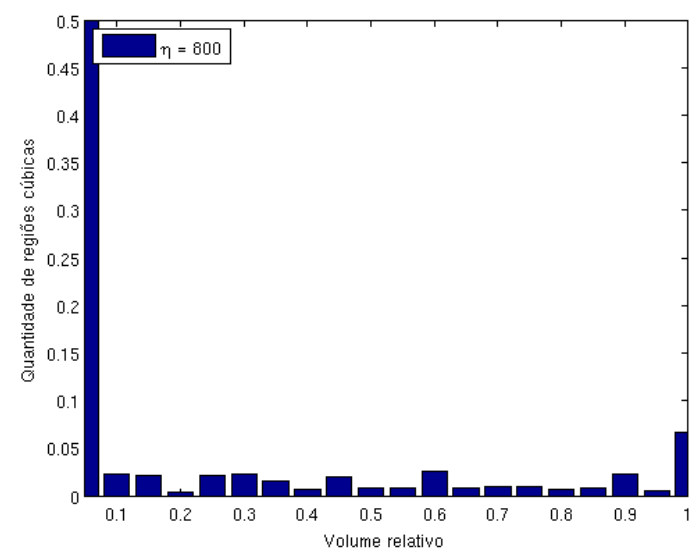

(b)

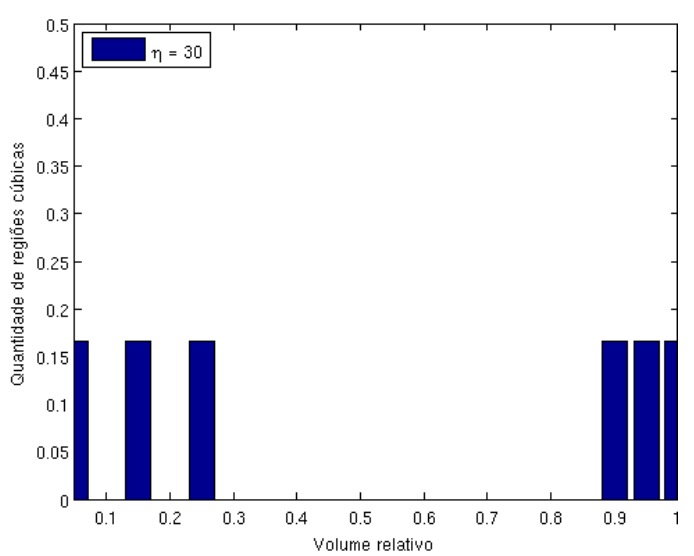

(d)

Figura 4.2: (a) Curvas aproximadas sobre os histogramas acumulados para distintos valores de $\eta$. É possível ver a relação entre a escolha de $\eta$ e o efeito que tem sobre o descritor final representado em (b), (c) e (d).

Para a análise de forma é preferível utilizar algum tipo de descritor que seja rápido de calcular e que sintetize efetivamente a forma do hipocampo. Desta maneira, é proposto fazer uso dos momentos invariantes tridimensionais. Estes valores estatísticos encontramse definidos por equações de segundo e terceiro grau que utilizam como entrada a máscara binária do objeto segmentado, e que foram definidos na Seção 3.3.3. Este extrator fornece como saída um vetor de cinco elementos para cada um dos dois hipocampos definido a seguir:

$$
S H P=\left\{M_{i r}, M_{j l}\right\}, i=1 \ldots 5, j=1 \ldots 5 .
$$


sendo que, os cinco primeiros elementos representam o hipocampo direito e os cinco seguintes o hipocampo esquerdo.

A terceira característica extraída é a simetria entre o hipocampo direito e esquerdo. Para atingir este objetivo, é desenvolvido um extrator baseado em medidas estatísticas obtidas por meio do alinhamento dos dois hipocampos. Primeiro, calcula-se o centro de massa de cada um dos hipocampos e são transladados a um ponto de referência comum. A partir deste alinhamento, um deles é refletido com a intenção de que os dois hipocampos possuam as suas partes principais coincidentes. Note-se que não é feito um alinhamento por meio de atlas ou algum outro tipo de deformação. Simplesmente é um sobreposicionamento de um hipocampo contra o outro. A partir desta operação são calculados dois conjuntos de voxels: conjunto de voxels coincidentes $o$ - aqueles voxels que no processo de alinhamento ficaram sobrepostos - e conjunto de voxels não coincidentes $o^{\prime}$ - o resto de voxels que não alcançou coincidência. O descritor é composto por um vetor de quatro elementos, definido a seguir:

$$
S Y M=\left\{\mu(o), \sigma(o), \mu\left(o^{\prime}\right), \sigma\left(o^{\prime}\right)\right\}
$$

na qual $\mu$ representa a média e $\sigma$ o desvio padrão para cada conjunto.

Todas as características extraídas: forma, volume e simetria, são combinadas em um descritor completo $y=\{S H P, V O L, S Y M\}$. O vetor $y$ é formado pelo encadeamento dos vetores individuais. O procedimento é feito para as $n$ imagens de treino, de modo que é formada uma matriz $Y$ com $n$ linhas. Para evitar que os valores em diferentes escalas distorçam os resultados é aplicado um processo de normalização sobre $Y$, baseado na seguinte expressão:

$$
y_{i j} *=\frac{y_{i j}-\mu\left(y_{j}\right)}{\sigma\left(y_{j}\right)}
$$

na qual, $y_{i j}$ representa um elemento da matriz $Y, \mu\left(y_{j}\right)$ e $\sigma\left(y_{j}\right)$ representam, respectivamente a média e desvio padrão da $j$-ésima coluna.

O processo de agrupamento deve ser automático e não precisar de alguma intervenção do usuário. Deste modo, é proposto o uso do Agrupamento por Correlação Multiresolução [23], o qual cumpre as características solicitadas. Este algoritmo possui um tempo de resposta rápido, pois ele é executado em tempo linear e foi testado em aplicações que tiveram um número similar de eixos (elementos do vetor de características). Assim, para cada $i$-ésimo grupo formado, as máscaras são alinhadas pelo seu centro de massa, levando todas elas a um ponto comum para construir uma nuvem $C_{i}$, como pode ser visto na representação da Figura 4.3. Cada nuvem é produzida pelo procedimento explicado na Seção 2.4.2 e o resultado é uma família de nuvens $C$, cada uma com o suas próprias regiões de fundo, objeto e incerteza. 


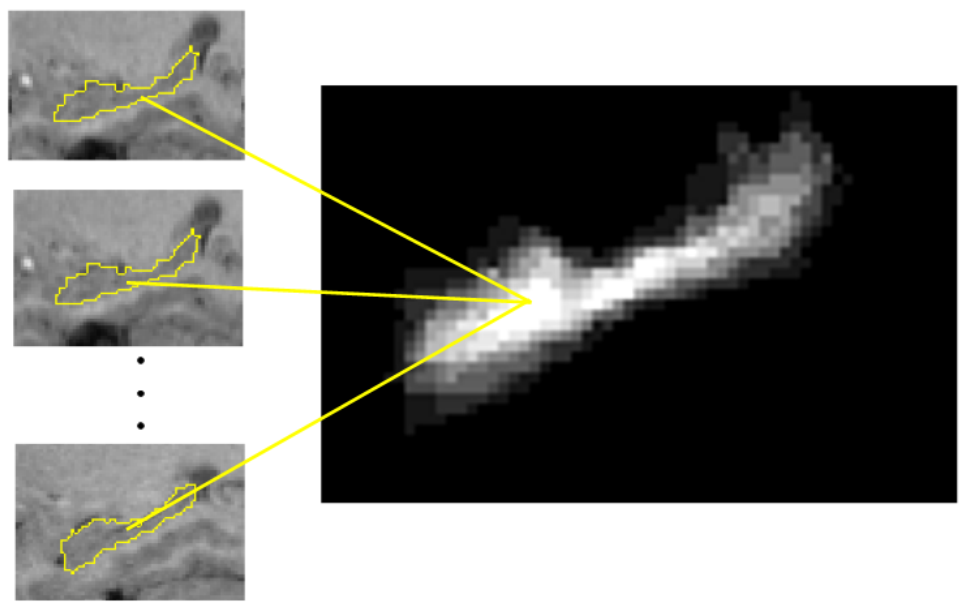

Figura 4.3: Representação da construção de uma Nuvem de Similaridade baseada na estrutura cerebral hipocampo.

O Algoritmo 4.1 constrói a Nuvem de Similaridade utilizando como entrada um conjunto de imagens de treino e um limiar $\lambda$ que indica a quantidade de imagens a ser utilizadas. Na linha 1 são escolhidas amostras do conjunto de entrada $X$ de modo aleatório. No laço da linha 2 são extraídas as características de volume, forma e simetria pelos extratores propostos e definidos anteriormente. Observe-se que nas linhas 7-9, utiliza-se uma variável auxiliar para acumular estes vetores, normalizá-los e finalmente construir os grupos. Nas linhas 10-17 são analisados os valores dos voxels das imagens dentro de cada grupo, permitindo finalmente a construção do conjunto de nuvens $C$.

\subsection{Localização por similaridade}

\subsubsection{Procedimento de busca}

Como foi mencionado anteriormente no processo de segmentação são utilizadas múltiplas nuvens, entretanto elas são processadas individualmente. Os procedimentos seguintes serão explicados considerando só uma nuvem, com o objetivo de facilitar a compreensão. Entretanto, vale a pena esclarecer que o resultado final é obtido pela comparação entre as segmentações retornadas pelo processamento de cada nuvem. Cada uma destas segmentações é comparada com base na sua qualidade, obviamente aquela com maior ganho, determina a segmentação final do hipocampo.

A definição de um procedimento de busca é necessária, pois a localização do hipocampo requer que a nuvem $C_{i} \in C$ percorra a imagem objetivo $I$ (imagem de entrada a ser segmentada). Assim, o centro de massa de $C$ deve ser alinhado com cada voxel $p \in I$. Contudo, executar um processo deste tipo é caro e eleva o tempo de resposta. A solução proposta para este problema é simplesmente a redução do espaço de busca fazendo só com- 


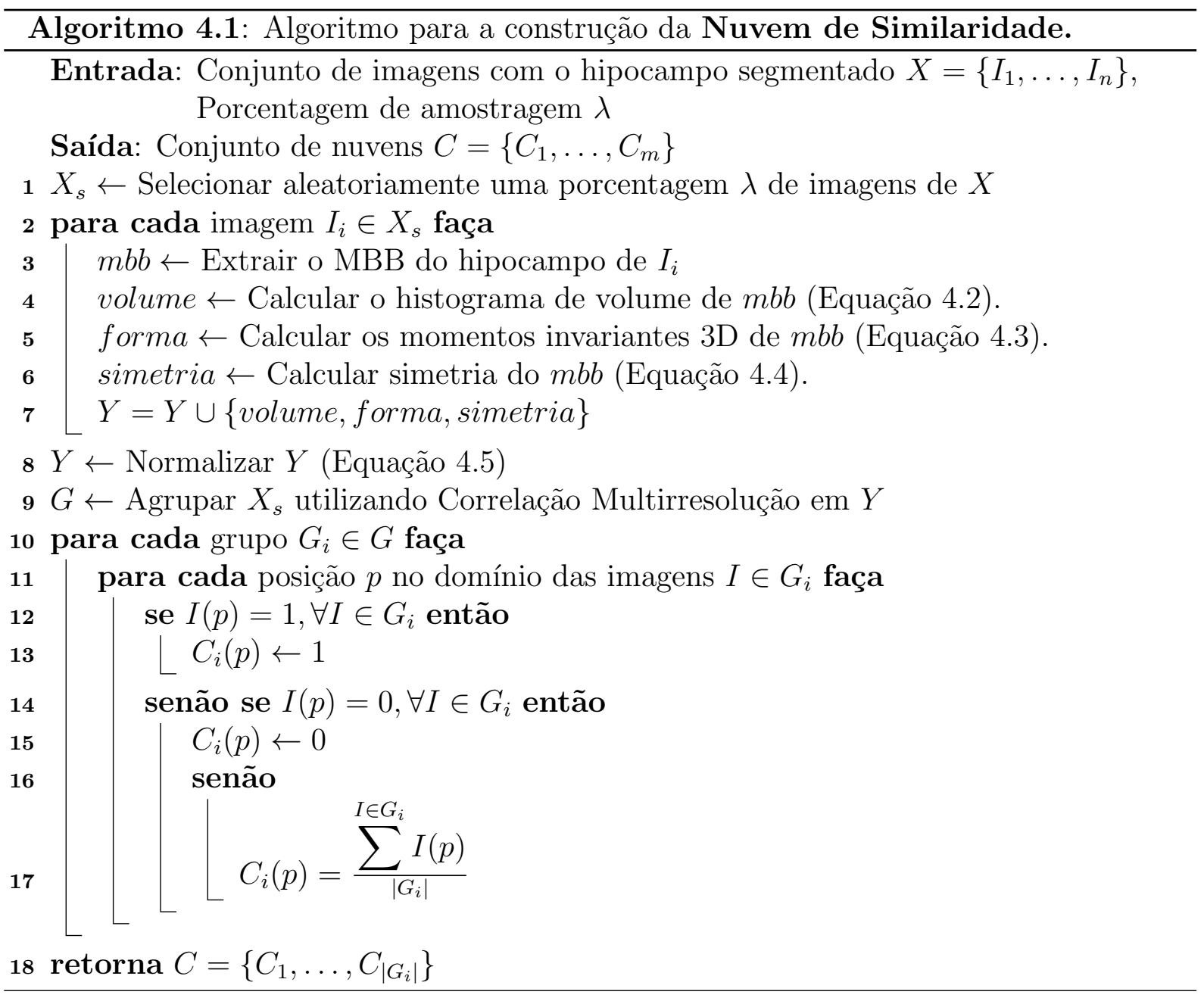

parações nos lugares com maior probabilidade de fazer parte do hipocampo. Um fator de utilidade é considerar a composição do hipocampo, pois é uma estrutura predominantemente de matéria cinzenta (Gray Matter - GM), o que ajuda a distingui-lo dentre outras regiões. Deste modo, é feita a estimação da GM dentro de $I$ usando Biparticionamento Automático do Histograma. O resultado é a separação da GM da matéria branca (White Matter - WM) e do líquido cerebroespinal (Cerebro Spinal fluid - CSF). Assim, a nuvem somente percorre aquelas regiões identificadas como GM reduzindo o espaço de busca e minimizando o número de operações necessárias. A Figura 4.4 (a) apresenta uma seção de um MRI de cérebro na qual foi estimada a presença de GM.

\subsubsection{Extração e medição de similaridade}

A avaliação da posição de nuvem $C_{i}$ está baseada na comparação por similaridade e é executada para cada voxel $p \in I$ percorrida por $C_{i}$. Para realizar esta medição é definido o funcional $F$, que é calculado sobre a imagem de entrada $I$ e a imagem etiquetada $L_{p}$. $L_{p}$ é resultado do sobreposicionamento de $\left\{\mathcal{O}_{C} \cup \mathcal{B}_{C}\right\} \subset C_{i}$ e a execução do algoritmo de delineamento $A$ - representado pela IFT-SC - na zona de incerteza $\mathcal{U}_{C} \subset C_{i}$, quando 
o centro de massa de $C_{i}$ está alinhado com um determinado voxel $p \in I$. F é aplicado sobre este resultado baseado na análise de cor e forma, o qual pode ser entendido como a medição explícita ou implícita da:

- Qualidade da escolha das sementes para o objeto - representadas pela região objeto $\mathcal{O}_{C}$ - e para o fundo - representadas pela região fundo $\mathcal{B}_{C}$.

- Qualidade da região escolhida como o tecido que possui a maior probabilidade de ser o hipocampo.

- Qualidade do delineamento feito pelo algoritmo $A$ (Algoritmo da IFT-SC 2.1).

A caracterização da cor $F_{\text {color }}$ é avaliada tendo como base o histograma de níveis de cinza das imagens de treinamento. Assim, a probabilidade de um determinado voxel $q \in L_{p}$ ser ou não parte do hipocampo é calculada pela função de densidade gaussiana $\mathcal{G}$ com a média e desvio padrão proveniente do conjunto de treino. $\mathrm{O}$ valor final de $F_{\text {color }}$ é dado pela média da probabilidade dos voxels em $L_{p}$ definido a seguir, considerando $n=\left|L_{p}\right|$.

$$
F_{\text {color }}\left(I, L_{p}\right)=\frac{1}{n} \sum_{q}^{q \in L_{p}} \mathcal{G}(I(q))
$$

Para a medição baseada na forma $F_{\text {shape }}$ é utilizada a comparação de vetores de características. A invariância é importante para este tipo de medição que envolve a Nuvem de Similaridade, pois ela não sofre nenhum tipo de alinhamento prévio. Neste caso, é utilizada a extração e a medição da similaridade simultaneamente:

$$
F_{\text {shape }}\left(I, L_{p}\right)=d_{\text {euc }}^{-1}\left(\overrightarrow{f v}_{\text {cloud }}, \overrightarrow{f v}_{L_{p}}\right)
$$

no qual $d_{e u c}(\cdot)$ é a distância Euclidiana entre dois vetores de características $\overrightarrow{f v}$. Cada vetor $\overrightarrow{f v}$ está composto por seis elementos: o primeiro é definido pelo volume ocupado de $L_{p}$ dentro de seu MBB, entretanto os cinco restantes são definidos pelos momentos invariantes tridimensionais aplicados da mesma maneira que foi para a construção da Nuvem de Similaridade.

A medição final é definida pela equação:

$$
F\left(I, L_{p}\right)=\beta_{1} F_{\text {color }}\left(I, L_{p}\right)+\beta_{2} F_{\text {shape }}\left(I, L_{p}\right)
$$

na qual $\beta_{1}+\beta_{2}=1$ representam a importância relativa para cada um dos membros da equação. O problema da busca pelo hipocampo dentro de $I$, pode ser visto como um problema de otimização, sendo necessária a resolução da seguinte expressão de maximização para a obtenção da melhor posição $p$ para $C_{i}$ : 


$$
p=\underset{p}{\arg \max } F\left(I, L_{p}\right)
$$

Devido ao fato que é considerado um conjunto de nuvens variável, a posição final será aquela que apresentou a medida com maior valor. Na Figura 4.4 (b) é apresentado o resultado do processo de medição onde as zonas mais brilhantes representam as regiões com maior probabilidade de ser parte do tecido do hipocampo. Depois de identificar a melhor posição para a Nuvem de Similaridade, o resultado entregue é o delineamento feito pelo algoritmo $A$. Esta saída é considerada uma segmentação primitiva e que ainda precisa ser melhorada como é apresentada na Figura 4.4 (c). As regiões vermelhas desta imagem representam os erros de segmentação ainda existentes.

O Algoritmo 4.2 implementa os procedimentos explicados anteriormente, localizando a Nuvem de Similaridade na posição mais provável onde possa estar o hipocampo. Para conseguir isto, é preciso haver definido a Nuvem de Similaridade por meio do Algoritmo 4.1 e escolhido como algoritmo de delineamento a IFT-SC. Nas linhas 1-3 são inicializadas as variáveis para o funcionamento correto do algoritmo. A estimação da matéria cinzenta para reduzir o espaço de busca é definido na linha 4 . No laço da linha 6 a Nuvem de Similaridade percorre a imagem inteira e para cada posição é medida a qualidade da saída da IFT-SC utilizando o funcional $F$ definido nos parágrafos anteriores. $\mathrm{Na}$ linha 7 , a IFT utiliza como sementes de objeto a região $\mathcal{O}_{C}$, como sementes de fundo à região $\mathcal{B}_{C}$ e executada somente nos voxels coincidentes com a zona de incerteza $\mathcal{U}_{C}$. Nas linhas 9-12 é escolhida aquela imagem etiquetada e a posição que representa o maior valor do funcional os quais finalmente conformam a saída do algoritmo.

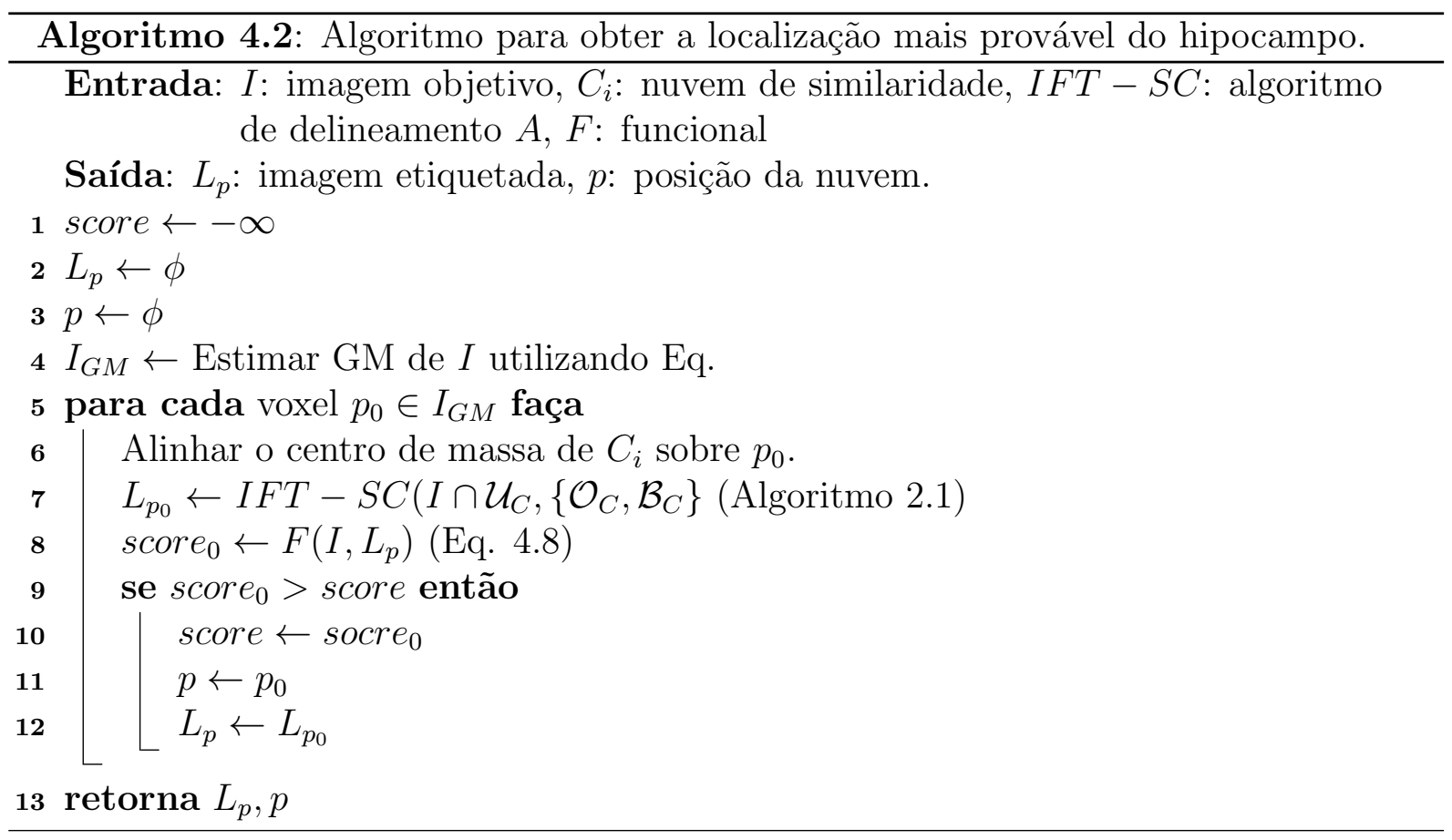




\subsection{Ajuste da Nuvem de Similaridade}

Nesta seção, a localização por similaridade realizada anteriormente é combinada com o ajuste da nuvem em um procedimento de duas fases para conseguir resolver o problema de delineamento. Basicamente, a localização do hipocampo fornece uma primeira segmentação. No entanto, o resultado deste processo é ainda um tanto grosseiro e com qualidade relativamente baixa. Desse modo, um procedimento de refinamento é necessário.

\subsubsection{Cálculo dos pesos das arestas}

O algoritmo de delineamento $A$ escolhido foi a IFT-SC (Algoritmo 2.1), porém ele somente é executado de maneira correta se os custos das bordas dos objetos são maiores do que aqueles nas regiões externas e internas. Esta condição garante que o algoritmo não quebre os contornos do objeto quando busca os caminhos ótimos. Assim, é necessário enfatizar as bordas entre a GM e a WM nas regiões do hipocampo. As informações sobre a estimação de tecidos obtidas no processo de localização (Seção 4.2) são utilizadas para ponderar todos os voxels de $I$ com a probabilidade de ser parte da GM como pode ser visto na Figura 4.4 (a). O algoritmo de delineamento 2.1 é modificado para que calcule os pesos das arestas on-the-fly atribuindo o valor absoluto da diferença entre $p$ e $q$, no qual $q \in \mathcal{A}(p)$ e $p \in$ às bordas da GM.

\subsubsection{Redefinição das zonas da Nuvem de Similaridade}

O ajuste da Nuvem de Similaridade é realizado por meio da redefinição das suas três componentes: $\mathcal{O}, \mathcal{B}, \mathcal{U}$. A imagem $I_{G M}$ produzida pela estimação do GM é utilizada como uma máscara binária (ver Figura $4.5(\mathrm{a})$ ), na qual $I_{G M}(p)=1$ indica que $p$ pertence à GM, ou à WM/CSG no caso contrário. Adicionalmente, é considerada a imagem etiquetada $L$, produzida pelo procedimento de localização anterior. Desse modo, se $L(p)=1$, o voxel $p$ foi etiquetado como parte da imagem, caso contrário pertence ao fundo. Com estes dois componentes é possível redefinir a nuvem de acordo com as seguintes regras:

$$
\begin{array}{lll}
\text { Objeto: } & L(p) \neq 0 \wedge G(p) \neq 0 \rightarrow p \in \mathcal{O}_{C} \\
\text { Fundo: } & L(p)=0 \wedge G(p)=0 \rightarrow p \in \mathcal{B}_{C} \\
\text { Incerteza: } & L(p) \neq G(p) & \rightarrow p \in \mathcal{U}_{C}
\end{array}
$$

Estas regras permitem analisar se os voxels situados em posições similares em $L$ e em $I_{G M}$ possuem os mesmos valores. Isto significa que, se um voxel $p$ é etiquetado como o hipocampo em $L$, e considerado como se fosse GM em $I_{G M}$, ele será um voxel parte da região objeto da nuvem ajustada. Por outro lado, se $p$ é considerado como fundo em $L$ e como WM/CSF em $I_{G M}, p$ será parte da região do fundo. Finalmente, se as etiquetas 


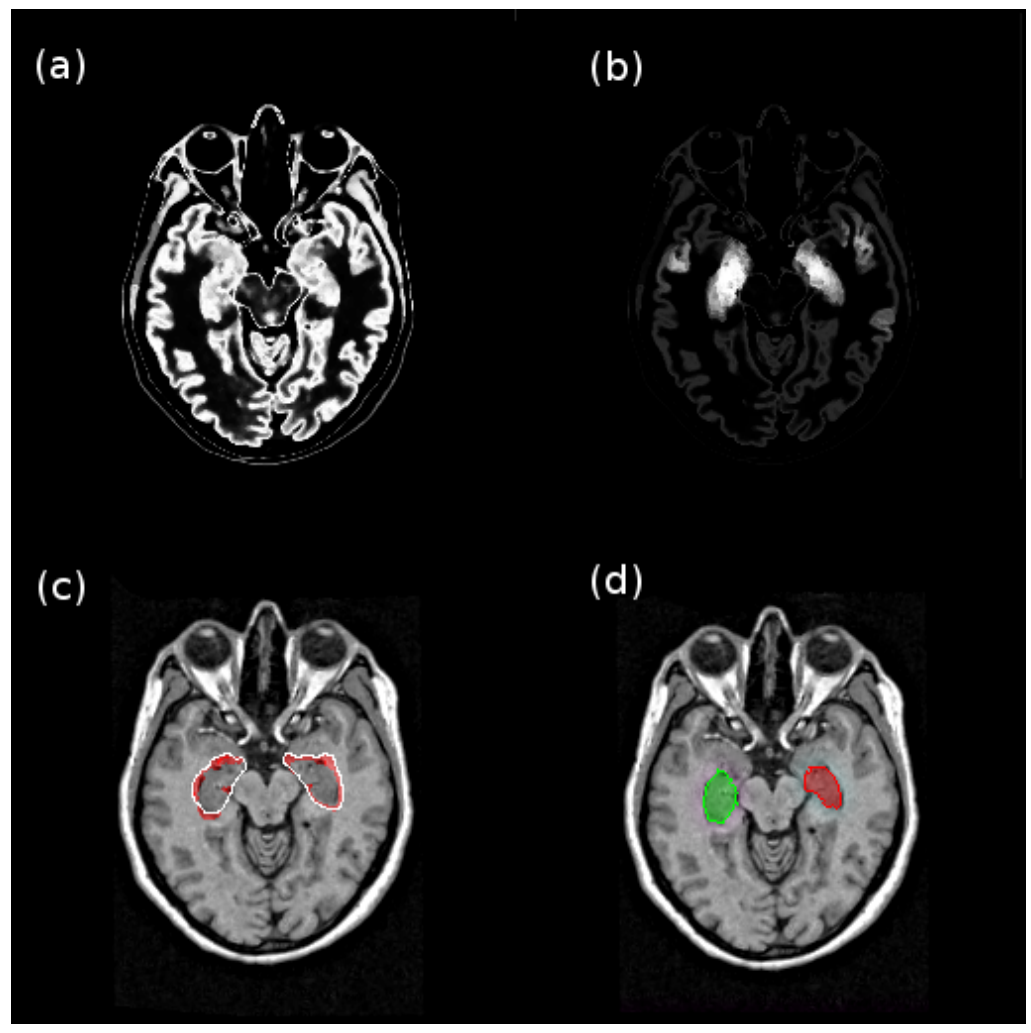

Figura 4.4: (a) Estimação do tecido da GM obtida por biparticionamento automático do histograma, (b) resultado do processo de localização por similaridade, (c) segmentação primitiva e (b) resultado final pelo delineamento com ajuste da Nuvem de Similaridade.

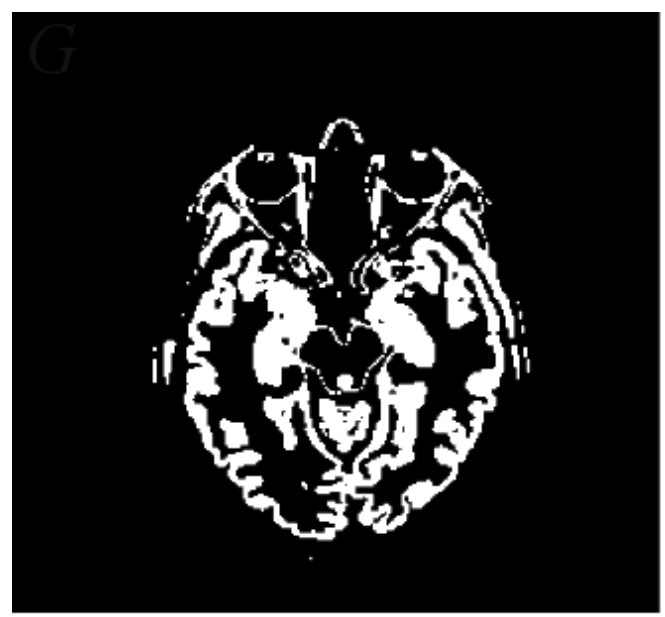

(a)

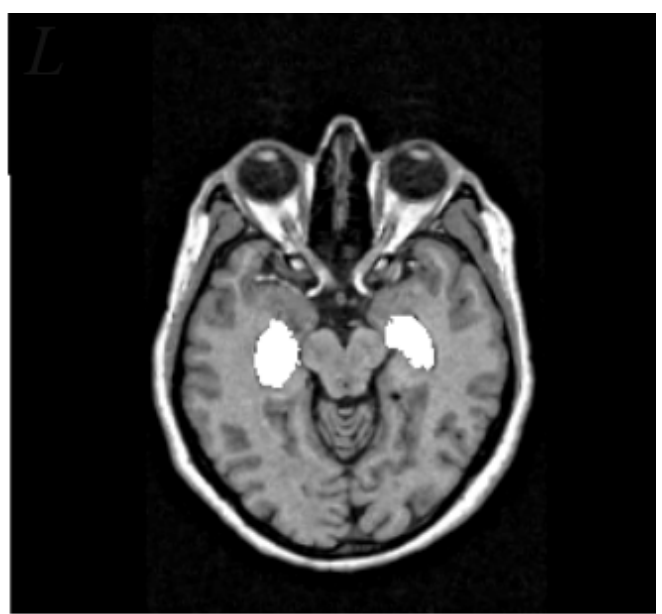

(b)

Figura 4.5: Elementos usados na reconfiguração da Nuvem de Similaridade: (a) a máscara binária da GM $I_{G M}$ e (b) a segmentação primitiva $L$

para o mesmo voxel em $I_{G M}$ e $L$ são diferentes, isto indica que aquele voxel será parte da região de incerteza.

Os elementos pertencentes a $\mathcal{O}_{C}$ continuam com o mesmo valor que a nuvem anterior, pois o objeto é uma zona semente e, portanto todos os voxels tem o valor igual a 1. No caso 
da zona de fundo $\mathcal{B}_{C}$, todos os voxels são etiquetados com 0. Assim, a zona de incerteza é redefinida por meio de novos valores tendo em consideração a seguinte equação.

$$
\mathcal{U}_{C}(p)=\frac{1}{n} \sum K(q), \forall q \in \mathcal{A}_{p}
$$

na qual $n=|K|$ e $K=L$, se $L(p) \neq 0$ ou $K=I_{G M}$ em outro caso. Isto é, o valor do voxel $p$ é baseado na média dos valores da sua vizinhança.

O Algoritmo 4.3 modifica as regiões da Nuvem de Similaridade escolhida como a mais adequada no algoritmo de localização (Algoritmo 4.2). Na linha 1 são posicionados corretamente a imagem etiquetada $L$ e a imagem da estimação da matéria cinzenta $I_{G M}$ na melhor localização encontrada dentro de $I$. Nas linhas 2-4 são implementadas efetivamente as regras da Equação 4.10. Para determinar os pesos finais da nuvem ajustada, no laço da linha 5 é aplicada a Equação 4.11 na zona de incerteza. O hipocampo segmentado é retornado pelo delineamento da IFT-SC em $I$, utilizando como sementes as regiões da Nuvem de Similaridade ajustada.

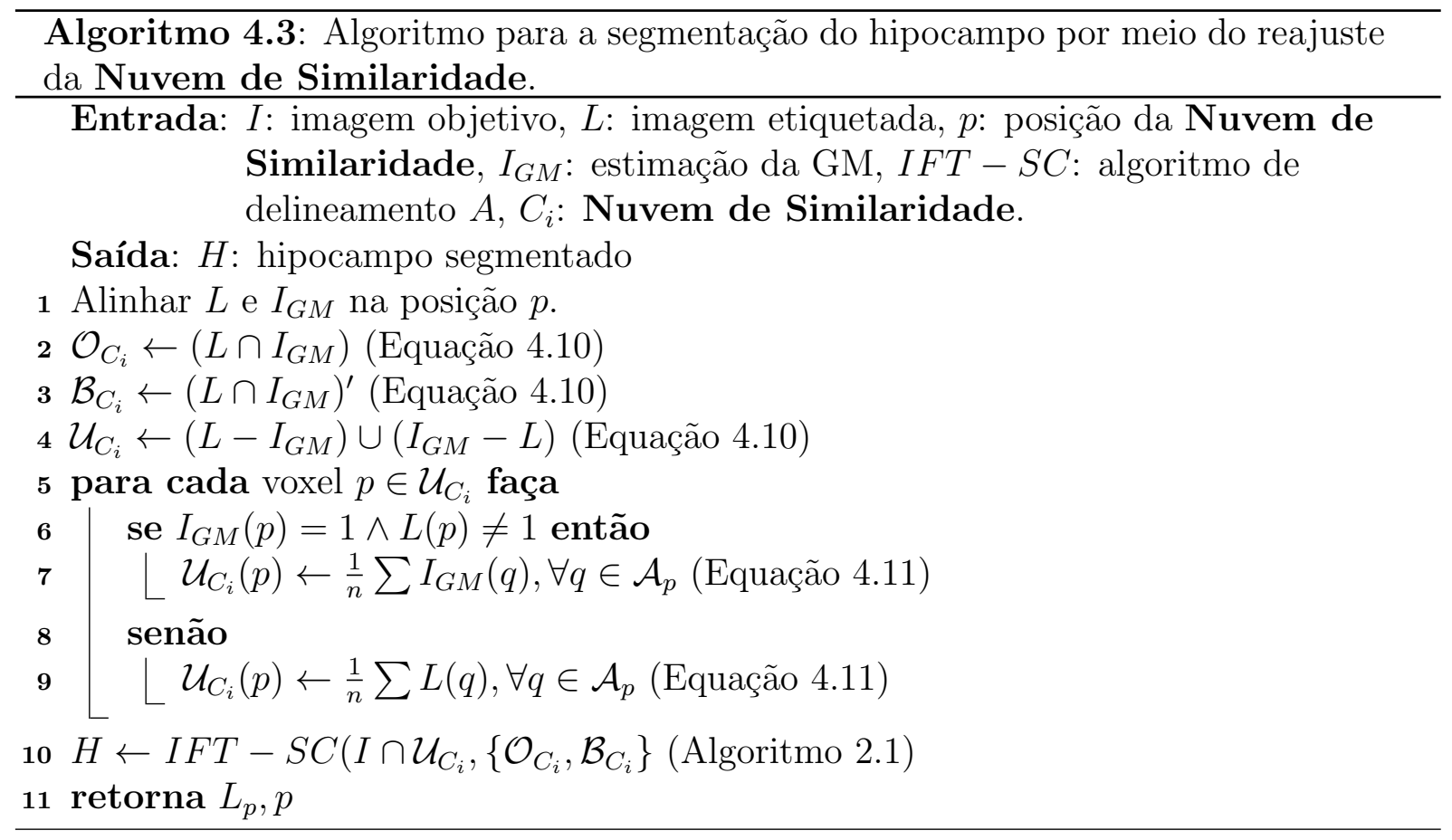

\subsection{Considerações finais}

Este capítulo apresentou o Modelo de Nuvem de Similaridade (SimCM), desenvolvido neste projeto de mestrado, que é sua principal contribuição. Foram apresentados cada um dos procedimentos necessários para o entendimento desta proposta por meio de explicações teóricas e os seus algoritmos correspondentes. Cada uma das fórmulas e fundamentos foram relacionados com os passos do algoritmo, providenciando um melhor ambiente para 
o entendimento do trabalho. No próximo capítulo serão apresentados os resultados de experimentos comparativos utilizando do método SimCM como base. 


\section{Capítulo \\ 5 \\ Experimentos e resultados}

\subsection{Considerações iniciais}

Nesta seção serão detalhados e discutidos os experimentos realizados para medir o desempenho do método proposto. Em primeiro lugar, é necessário definir um conjunto válido de imagens. Nesta proposta são utilizadas imagens obtidas na prática médica, nas quais são inclusas imagens de controle - pessoas sem doenças cerebrais - e imagens de pacientes com epilepsia. Para efetuar a avaliação utilizando este conjunto de imagens, foi feita uma comparação dos resultados com outros métodos populares por meio de medidas de qualidade. Adicionalmente, foi analisado o tempo de resposta com o objetivo de comprovar a aplicabilidade na prática médica.

\subsection{Conjunto de dados}

As imagens utilizadas nos experimentos foram providenciadas pelo Hospital das Clínicas de Ribeirão Preto da Universidade de São Paulo. Este conjunto de imagens possui dois subconjuntos que representam duas classes: um conjunto de controle - 54 imagens - e um conjunto de pacientes - 181 imagens. O subconjunto de pacientes pertence a um grupo de pessoas diagnosticadas com epilepsia do lobo temporal. É de interesse o uso deste tipo imagens, pois o hipocampo é uma estrutura afetada por esta doença gerando distorções na sua forma. Porém, a segmentação correta de um hipocampo de um paciente com epilepsia ajuda a entender o grau de comprometimento deste órgão. Para resguardar os dados das pessoas examinadas, as imagens de ambos subconjuntos foram totalmente 
anonimizadas. O conjunto de imagens são exames MRI não alinhados do cérebro obtidos de um equipamento T1-weighted de marca Siemens com um campo de 1.5 T. As imagens foram normalizadas para um tamanho de $256 \times 256 \times 256$ voxels e com resolução de $1 \mathrm{~mm}^{3}$. Nas imagens recebidas não foi aplicado nenhum tipo de alinhamento prévio, convertendo este conjunto de imagens em um grupo de teste com complexidade alta. O resultado da segmentação foi comparado com máscaras binárias obtidas pela segmentação do hipocampo por meio do software FreeSurfer [32]. Este tipo de ground-truth foi considerado, pois é o mesmo utilizado na prática clínica, no Centro de Ciências de Imagens e Física Médica do HCRP-USP.

Como são feitas operações de estimação de tecidos baseados no nível de intensidade obtida é preciso homogeneizar as imagens para um adequado funcionamento do método. Assim, é aplicada a correção de intensidade N3 [60]. De maneira sucinta, o método N3 é um algoritmo de correção de inhomogeneidade de intensidade. O processo está baseado na premissa de que a imagem de entrada é representada como a soma de um campo de distorção da intensidade mais a imagem correta. Deste modo, o algoritmo baseia-se no cálculo deste perfil de distorção utilizando funções de probabilidade, para cada perfil calculado ele é retirado da imagem de entrada. O algoritmo termina quando a imagem não apresenta mais mudanças ou por uma quantidade de iteraçãoes específica.

\subsection{Segmentação do hipocampo}

A proposta deste trabalho denominada Modelo de Nuvem de Similaridade (Similarity Cloud Model - SimCM), é comparada com métodos conhecidos para a segmentação de imagens médicas por meio do Coeficiente Dice (Dice Coefficient - DC) e da Diferença Relativa de Volume (Relative Volume Difference - RVD), que são definidos a seguir:

$$
\begin{gathered}
D C=\frac{2 \times\left(S^{\prime} \cap S^{\prime \prime}\right)}{S^{\prime}+S^{\prime \prime}} \\
R V D=\frac{S^{\prime}-S^{\prime \prime}}{S^{\prime \prime}}
\end{gathered}
$$

no qual $S^{\prime}$ representa a saída de uma segmentação particular e $S^{\prime \prime}$ a máscara do groundtruth.

Para medir a efetividade do SimCM foram experimentos com técnicas de segmentação como o Corte de Grafos (Graph-Cut - GC) [13] e o Modelo Bayesiano (Bayesian Model - BM) [56] (a implementação do BM está disponível em http://fsl.fmrib.ox.ac.uk/ fsl/first/). Como o SimCM está baseado na aplicação de nuvens, ele também é comparado com a proposta original do Modelo de Nuvens (Cloud Model - CM) e o Modelo de Nuvens com Localização por Similaridade (Cloud Model with Localization by Similarity $C M L S)$ o qual é também uma proposta deste trabalho e foi apresentado na Seção 2.4.2. 
Os testes feitos foram divididos em três partes, considerando a utilização do: i) conjunto de pacientes, ii) conjunto de controle e iii) do conjunto completo. Os gráficos da Figura 5.1 revelam um comportamento superior do SimCM em todos os experimentos. Na Tabela 5.1 pode-se observar com mais detalhe os valores da média e desvio padrão dos coeficientes Dice obtidos nos experimentos executados. Os resultados confirmam a superioridade do SimCM frente aos métodos analisados com um ganho no intervalo de $91 \%$ a $116 \%$.

Resultados obtidos pela aplicação do GC, BM e SimCM sobre uma mesma imagem do conjunto de controle podem ser vistos nas Figuras 5.2, 5.3 e 5.4 respectivamente. Nestas imagens cada linha é um corte diferente do mesmo volume MRI. Da igual maneira, a aplicação destes métodos sobre uma mesma imagem do conjunto de pacientes é apresentada nas Figuras 5.5, 5.6 e 5.7. Para avaliar visualmente os resultados, é possível comparar as marcas vermelhas e azuis nas imagens. As marcas vermelhas representam os erros da segmentação quando ela é comparada com o ground-truth. Por outro lado, as marcas azuis indicam as bordas do hipocampo determinadas pelo método utilizado.

\begin{tabular}{|l|l||l|l|l|c|}
\hline & \multicolumn{1}{|l||}{} & \multicolumn{2}{c|}{ Hipocampo direito } & \multicolumn{2}{c|}{ Hipocampo esquerdo } \\
\hline Experimento & Método & Média & Desvio & Média & Desvio \\
\hline \multirow{5}{*}{ Controle } & SimCM & 0.9019 & 0.0536 & 0.8868 & 0.0214 \\
& BM & 0.8425 & 0.0478 & 0.8450 & 0.0236 \\
& CMLS & 0.6827 & 0.0458 & 0.7121 & 0.0329 \\
& GC & 0.6808 & 0.0632 & 0.5796 & 0.0609 \\
& CM & 0.4343 & 0.0461 & 0.4090 & 0.0736 \\
\hline \hline \multirow{5}{*}{ Paciente } & SimCM & 0.8542 & 0.0251 & 0.9079 & 0.0749 \\
& BM & 0.8266 & 0.0496 & 0.8450 & 0.0127 \\
& CMLS & 0.6646 & 0.0351 & 0.7212 & 0.0506 \\
& GC & 0.6524 & 0.0567 & 0.6911 & 0.0636 \\
& CM & 0.4199 & 0.0238 & 0.4491 & 0.0534 \\
\hline \hline \multirow{5}{*}{ Completo } & SimCM & 0.8518 & 0.0654 & 0.8694 & 0.0320 \\
& BM & 0.8123 & 0.0715 & 0.8212 & 0.0614 \\
& CMLS & 0.7121 & 0.0624 & 0.7305 & 0.0907 \\
& GC & 0.6589 & 0.0529 & 0.6769 & 0.0641 \\
& CM & 0.4321 & 0.0419 & 0.4558 & 0.0627 \\
\hline
\end{tabular}

Tabela 5.1: Valores do coeficiente Dice (DC) para os experimentos executados. 


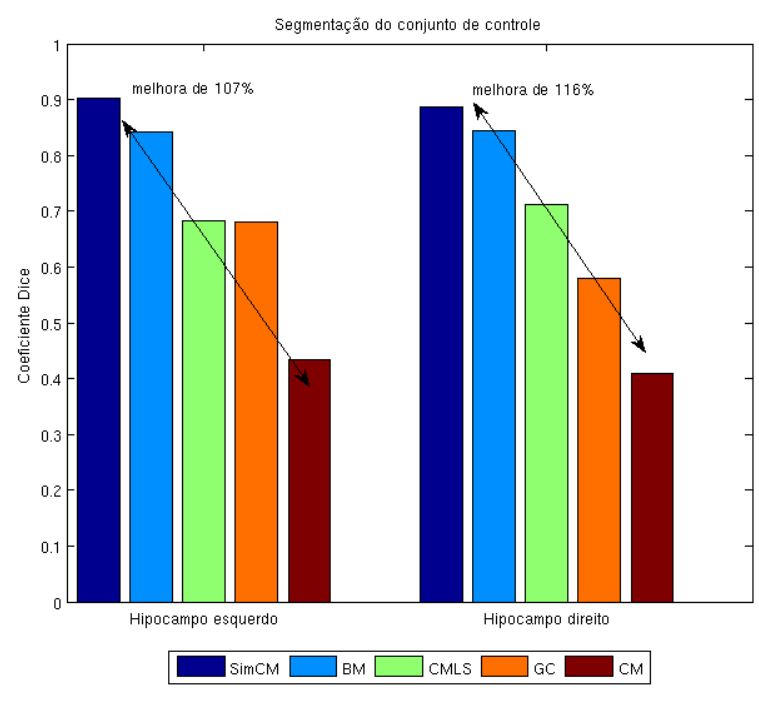

(a)
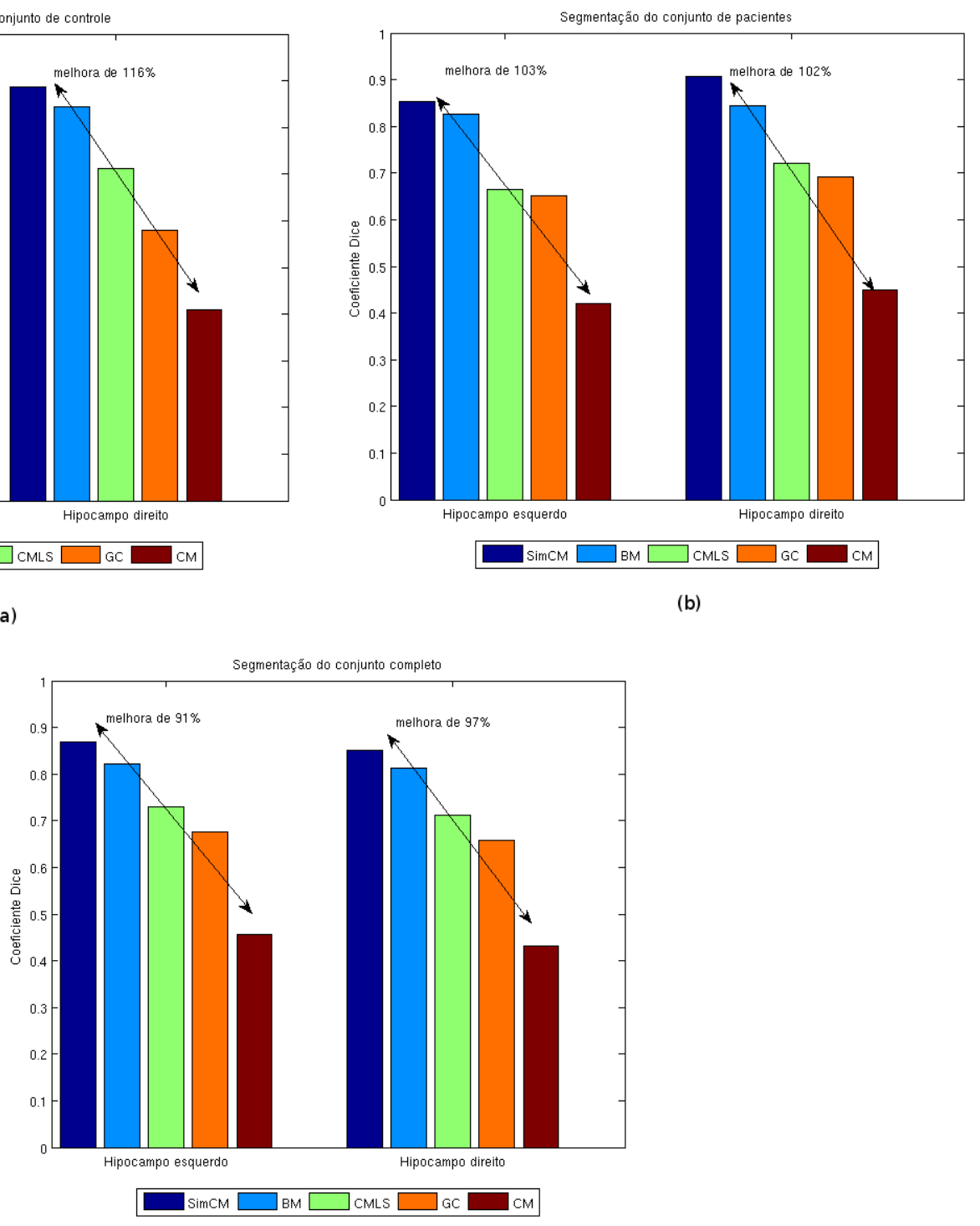

(c)

Figura 5.1: Gráficos de barras representando o DC para o conjunto (a) de controle, (b) de pacientes e (c) completo. 

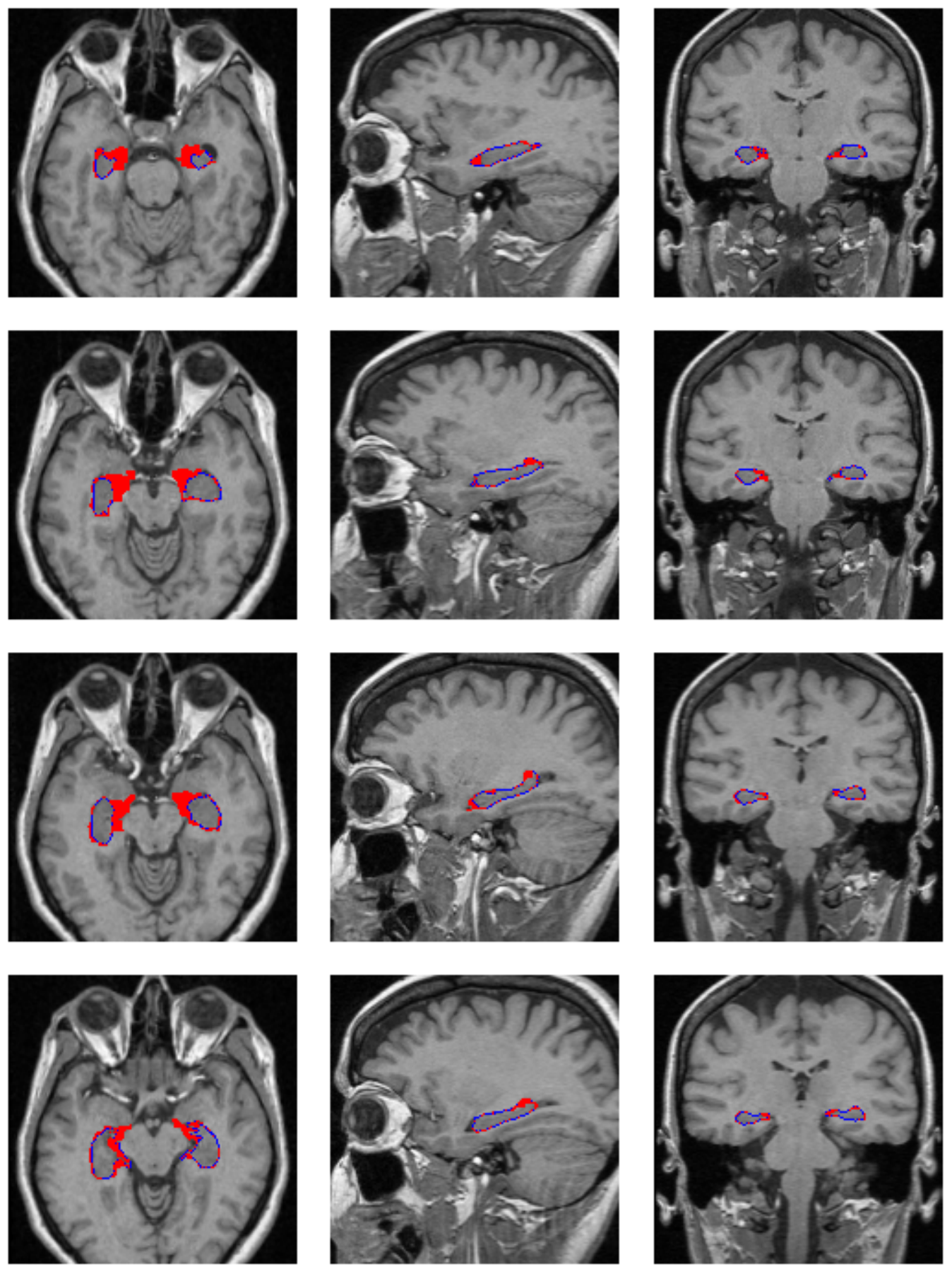

Figura 5.2: Resultado da aplicação do Corte de Grafos (GC) sobre uma imagem do conjunto de controle. As marcas azuis representam o contorno da segmentação obtida e as marcas vermelhas os erros encontrados quando foi feita a comparação com o ground-truth (máscaras produzidas pelo software FreeSurfer) 

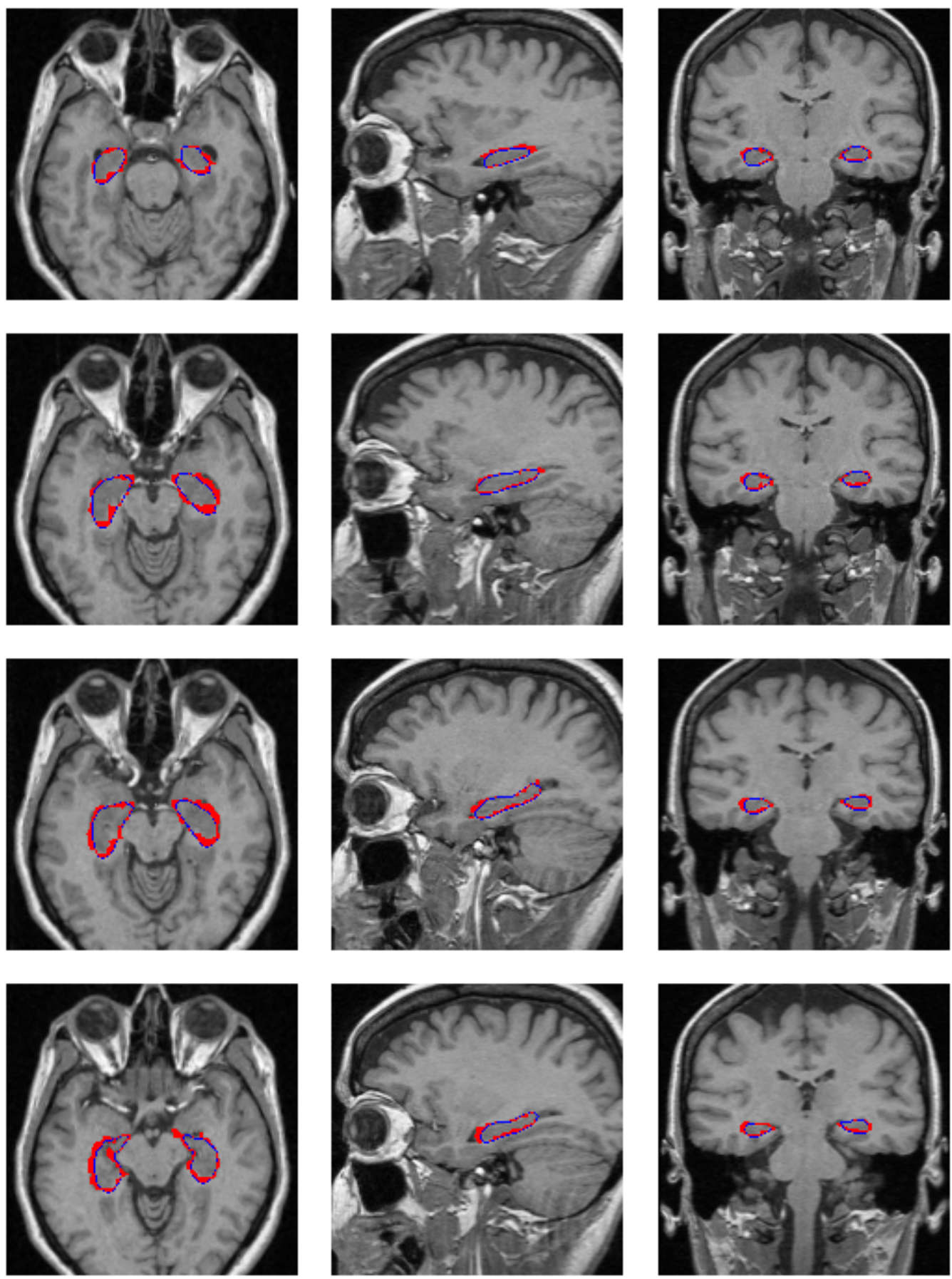

Figura 5.3: Resultado da aplicação do Modelo Bayesiano (BM) sobre uma imagem do conjunto de controle. As marcas azuis representam o contorno da segmentação obtida e as marcas vermelhas os erros encontrados quando foi feita a comparação com o ground-truth (máscaras produzidas pelo software FreeSurfer). 

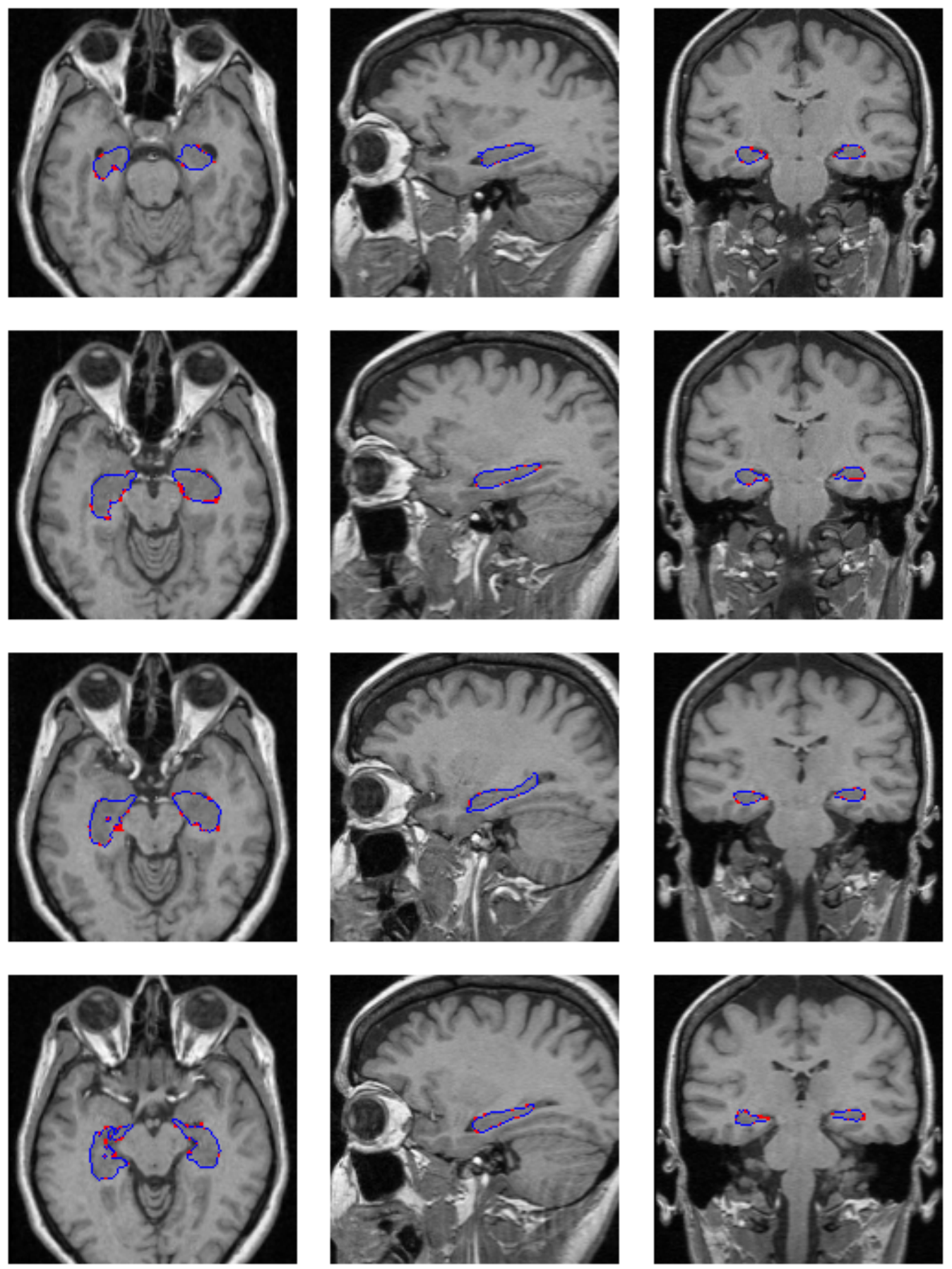

Figura 5.4: Resultado da aplicação do SimCM sobre uma imagem do conjunto de controle. As marcas azuis representam o contorno da segmentação obtida e as marcas vermelhas os erros encontrados quando foi feita a comparação com o ground-truth (máscaras produzidas pelo software FreeSurfer). 

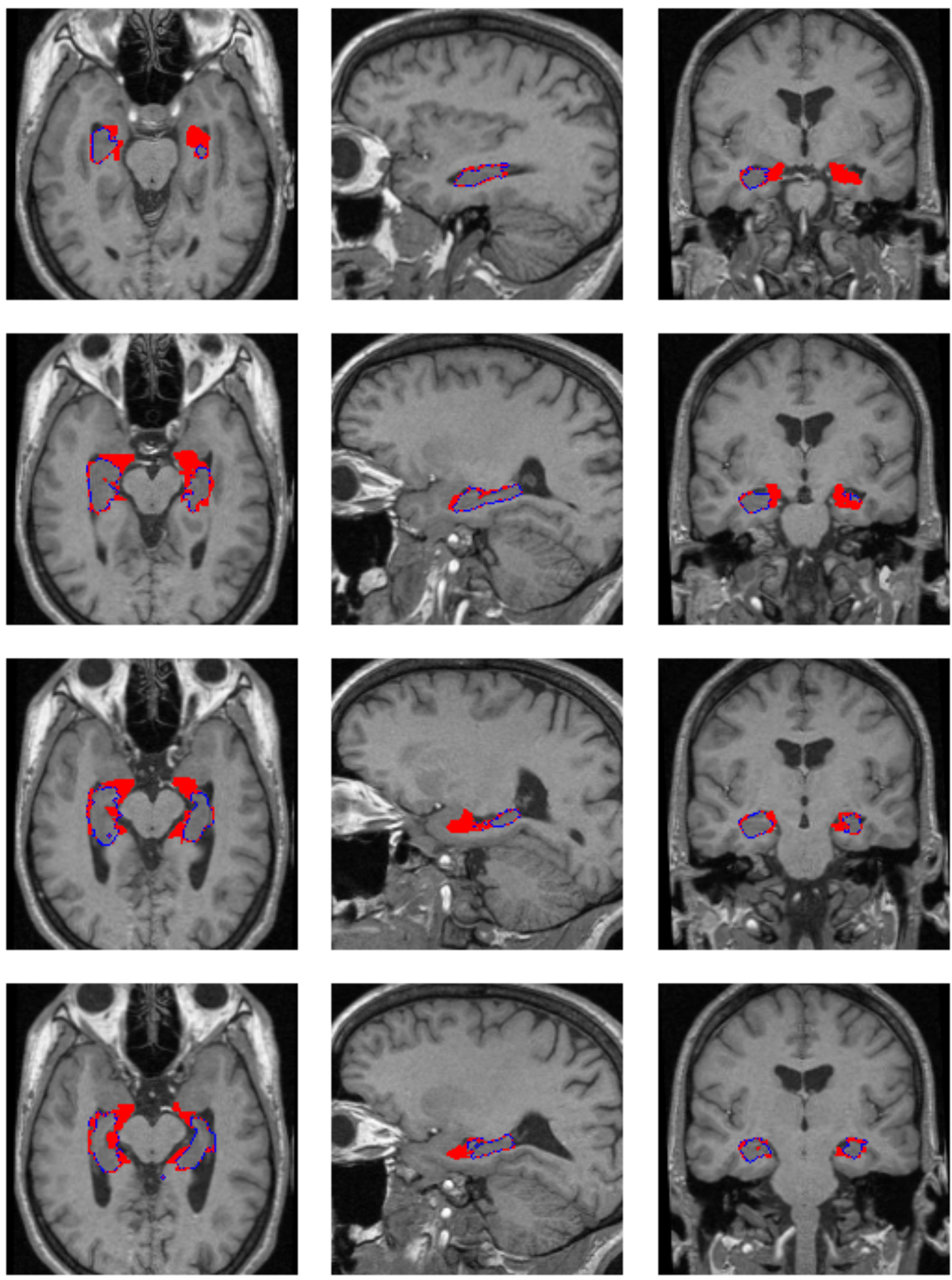

Figura 5.5: Resultado da aplicação do Corte de Grafos (GC) sobre uma imagem do conjunto de paciente. As marcas azuis representam o contorno da segmentação obtida e as marcas vermelhas os erros encontrados quando foi feita a comparação com o ground-truth (máscaras produzidas pelo software FreeSurfer). 

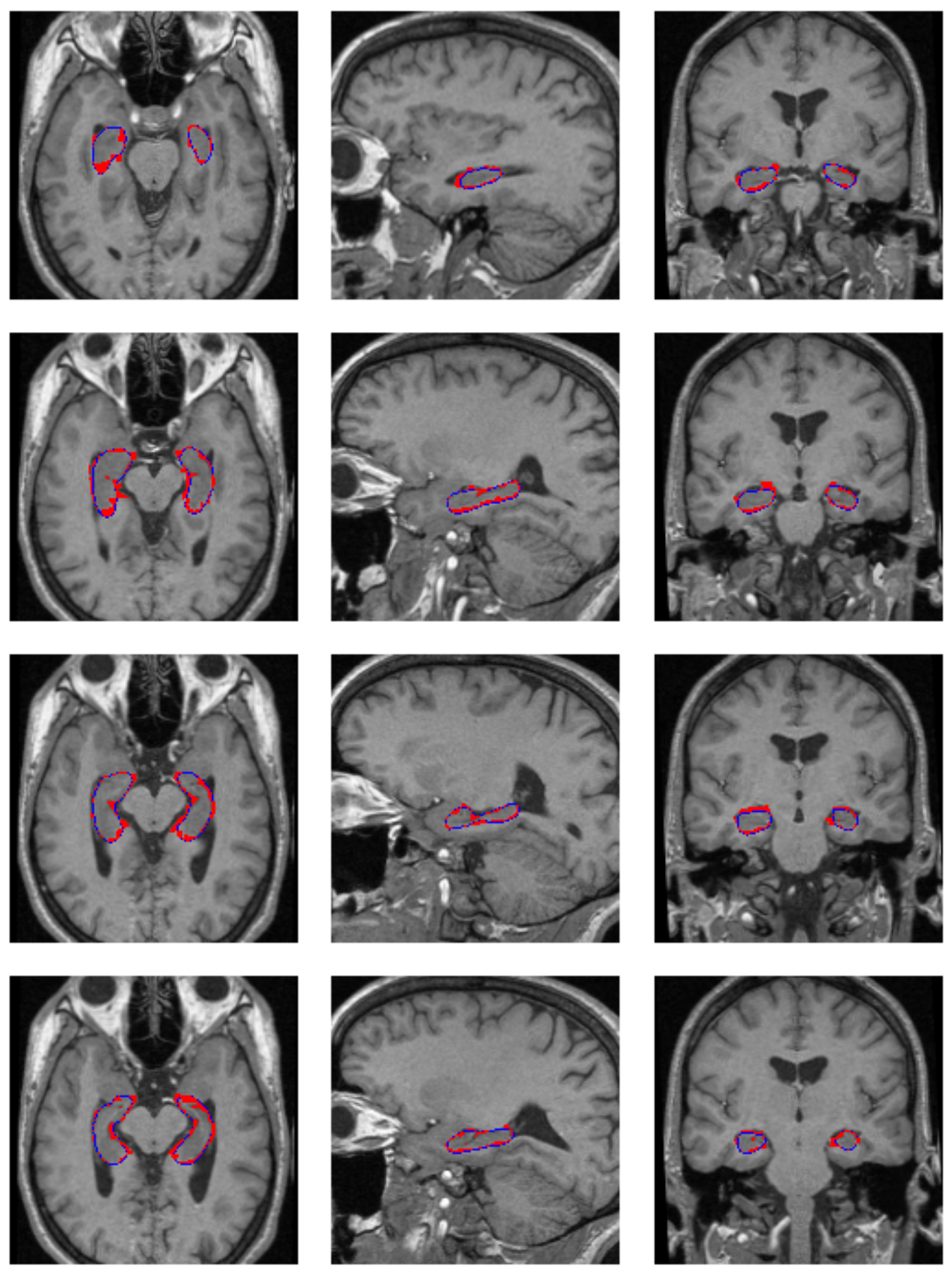

Figura 5.6: Resultado da aplicação do Modelo Bayesiano (BM) sobre uma imagem do conjunto de paciente. As marcas azuis representam o contorno da segmentação obtida e as marcas vermelhas os erros encontrados quando foi feita a comparação com o ground-truth (máscaras produzidas pelo software FreeSurfer). 

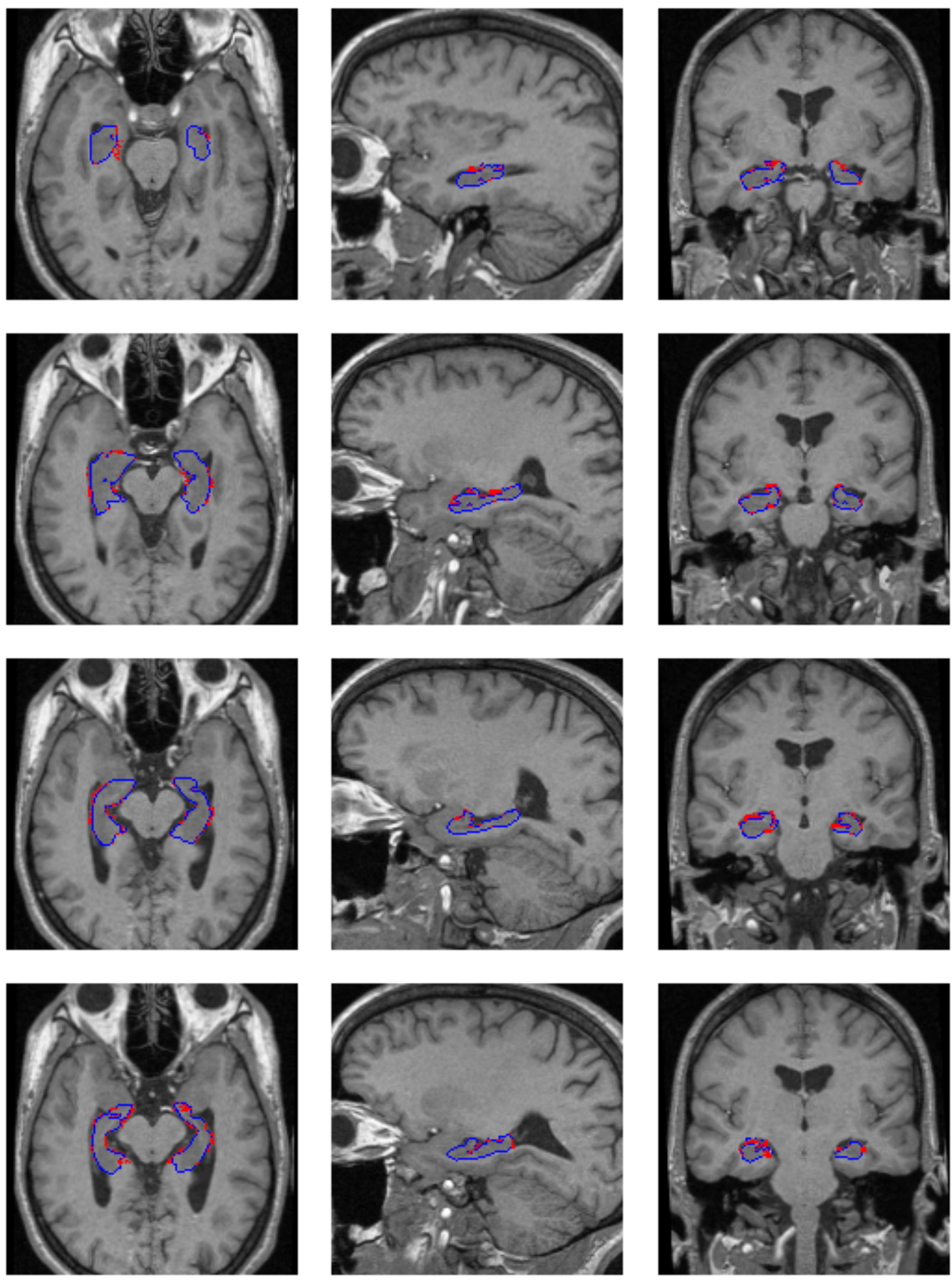

Figura 5.7: Resultado da aplicação do SimCM sobre uma imagem do conjunto de paciente. As marcas azuis representam o contorno da segmentação obtida e as marcas vermelhas os erros encontrados quando foi feita a comparação com o ground-truth (máscaras produzidas pelo software FreeSurfer). 
A diferença de volume foi comparada por meio da RVD e é apresentada nos boxplots da Figura 5.8. Entendam-se os quadros azuis como 50\% dos dados e a linha vermelha como o valor da mediana do conjunto. Os pontos vermelhos representam aqueles resultados que fogem do conglomerado do conjunto. No pior dos casos estes outliers equivalem a $8 \%$ do conjunto.

A média do RVD para o SimCM é de $0.0925 \pm 0.0273$ para o hipocampo esquerdo e de $0.1184 \pm 0.0331$ para o direito. Note-se que embora o experimento da Figura 5.8 (c) tenha sido executado utilizando a mistura dos dois subconjuntos, a qualidade não chegar a ser afetada. Este fato se deve a que as nuvens foram agrupadas por similaridade, deste modo elas atuam independentemente do tipo de conjunto inserido no treino. Assim, um hipocampo pertencente ao grupo paciente é processado por aquela nuvem que se ajusta melhor, de acordo com as características extraídas.

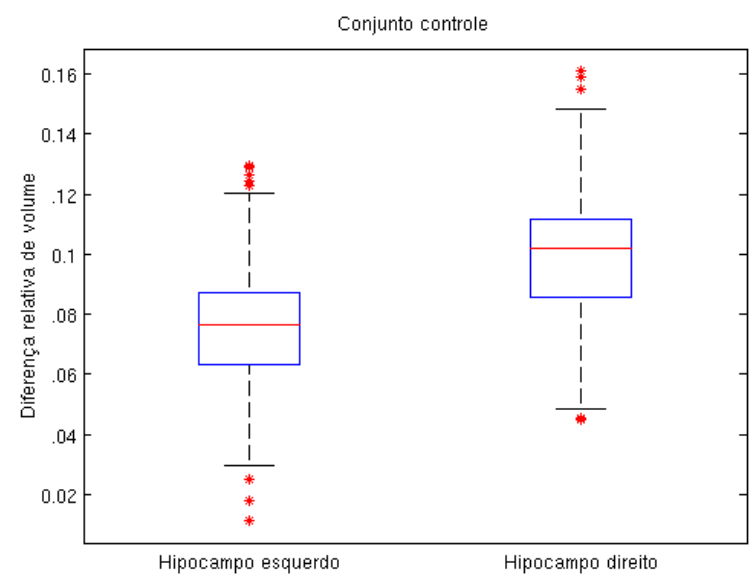

(a)

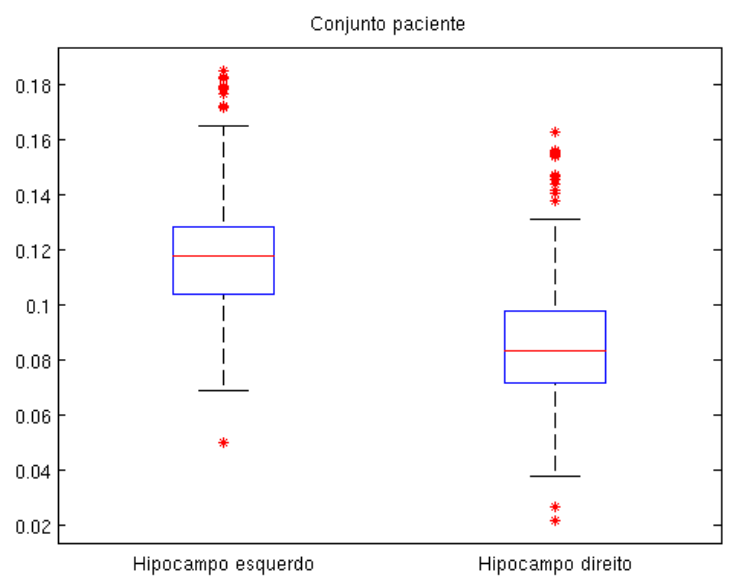

(b)

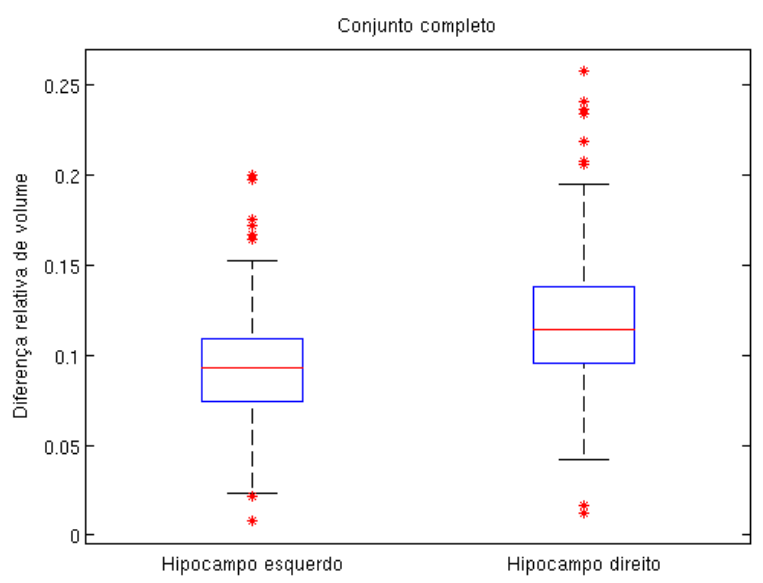

(c)

Figura 5.8: Boxplots para os experimentos rodados sobre os conjuntos (a) controle, (b) paciente e (c) completo. 


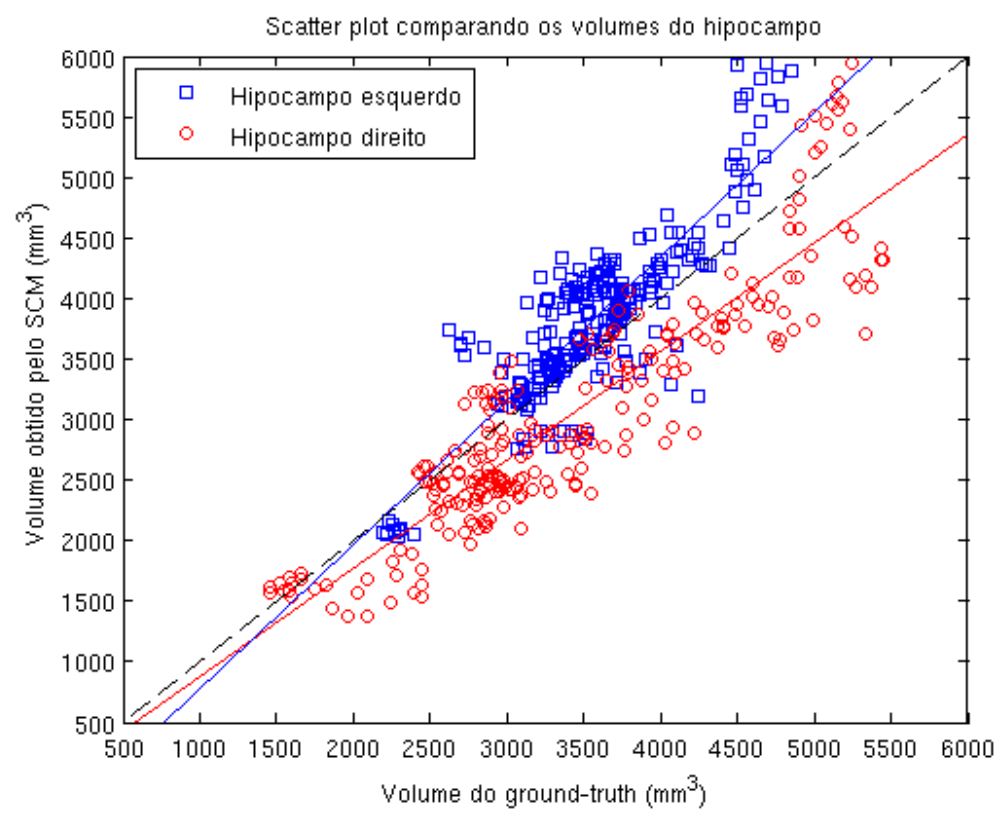

Figura 5.9: Scatter plot comparando os volumes dos hipocampos no conjunto completo.

Na Figura 5.9 é apresentado um scatter plot contrastando os volumes encontrados pelo SimCM com respeito ao volume do ground-truth. É possível observar que as retas aproximadas neste gráfico possuem uma tendência linear e cujos coeficientes angulares são de 1.189 e 0.894 para o hipocampo esquerdo e direito respectivamente. Como o objetivo deste projeto foi o desenvolvimento de uma técnica totalmente automática, não deve ser necessário realizar uma divisão prévia do conjunto completo (paciente ou controle). Assim, os experimentos e gráficos seguintes foram obtidos pelo processamento do conjunto inteiro.

\subsection{Construção da nuvem}

A construção da nuvem é feita sobre uma porcentagem total do conjunto de imagens. Para determinar a quantidade ideal, foi realizada uma bateria de experimentos considerando intervalos de $5 \%$. Isto é, para a primeira iteração a nuvem foi construída com $5 \%$ do total de imagens e a qualidade destes resultados foi medida pelo DC. Para cada nova iteração, o conjunto de treino foi incrementado com a mesma quantidade de imagens utilizada na iteração inicial. Assim o resultado deste teste é apresentado na forma de uma curva de aprendizado na Figura 5.10. Adicionalmente ao SimCM, foram testados o CM e o CMLS. Observe-se que o ganho do SimCM é mantido durante todas as iterações mostrando que para a mesma quantidade de imagens de treino o SimCM apresenta uma maior qualidade na segmentação. Os experimentos apresentados na seção anterior utilizaram uma nuvem construída com $30 \%$ do total de imagens. 


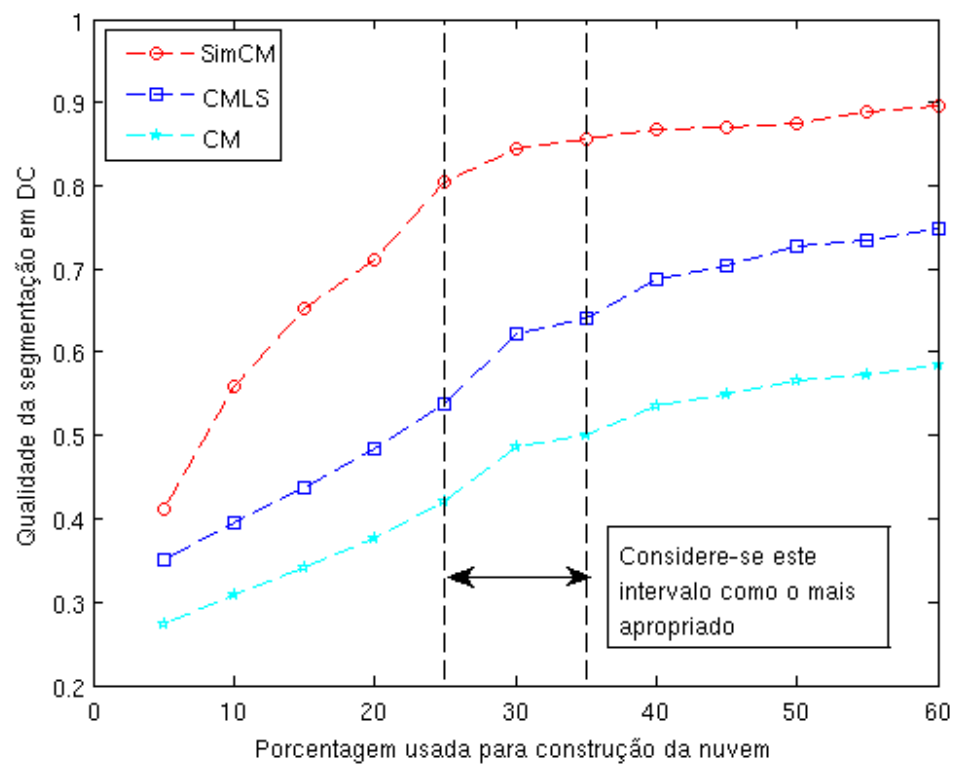

Figura 5.10: Curva de aprendizado do SimCM, CM e CMLS. O gráfico revela que o SimCM pode ser treinado satisfatoriamente com uma quantidade de imagens no intervalo do $25 \%$ ao $35 \%$ do total.

\subsection{Tempo de resposta}

O tempo de resposta foi medido em um computador Intel Core i7 $2.67 \mathrm{GHz}$ com $6 \mathrm{~Gb}$ de RAM no sistema operacional Linux 2.6. Nos experimentos apresentados foram utilizadas quatro nuvens e foi obtido um tempo de resposta médio de $67.454 \pm 9.571$ segundos. O tempo de resposta foi comparado com o Modelo Bayesiano (BM), pois ele é também um método totalmente automático e requer somente como entrada a imagem a ser segmentada. Deste modo, utilizando o BM foi obtido um tempo médio de $191.125 \pm 15.632$ segundos. Na Figura 5.11 é possível comparar graficamente o ganho do SimCM frente ao BM no tempo de resposta para o conjunto completo.

No caso do tempo utilizado para a construção das nuvens, ele foi de $27.541 \pm 5.943$ segundos utilizando 30\% de imagens do conjunto completo. Neste tempo estão considerados os processos de seleção aleatória das amostras, extração de características e agrupamento. Por outro lado, o tempo médio que o modelo original de nuvens CM, necessita para produzir nuvens com o mesmo conjunto é de $20.514 \pm 2.937$ minutos. Assim, o ganho neste aspecto é muito alto, fato que permite encontrar o melhor agrupamento de nuvens em tempo curto. 


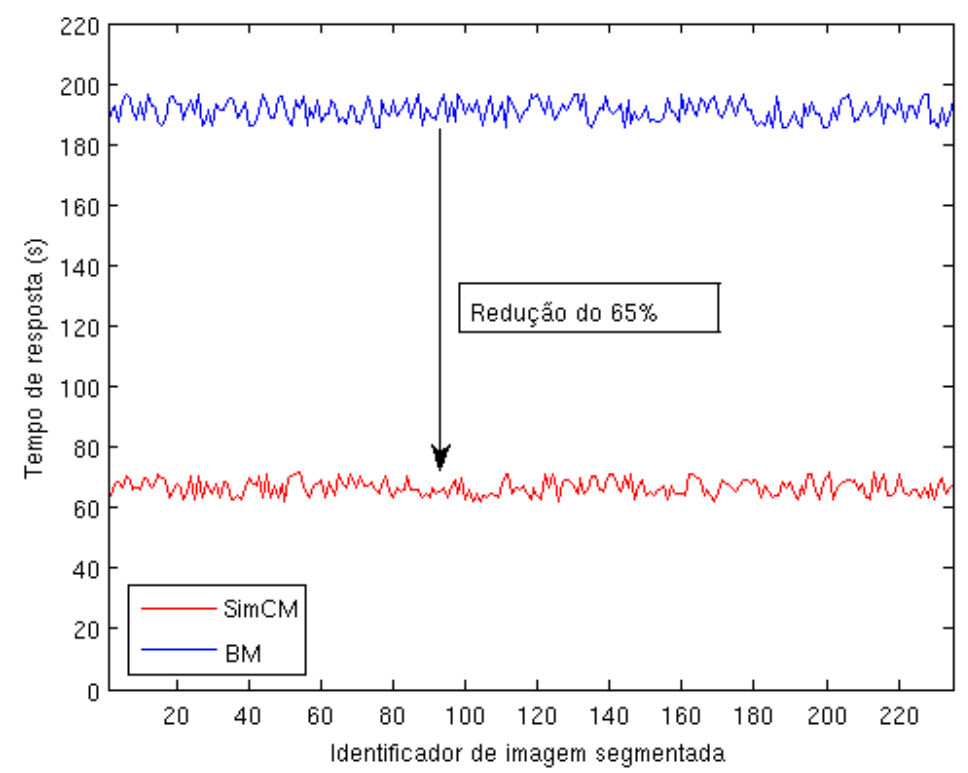

Figura 5.11: Comparação do tempo de resposta entre o SimCM e o BM, no qual o SimCM consegue reduzir o tempo em $65 \%$.

\subsection{Considerações finais}

Com os resultados obtidos é possível observar que o método proposto apresenta um comportamento muito superior frente a métodos similares, tanto no aspecto de eficiência como de eficácia. Utilizando medidas de qualidade sobre os hipocampos segmentados, a avaliação dos resultados revela um ganho que varia de 5\% a 90\%. Deve-se observar também que os experimentos foram executados sobre um conjunto real e considera casos clínicos como são os pacientes com epilepsia, dificultando ainda mais o processo de delineamento. No próximo capítulo serão apresentadas as conclusões derivadas destes resultados. 
Capítulo

6

\section{Conclusões e linhas de futuras pesquisas}

\subsection{Considerações finais}

No decorrer desta dissertação foram discutidos tópicos sobre a segmentação de imagens médicas e consultas por similaridade, os quais conduziram ao desenvolvimento da proposta do mestrado: Modelo de Nuvem de Similaridade (Similarity Cloud Model - SimCM) - O SimCM é composto por uma operação de dois passos, a primeira é a localização por similaridade - resolvendo o problema de reconhecimento - e a segunda é o ajuste da nuvem - atingindo um delineamento correto. Estas duas tarefas estão intimamente relacionadas com a extração de características do hipocampo, condição que fornece uma grande capacidade para o processo de segmentação.

Como resultado desta pesquisa foi publicado no "24st IEEE International Symposium on Computer-Based Medical Systems" o artigo The Similarity Cloud approach: a novel and efficient hippocampus segmentation technique. Deste modo, o trabalho feito durante o mestrado encontra-se registrado em um evento representativo da área de pesquisa. O artigo foi aceito para apresentação oral durante o evento e foi publicado no track de processamento de imagens médicas.

\subsection{Contribuições deste trabalho}

As principais contribuições deste trabalho estão orientadas à segmentação automática do hipocampo. Deste modo, estas contribuições podem ser descritas da seguinte maneira: 
- Uma nova forma de caracterizar o hipocampo por meio das suas propriedades mais relevantes. Isto é, considerar o hipocampo como uma estrutura tridimensional e extrair dela as mesmas características que os radiologistas consideram como mais importantes. Este tipo de procedimento permite que qualquer processo de comparação seja mais efetivo, pois ele permite que o conhecimento médico seja incorporado na ferramenta computacional, trazendo benefícios reais para a prática médica. Deste modo, a lacuna existente entre o desejado pelos especialistas e a tecnologia que os assiste é reduzida.

- Integração da extração de características nos processos de localização e delineamento do hipocampo. As características extraídas de um banco de imagens de treino são consideradas um tipo de molde que percorre a imagem objetivo na busca da posição mais provável na qual possa estar o hipocampo. Este processo mostrou-se bastante apropriado, pois ele representa o modo como os seres humanos procuram por algum objeto. Assim, por meio da comparação de características entre a imagem padrão construída a priori e um conjunto de imagens candidatas, essa abordagem mostrouse satisfatória. Um processo como este, está relacionado com CBIR, pois possui uma imagem de consulta - a imagem padrão - e um conjunto de imagens candidatas - localizações possíveis do hipocampo. Em poucas palavras, esta nova forma de segmentação é vista como uma busca de um objeto em um espaço tridimensional.

- Um método automático para a segmentação do hipocampo. A proposta apresentada requer como entrada somente a imagem objetivo e não precisa da configuração de tipo algum de parâmetro. Esta característica fornece um ambiente ideal para a aplicação do método em um conjunto grande de imagens, pois para que o método seja executado não é necessária a intervenção do usuário. Pode-se considerar como intervenção o processo de construção da nuvem, pois ele precisa de um conjunto de treino, entretanto ele é executado somente uma vez e é totalmente independente do processo de segmentação per se.

- Um método rápido para a segmentação do hipocampo. Os tempos de resposta são de grande importância na prática médica, pois a atenção de um paciente é prioridade e deve ser concluído o mais brevemente possível e com maior qualidade. Deste modo, a proposta desenvolvida apresenta tempos de resposta baixos quando é comparado com métodos similares. Os tempos de resposta encontram-se na ordem dos segundos, fato que permite a introdução em um sistema que precise de resultados em tempo real. Aplicações convencionais e utilizadas na prática muitas vezes não se encaixam nos requerimentos dos médicos e executam processos além do necessário, tornando-os demorados e chegando a produzir respostas em algumas horas. 


\subsection{Linhas de futuras pesquisas}

A pesquisa realizada até o momento propicia a abertura de algumas linhas de pesquisas futuras, pois o processamento de imagens médicas é uma vasta área de atuação. As principais linhas futuras e que servem como contribuições para pesquisadores futuros são descritas resumidamente a seguir:

- A caracterização do hipocampo pode ser melhorada com processos de seleção de características, visando contribuir com maior poder de discriminação da Nuvem de Similaridade. Isto é, sendo os vetores de características baseados nas propriedades relevantes para os especialistas, escolher aqueles valores que realmente ajudem ao reconhecimento e excluir aqueles, que em alguma forma, possam introduzir distorções.

- Utilizar conceitos de aprendizado ou de retroalimentação para aumentar a qualidade da segmentação. Um procedimento de aprendizado permite que o método seja mais eficiente e atue como o usuário realmente deseja. Neste ambiente, um especialista pode introduzir correções manuais nos resultados obtidos e permitir que a nuvem seja ponderada com certa confiabilidade. Portanto, além da nuvem conter os pesos entre 0 e 1 na zona de incerteza, ele é também é ponderado nas zonas do fundo e do objeto. Obviamente, deve ser considerado um novo funcional $F$ que permita medir o grau de confiabilidade.

- O ajuste da nuvem pode ser estendido para utilizar informações adicionais, como gradiente ou um perfil estatístico das bordas. Deste modo, é possível fornecer um delineamento melhor do hipocampo, pois embora ele esteja envolvido por WM e CSF, a identificação deste tipo de tecidos não é sempre exata. 


\section{Referências Bibliográficas}

[1] T. Acharya and A. Ray. Image Processing: Principles and Applications. WileyInterscience, 2005.

[2] P. Aljabar, R. Heckemann, A. Hammers, J. Hajnal, and D. Rueckert. Multi-atlas based segmentation of brain images: Atlas selection and its effect on accuracy. NeuroImage, 46:726-738, July 2009.

[3] P. Andersen. The hippocampus book. Oxford Neuroscience Series. Oxford University Press, 2007.

[4] S. Antani, R. Long, and G. Thoma. Bridging the gap: Enabling cbir in medical applications. In Proceedings of 21st IEEE International Symposium on ComputerBased Medical Systems, 2008. CBMS '08., pages 4-6, June 2008.

[5] Athinoula A. Martinos Center for Biomedical Imaging. Freesurfer. http://surfer.nmr.mgh.harvard.edu/.

[6] A. G. R. Balan. Métodos adaptativos de segmentação aplicados à recuperação de imagens por conteúdo. PhD thesis, USP-ICMC, 2007.

[7] F. P. Bergo. Segmentação interativa de volumes baseada em regiões. Master's thesis, Instituto de Computação, Unicamp, February 2004.

[8] F. P. Bergo, A. X. Falcão, P. A. Miranda, and L. M. Rocha. Automatic image segmentation by tree pruning. J. Math. Imaging Vis., 29(2-3):141-162, 2007.

[9] S. Beucher and F. Meyer. The morphological approach to segmentation: the watershed transformation. In Mathematical Morphology in Image Processing, pages 433-481, 1993.

[10] Y. Boykov and G. Funka-Lea. Graph cuts and efficient nd image segmentation. Int. J. Comp. Vision, 70(2):109-131, 2006.

[11] Y. Boykov and V. Kolmogorov. An experimental comparison of min-cut/max-flow algorithms of energy minimization vision. Pattern Analysis and Machine Intelligence, IEEE Transactions on, 26(9):1124-1137, Sept. 2004. 
[12] Y. Boykov and O. Veksler. Graph cuts in vision and graphics: Theories and applications. In Handbook of Mathematical Models in Computer Vision, 2006.

[13] Y. Y. Boykov and M. P. Jolly. Interactive graph cuts for optimal boundary \& region segmentation of objects in n-d images. In Proceedings of International Conference on Computer Vision, volume 1, pages 105-112 vol.1, 2001.

[14] J. M. Bueno. Suporte à Recuperação de Imagens Médicas Baseada em Conteúdo através de Histogramas Métricos. PhD thesis, USP-ICMC, 2001.

[15] P. Bugatti. Análise da influência de funções de distância para o processamento de consultas por similaridade em recuperação de imagens por conteúdo. Master's thesis, ICMC - USP, 2007.

[16] B. Bustos, D. A. Keim, D. Saupe, T. Schreck, and D. V. Vranić. Feature-based similarity search in 3d object databases. ACM Computing Surveys, 37:345-387, December 2005 .

[17] C. A. B. Castañón. Recuperação de imagens por conteúdo através de análise multiresolução por wavelets. Master's thesis, USP-ICMC, 2003.

[18] E. Chávez, G. Navarro, R. Baeza-Yates, and J. L. Marroquín. Searching in metric spaces. ACM Comput. Surv., 33(3):273-321, 2001.

[19] G. Chetelat and J.-C. Baron. Early diagnosis of alzheimer's disease: contribution of structural neuroimaging. NeuroImage, 18(2):525-541, January 2003.

[20] M. Chupin, R. Cuingnet, L. Lemieux, S. Lehéricy, H. Benali, L. Garnero, O. Colliot, and the Alzheimer's Disease Neuroimaging Initiative. Fully automatic hippocampus segmentation discriminates between alzheimer's disease and normal aging - data from the adni database. In MICCAI 2008 Workshop on Computational Anatomy and Physiology of the Hippocampus, pages 35-45, May 2008.

[21] M. Chupin, A. Hammers, R. Liu, O. Colliot, J. Burdett, E. Bardinet, J. Duncan, L. Garnero, and L. Lemieux. Automatic segmentation of the hippocampus and the amygdala driven by hybrid constraints: Method and validation. NeuroImage, 46:749761,2009 .

[22] T. F. Cootes, C. J. Taylor, D. H. Cooper, and J. Graham. Active shape models: their training and application. Comput. Vis. Image Underst., 61:38-59, January 1995.

[23] R. Cordeiro, A. Traina, C. Faloutsos, and C. Traina. Finding clusters in subspaces of very large, multi-dimensional datasets. In Data Engineering (ICDE), 2010 IEEE 26th International Conference on, pages 625 -636, march 2010.

[24] J. Csernansky, L. Wang, S. Joshi, J. Miller, M. Gado, D. Kido, D. McKeel, J. Morris, and M. Miller. Early dat is distinguished from aging by high-dimensional mapping of the hippocampus. dementia of the alzheimer type. Neurology, 55:1636-1643, 2000.

[25] S. Das, D. Mechanic-Hamilton, M. Korczykowski, B. Avants, J. Detre, J. Gee, and P. Yushkevich. Spatial correspondence based asymmetry analysis in fmri. In 5th IEEEInternational Symposium on Biomedical Imaging: From Nano to Macro, 2008. ISBI 2008., pages 616-619, May 2008. 
[26] R. Datta, D. Joshi, J. Li, and J. Z. Wang. Image retrieval: Ideas, influences, and trends of the new age. ACM Comput. Surv., 40(2):1-60, 2008.

[27] T. Deserno, L. Long, and H. Greenspan. Content-based image retrieval: Major challenges for biomedical applications. International Journal of Healthcare Information Systems and Informatics, 4(1):1-3, January 2009.

[28] E. W. Dijkstra. A note on two problems in connexion with graphs. Numerische Mathematik, 1(1):269-271, December 1959.

[29] A. Falcão, J. Stolfi, and R. Lotufo. The image foresting transform: Theory, algorithms, and applications. IEEE Trans. Pattern Anal. Mach. Intell., 26(1):19-29, 2004 .

[30] A. X. Falcão and F. P. G. Bergo. Interactive volume segmentation with differential image foresting transforms. IEEE Transactions on Medical Image, 23(9):1100-1109, September 2004.

[31] F. O. Favretto, F. P. G. Bergo, and A. X. Falcão. A fast and automatic method for $3 \mathrm{~d}$ rigid registration of $\mathrm{mr}$ images of the human brain. In SIBGRAPI '08, pages 121-128, Washington, DC, USA, 2008. IEEE Computer Society.

[32] B. Fischl, D. Salat, E. Busa, M. Albert, M. Dieterich, C. Haselgrove, A. Kouwe, R. Killiany, D. Kennedy, S. Klaveness, A. Montillo, N. Makris, B. Rosen, and A. Dale. Whole brain segmentation: Automated labeling of neuroanatomical structures in the human brain. Neuron, 33(3):341 - 355, 2002.

[33] B. Fischl, A. van der Kouwe, C. Destrieux, E. Halgren, F. Ségonne, D. Salat, E. Busa, L. J. Seidman, J. Goldstein, D. Kennedy, V. Caviness, N. Makris, B. Rosen, and A. M. Dale. Automatically parcellating the human cerebral cortex. Cerebral cortex, 14(1):11-22, 2004.

[34] R. Gonzalez and R. Woods. Digital Image Processing. Prentice Hall, 3 edition, 2008.

[35] R. M. Haralick and L. G. Shapiro. Image segmentation techniques. Computer Vision, Graphics, and Image Processing, 29:100-132, 1985.

[36] W. Hsu, S. Antani, L. R. Long, L. Neve, and G. R. Thoma. Spirs: A web-based image retrieval system for large biomedical databases. International Journal of Medical Informatics, 78(Supplement 1):S13 - S24, 2009. MedInfo 2007.

[37] G. Kempermann. Why new neurons? possible functions for adult hippocampal neurogenesis. The Journal of Neuroscience, 22:635-638, 2002.

[38] R. Kuzniecky and G. Jackson. Magnetic resonance in epilepsy. Academic Press, 2 edition, 2005.

[39] K. Leemput, A. Bakkour, T. Benner, G. Wiggins, L. Wald, J. Augustinak, B. Dickerson, P. Goland, and B. Fischl. Model-based segmentation of hippocampal subfields in ultra-high resolution in vivo mri. In MICCAI 2008 Workshop on Computational Anatomy and Physiology of the Hippocampus, pages 46-65, 2008. 
[40] T. Lehmann, M. Guld, C. Thies, B. Fisch, K. Spitzer, D. Keysers, H. Ney, M. Kohnen, H. Schubert, and B. Wein. Content-based image retrieval in medical applications. Methods of Informatics in Medicine, 43:354-361, 2004.

[41] L. Liang, K. Rehm, R. P. Woods, and D. A. Rottenberg. Automatic segmentation of left and right cerebral hemispheres from mri brain volumes using the graph cuts algorithm. NeuroImage, 34:1160-1170, 2007.

[42] F. Lijn, T. Heijer, M. Breteler, and W. Niessenmaster. Hippocampus segmentation in mri using atlas registration, voxel classification, and graph cuts. NeuroImage, 43:708-720, 2008.

[43] F. Long, H. Zhang, and D. Feng. Multimedia information retrieval and management. technological fundamentals and applications. capítulo 1. Ed. Springer, 2003.

[44] R. Lotufo and A. Falcão. The ordered queue and the optimality of the watershed approaches. Mathematical Morphology and its Applications to Image and Signal Processing, 18:341-350, 2000.

[45] H. Lu, B.-C. Ooi, , and K.-L. Tan. Efficient image retrieval by color contents. First International Conference of Application Databases, 819:95-108, June 1994.

[46] M. F. Milan Sonka. Handbook of Medical Imaging. Spie Press, 2000.

[47] P. Miranda, A. Falcao, and J. Udupa. Cloud bank: A multiple clouds model and its use in mr brain image segmentation. In Biomedical Imaging: From Nano to Macro ISBI. IEEE Intl Symp on, pages 506 -509, 2009.

[48] P. A. Miranda. Reconhecimento e delineamento sinergicos de objetos em imagens com aplicações na medicina. PhD thesis, UNICAMP, 2009.

[49] P. A. Miranda and A. X. Falcão. Links between image segmentation based on optimum-path forest and minimum cut in graph. J. Math. Imaging Vis., 35(2):128$142,2009$.

[50] J. Morra, Z. Tu, L. Apostolova, A. Green, C. Avedissian, S. Madsen, N. Parikshak, X. H., A. Toga, C. Jack, N. Schufj, M. Weiner, and P. Thompson. Mapping hippocampal degeneration in 400 subjects with a novel automated segmentation approach. In 5th IEEE Intl Sym on Biomedical Imaging: From Nano to Macro. ISBI, pages 336-339, 2008.

[51] J. Morra, Z. Tu, L. G. Apostolova, A. E. Green, A. W. Toga, and P. M. Thompson. Automatic subcortical segmentation using a contextual model. In MICCAI 2008 Workshop on Computational Anatomy and Physiology of the Hippocampus, pages 194-201. Springer-Verlag, 2008.

[52] H. Müller, N. Michoux, D. Bandon, and A. Geissbuhler. A review of content-based image retrieval systems in medical applications-clinical benefits and future directions. International Journal of Medical Informatics, 73(1):1-23, February 2004.

[53] B. Ng, R. Abugharbieh, X. Huang, and M. McKeown. Spatial characterization of fmri activation maps using invariant 3-d moment descriptors. Medical Imaging, IEEE Trans on, 28(2):261 -268, 2009. 
[54] M. S. Nixon and A. S. Aguado. Feature Extraction and Image Processing. Academic Press, 2002.

[55] G. Pass, R. Zabih, and J. Miller. Comparing images using color coherence vectors. In MULTIMEDIA '96: Proceedings of the fourth ACM international conference on Multimedia, pages 65-73, New York, NY, USA, 1996. ACM.

[56] B. Patenaude, S. M. Smith, D. N. Kennedy, and M. Jenkinson. A bayesian model of shape and appearance for subcortical brain segmentation. NeuroImage, In Press, 2011.

[57] W. K. Pratt. Digital Image Processing: PIKS Inside. Wiley-Interscience, 4 edition, 2007.

[58] R. M. Rangayyan. Biomedical Image Analysis. The Biomedical Engineering Series. CRC Press, 2005.

[59] T. Riklin-Raviv, N. Sochen, N. Kiryati, N. Ben-Zadok, S. Gefen, L. Bertand, and J. Nissanov. Propagating distributions for segmentation of brain atlas. In 4th IEEE International Symposium on Biomedical Imaging: From Nano to Macro. ISBI 200\%., pages 1304-1307, April 2007.

[60] J. Sled, A. Zijdenbos, and A. Evans. A non parametric method for automatic correction of intensity nonuniformity in mri data. Med. Imaging, IEEE Trans on, 17(1):8797, 1998.

[61] R. O. Stehling, M. A. Nascimento, and A. X. Falcão. A compact and efficient image retrieval approach based on border/interior pixel classification. In CIKM '02: Proceedings of the eleventh international conference on Information and knowledge management, pages 102-109. ACM, 2002.

[62] M. Styner, J. Lieberman, and G. Gerig. Boundary and medial shape analysis of the hippocampus in schizophrenia. Medical Image Computing and Computer Assisted Intervention, 8:464-471, September 2003.

[63] P. Suetens. Fundamentals of Medical Imaging. Cambridge University Press, 2002.

[64] J. Talairach and P. Tournoux. Co-planar stereotaxic atlas of the human brain: 3dimensional proportional system : an approach to cerebral imaging. Thieme Classics. G. Thieme, 1988.

[65] F. van der Lijn. Automated Atlas-Based Segmentation of Brain Structures in MR Images: Application to a Population-Based Imaging Study. PhD thesis, Erasmus University Rotterdam, 2010.

[66] R. Wolz, P. Aljabar, D. Rueckert, R. A. Heckemann, and A. Hammers. Segmentation of subcortical structures and the hippocampus in brain mri using graph-cuts and subject-specific a-priori information. In IEEE International Symposium on Biomedical Imaging: From Nano to Macro, pages 470-473, August 2009.

[67] P. Yushkevich and L. Wang, editors. MICCAI 2008 Workshop on Computational Anatomy and Physiology of the Hippocampus, 2008. 
[68] B. Zitova. Image registration methods: a survey. Image and Vision Computing, 21(11):977-1000, October 2003. 